Métodos implícitos para a reconstrução de superfícies a partir de nuvens de pontos

\author{
Valdecir Polizelli Junior
}



Data de Depósito:

Assinatura:

\title{
Métodos implícitos para a reconstrução de superfícies a partir de nuvens de pontos
}

\author{
Valdecir Polizelli Junior \\ Orientador: Prof. Dr. Antonio Castelo Filho
}

Dissertação apresentada ao Instituto de Ciências Matemáticas e de Computação - ICMC-USP, como parte dos requisitos para obtenção do título de Mestre em Ciências - Ciências de Computação e Matemática Computacional.

USP - São Carlos

Fevereiro de 2008 

Aos meus pais. 



\section{Agradecimentos}

Agradeço primeiramente aos meus pais, pelo apoio e dedicação e por terem me ensinado o valor da educação e agido de forma decisiva para a formação do meu caráter. Também agradeço aos meus irmãos, pelo companheirismo e pela paciência durante meus períodos de estresse.

À minha namorada Elen, pela compreensão diante dos meus intermináveis dias e fins de semana de trabalho árduo e por sempre me animar e me dar apoio nos momentos mais complicados.

Ao meu orientador e professor, Antonio Castelo Filho, pela orientação no desenvolvimento deste trabalho e pela excelente convivência nesses dois anos em que fiz parte de seu grupo de alunos. Também estendo meus agradecimentos aos professores do ICMC-USP que fizeram parte de minha formação nesses últimos anos, em especial, aos professores Luís Gustavo Nonato, José Alberto Cuminato e Maria Cristina Ferreira de Oliveira.

Aos meus amigos e parceiros no desenvolvimento desse projeto, João Paulo Gois e Tiago Etiene Queiroz pelo companheirismo, pela determinação e pela valiosa contribuição. Também gostaria de agradecer à Carolina Ferraz e Fernando Bissi, pelas contribuições no desenvolvimento da triangulação $J_{1}^{a}$.

Aos colegas do laboratório LCAD, pelo agradabilíssimo convívio nesses últimos dois anos e pelos momentos de descontração. Em especial, ao amigo Ícaro Cunha pela ajuda na revisão desta dissertação.

Aos meus companheiros de república, Pedro Munari e Rogério Tott, pelo nosso 
confuso, porém habitável lar.

À FAPESP, pelo financiamento deste projeto.

E, finalmente, a todos que contribuíram para este trabalho com sugestões ou críticas, em especial, ao professor Marcelo Ferreira Siqueira (UFMS), ao professor João Comba (UFRGS) e ao aluno Carlos Dietrich (UFRGS). 


\section{Resumo}

A reconstrução de superfícies a partir de nuvens de pontos faz parte de um novo paradigma de modelagem em que modelos computacionais para objetos reais são reconstruídos a partir de dados amostrados sobre a superfície dos mesmos. O principal problema que surge nesse contexto é o fato de que não são conhecidas relações de conectividade entre os pontos que compõe a amostra. Os objetivos do presente trabalho são estudar métodos implícitos para a reconstrução de superfícies e propor algumas melhorias pouco exploradas por métodos já existentes. O uso de funções implícitas no contexto da reconstrução conduz a métodos mais robustos em relação a ruídos, no entanto, uma das principais desvantagens de tais métodos está na dificuldade de capturar detalhes finos e sharp features. Nesse sentido, o presente trabalho propõe o uso de abordagens adaptativas, tanto na poligonalização de superfícies quanto na aproximação de superfícies. Além disso, questões relativas à robustez das soluções locais e à qualidade da malha também são abordadas. Por fim, o método desenvolvido é acoplado a um software traçador de raios a fim de se obter uma maneira de modelar cenas tridimensionais utilizando nuvens de pontos, além dos objetos gráficos tradicionais. Os resultados apresentados mostram que muitas das soluções propostas oferecem um incremento à qualidade dos métodos de reconstrução anteriormente propostos. 


\section{Abstract}

Surface reconstruction from point clouds is part of a new modeling paradigm in which computational models for real objects are reconstructed from data sampled from their surface. The main problem that arises in this context is the fact that there are no known connectivity relationships amongst the points that compose the sample. The objectives of the present work are to study implicit methods for surface reconstruction and to propose some improvements scarcely explored by previous work. The use of implicit functions in the context of surface reconstruction leads to less noise sensitive methods; however, one major drawback of such methods is the difficulty in capturing fine details and sharp features. Towards this, the present work proposes the use of adaptive approaches, not only in the polygonization but also in the surface approximation. Besides, robustness issues in local solutions and mesh quality are also tackled. Finally, the developed method is embedded in a ray tracer software in order to set a basis for modeling tridimensional scenes using point sets, in addition to traditional graphic objects. The presented results show that a great deal of the proposed solutions offer a quality increase to the reconstruction method previously proposed. 


\section{Conteúdo}

Conteúdo

vii

Lista de Figuras $\quad$ xi

1 Introdução 1

1.1 Contextualização e motivação . . . . . . . . . . . . . . . . 1

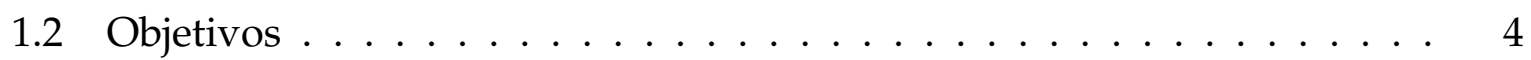

1.3 Organização da dissertação . . . . . . . . . . . . . . 4

2 Reconstrução de Superfícies a partir de nuvens de pontos 7

2.1 Considerações iniciais . . . . . . . . . . . . . . 7

2.2 Caracterização do problema . . . . . . . . . . . . . . 8

2.2.1 Definição formal do problema . . . . . . . . . . . 8

2.2.2 Classificação dos métodos . . . . . . . . . . . . . . . 9

2.3 Métodos de esculpimento . . . . . . . . . . . . . . . . 11

2.4 Métodos incrementais . . . . . . . . . . . . . . . . . . 15

2.5 Métodos baseados em modelos deformáveis . . . . . . . . . . . . . . 18

2.6 Métodos da família Crust . . . . . . . . . . . . . . . . . . . . . 18

2.7 Métodos implícitos . . . . . . . . . . . . . . . . . . . . 22

2.8 Considerações finais . . . . . . . . . . . . . . . . 35 
Conteúdo

3 Extração de isosuperfícies $\quad 37$

3.1 Considerações iniciais . . . . . . . . . . . . . . . . 37

3.2 Definição do problema . . . . . . . . . . . . . . . . . . . . 37

3.3 Revisão dos métodos . . . . . . . . . . . . . . . . . . . . . 38

3.3.1 Métodos baseados em grades regulares . . . . . . . . . . . 38

3.3.2 Métodos não baseados em grades regulares . . . . . . . . . . . . 47

3.3.3 Resumo das características dos algoritmos . . . . . . . . . . . 49

3.4 Considerações Finais . . . . . . . . . . . . . . . . . . . . . . . . . 49

4 Desenvolvimento $\quad 51$

4.1 Considerações iniciais . . . . . . . . . . . . . . . . . . 51

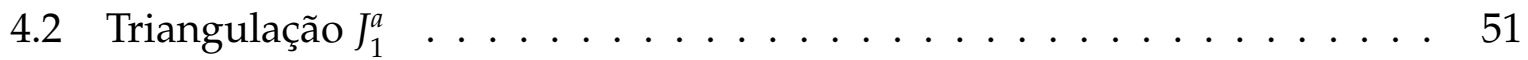

4.2.1 Identificação de simplexos . . . . . . . . . . . . . . . . . . . 52

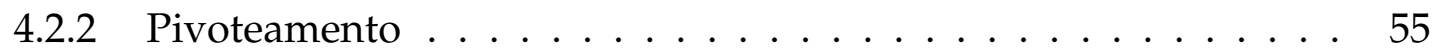

4.2 .3 Rotulagem . . . . . . . . . . . . . . . . . 57

4.2.4 Gerenciamento de blocos . . . . . . . . . . . . . . . 58

4.2 .5 Utilização da estrutura . . . . . . . . . . . . . . . . . . . . 60

4.3 Reconstrução da superfície . . . . . . . . . . . . . . . . . 62

4.3.1 Superfícies Implícitas de Partição da Unidade Multinível . . . . . 63

4.3.2 Cálculo de aproximações locais . . . . . . . . . . . . . . . . . . 64

4.3 .3 Avaliação da função implícita . . . . . . . . . . . . . . . . . 70

4.3.4 Extensões ao método original . . . . . . . . . . . . . . . . 71

4.4 Extração da isosuperfície . . . . . . . . . . . . . . . . 73

4.4 .1 Visão geral . . . . . . . . . . . . . . . . . 73

4.4 .2 Estruturas de dados . . . . . . . . . . . . . . 74

4.4 .3 Determinação do simplexo inicial . . . . . . . . . . . . 75

4.4.4 Cálculos de interseção e construção da malha . . . . . . . . . . 78

4.4 .5 Melhoramento da malha . . . . . . . . . . . . . . 80

4.5 Modelador genérico . . . . . . . . . . . . . . . . . . . . 82

4.6 Considerações finais . . . . . . . . . . . . . . . . 86 
Conteúdo

5 Resultados $\quad 87$

5.1 Considerações iniciais . . . . . . . . . . . . . . . 87

5.2 Extração de Isosuperfícies . . . . . . . . . . . . . . . . . . 87

5.3 Reconstrução de Superfície . . . . . . . . . . . . . . . . . . . . 89

5.3.1 Tempo de processamento e exemplos de reconstrução . . . . . . . 90

5.3.2 Representação de sharp features . . . . . . . . . . . . . . . 93

5.3.3 Critérios de Robustez . . . . . . . . . . . . . . . . 96

5.3 .4 Edição de Função . . . . . . . . . . . . . . . . . . . . . . . . . . . 98

5.4 Qualidade de malha . . . . . . . . . . . . . . . . . . 99

5.5 Considerações finais . . . . . . . . . . . . . . . . . . . 102

$\begin{array}{lll}6 & \text { Conclusão } & 103\end{array}$

6.1 Discussão dos resultados . . . . . . . . . . . . . . . . . . . . 103

6.2 Trabalhos futuros . . . . . . . . . . . . . . . . . . . 104

$\begin{array}{ll}\text { Referências Bibliográficas } & 107\end{array}$ 
Conteúdo 


\section{Lista de Figuras}

1.1 Modelagem de um personagem de animação através de amostras. . . . . 2

1.2 Representação de uma fronteira de fluido, em deformação, através de

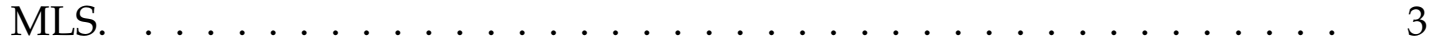

2.1 Propriedades topológicas e geométricas . . . . . . . . . . . . . . 9

2.2 Exemplos de $\alpha$-shapes para um objeto com 11885 pontos . . . . . . . . 13

2.3 O teste da esfera em escala anisotrópica $\ldots \ldots \ldots \ldots$

2.4 A reconstrução do algoritmo Ball pivoting em relação ao parâmetro $\rho$ . 17

2.5 Passos da reconstrução do algoritmo Crust . . . . . . . . . . . . . . . 20

2.6 Problema da aproximação do eixo medial pelo diagrama de Voronoi em

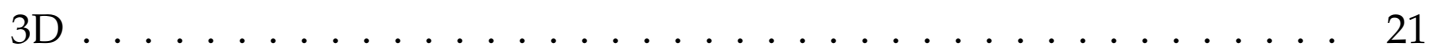

2.7 Método de reconstrução da superfície (Hoppe et al., 1992). . . . . . . . . 25

2.8 Ilustração da vizinhança natural de $p . \ldots$. . . . . . . . . . . . . 27

2.9 Relação entre gradiente da função indicadora e amostra de pontos . . . . 33

3.1 Tabela de casos do algoritmo marching cubes . . . . . . . . . . . . . . 39

3.2 Inconsistências no algoritmo marching cubes . . . . . . . . . . . . . . . 39

3.3 Subdivisões de cubos em tetraedros . . . . . . . . . . . . . . . 40

3.4 Ambigüidades de face marching cubes . . . . . . . . . . . . . . . . 42

3.5 Dificuldades da poligonalização baseada em octree . . . . . . . . . . . . . 43

3.6 Representação do dual geométrico da octree . . . . . . . . . . . . . . . . . 44 


\section{Lista de Figuras}

3.7 Ilustração do algoritmo de Kobbelt et al. (2001) . . . . . . . . . . . . . . . 45

3.8 Divisão de hipercubos em hipertetraedros . . . . . . . . . . . . . . 46

3.9 Funcionamento do algoritmo de Bhaniramka et al. (2004) . . . . . . . . 46

4.1 Construção da grade da triangulação $J_{1}^{a} \ldots \ldots \ldots$. . . . . . . . . . 53

4.2 Ilustração de uma triangulação $J_{1}^{a}$ em duas dimensões . . . . . . . . . . . 54

4.3 Exemplo de operações de pivoteamento na triangulação $J_{1}^{a} \ldots \ldots$. . . . 56

4.4 Estrutura de dados para os blocos . . . . . . . . . . . . . 59

4.5 Ordem em que são percorridas as faces de um bloco. . . . . . . . . . . 61

4.6 Caso específico de blocos de transição no iterador de blocos . . . . . . . 62

4.7 Comportamento da triangulação $J_{1}^{a}$ durante a aproximação da função. 64

4.8 Ilustração da cobertura do domínio . . . . . . . . . . . . . . . 66

4.9 Situação de determinação do simplexo inicial . . . . . . . . . . . . . 76

4.10 Casos de intersecção de tetraedros com a superfície. . . . . . . . . . . 78

4.11 Percurso na estrela de uma aresta . . . . . . . . . . . . . . . . . 79

4.12 Comparação de malha original com malha melhorada . . . . . . . . . . . 81

4.13 Processo de melhoramento de malhas. . . . . . . . . . . . . . . . . . . . 82

5.1 Triangulação $J_{1}^{a}$ em três dimensões $\ldots \ldots$. . . . . . . . . . . 88

5.2 Superfícies de exemplo do poligonalizador . . . . . . . . . . . . . 89

5.3 Códigos de cores da interface gráfica . . . . . . . . . . . . . . . 90

5.4 Seleção de blocos e renderização de funções . . . . . . . . . . . . . . . . . 91

5.5 Malhas geradas para alguns modelos clássicos . . . . . . . . . . . . . 92

5.6 Demostração das capacidades do modelador genérico. . . . . . . . . . 94

5.7 Ilustração da funcionalidade de sharp features. . . . . . . . . . . . . . . . 95

5.8 Importância do critério de robustez. . . . . . . . . . . . . . . . . . . . 97

5.9 Melhorando a reconstrução através da edição de função . . . . . . . . . . 98

5.10 Histograma da razão de aspecto das malhas melhorada e original. . . . . 99

5.11 Exemplo de melhoria de malhas (1) . . . . . . . . . . . . . . . . 101

5.12 Melhoramento da malha aplicado ao modelo Dragon. . . . . . . . . . . . 102 


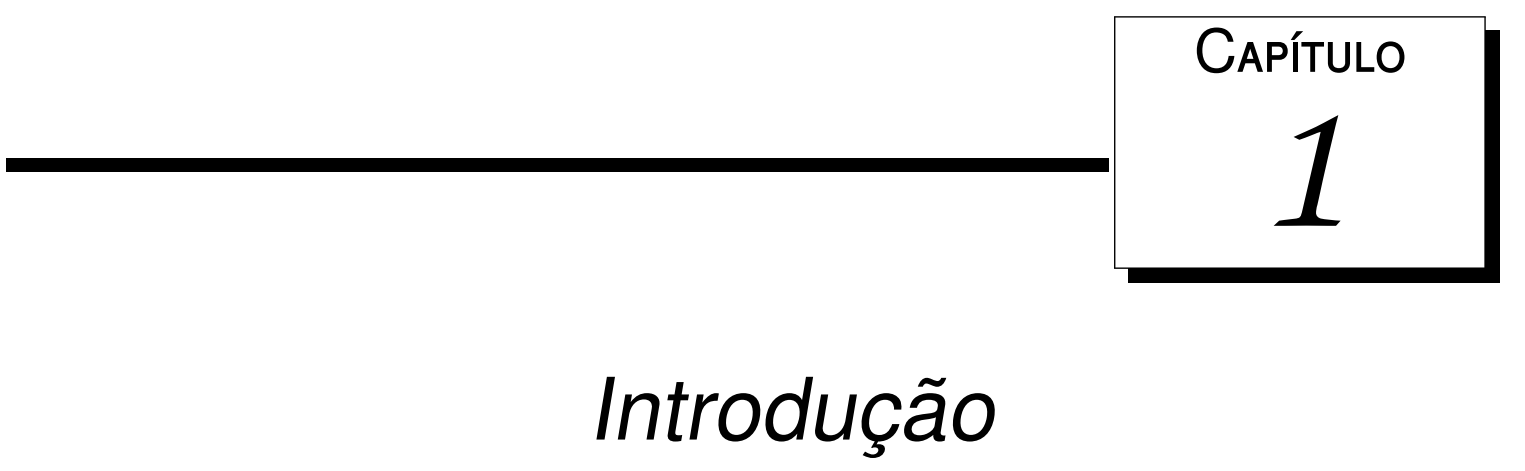

\subsection{Contextualização e motivação}

Inicialmente, o problema da reconstrução a partir de amostras surgiu na forma de reconstrução de superfícies de contorno em imagens médicas, na qual um conjunto de cortes seccionais obtidos a partir de tomografias computadorizadas (CT - Computer Tomography) ou de ressonâncias magnéticas (MRI - Magnetic Ressonance Imaging) precisavam ser unidos. Esse tipo de reconstrução é conhecido como reconstrução a partir de seções planares e as abordagens que tratam desse problema apresentam, geralmente, as seguintes etapas principais (Nonato et al., 2005):

- Detectar os contornos de cada imagem;

- Gerar os pontos sobre esses contornos;

- Conectar os contornos a fim de definir uma representação tridimensional.

Além das aplicações voltadas à medicina, outras áreas do conhecimento, tais como ciência e engenharia, necessitam de modelagens computacionais de objetos físicos para simulações, engenharia reversa, análise e projeto. Até recentemente, a maioria das 

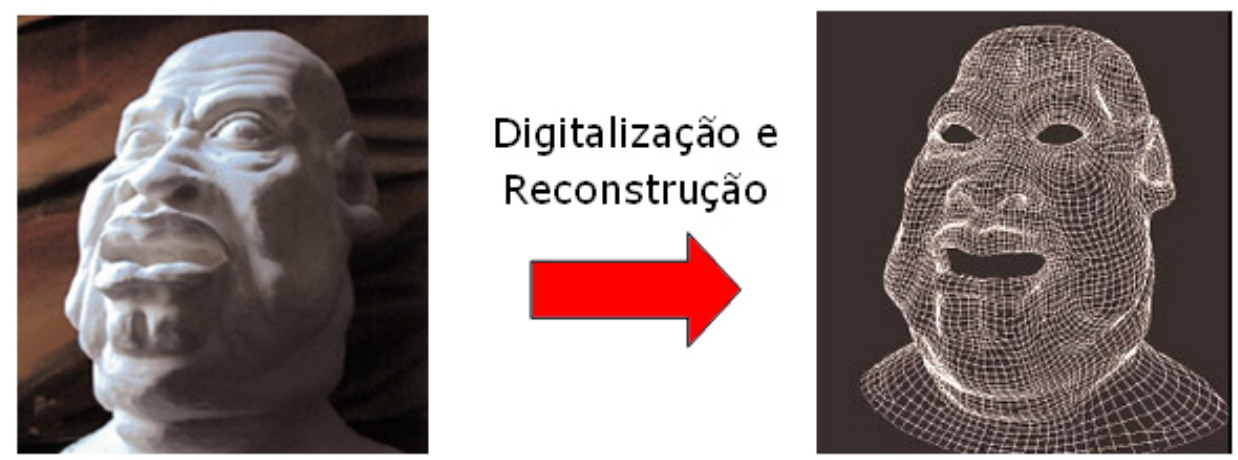

Figura 1.1: Modelagem de um personagem de animação através de amostras.

aplicações obtinham tais objetos de maneira sintética. Dentre esses tipos de modelagem podemos destacar:

- Modelagens a partir de primitivas geométricas: o usuário dispõe de formas básicas tais como pontos e polígonos para constituir o objeto desejado. Normalmente essa abordagem é empregada em softwares CAD (Computer Aided-Design);

- Modelagem a partir de funções implícitas ou paramétricas: podem ser definidas superfícies ou curvas;

- Modelagem CSG (Constructive solid geometry): nesse tipo de modelagem são usadas primitivas de sólidos que são combinadas através de operações de conjuntos (união, intersecção e diferença).

Essas abordagens envolvem um volume muito grande de trabalho, o que as torna inviáveis para determinadas aplicações. A Figura 1.1 mostra o exemplo de um objeto que demandaria muito tempo para ser reconstruído usando técnicas convencionais. Por esse motivo e pelo grande desenvolvimento atual de equipamentos para aquisição de dados espaciais (por exemplo, scanners $3 D$ ), técnicas alternativas em que os objetos são diretamente convertidos para modelos computadorizados estão ganhando espaço e tornando-se viáveis. Porém, para que uma representação útil do objeto seja obtida, é necessário que os pontos obtidos sejam processados e transformados em modelos adequados e, é para esse fim, que a reconstrução de superfícies a partir de pontos surge. 


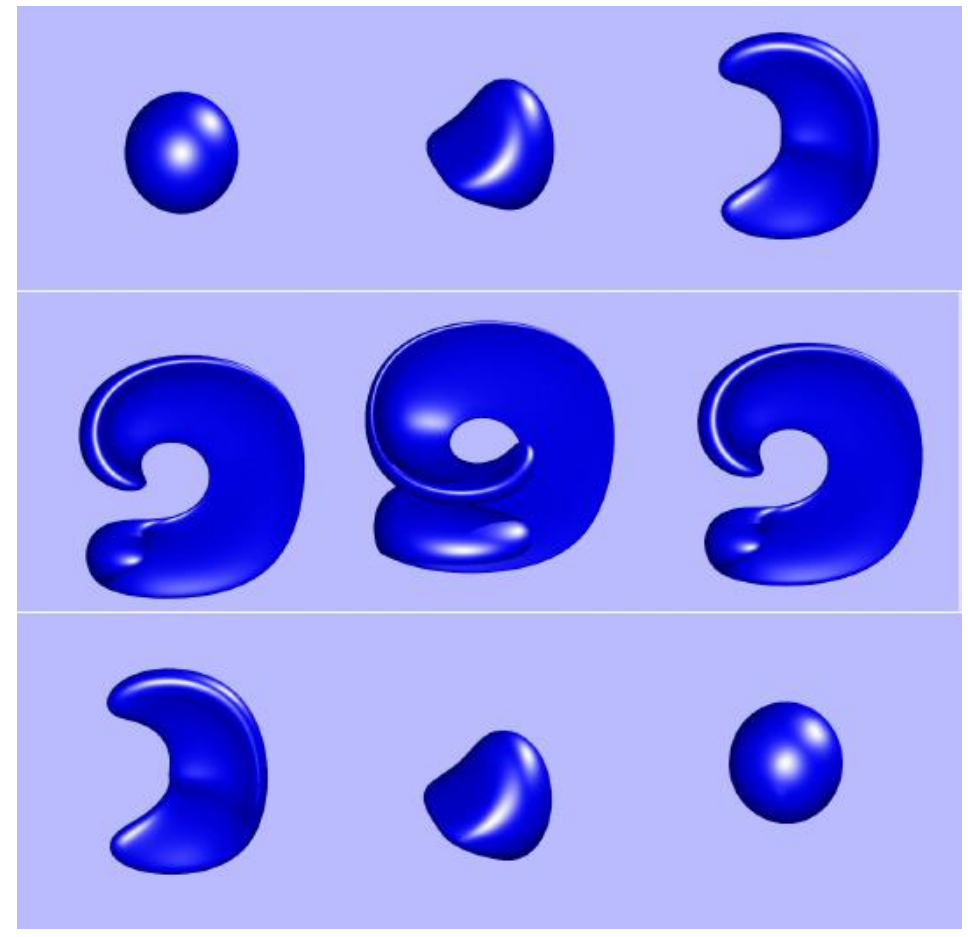

Figura 1.2: Representação de uma fronteira de fluido, em deformação, através de MLS.

Tais etapas de aquisição e de reconstrução da superfície definem um novo paradigma de modelagem denominado modelagem geométrica baseada em amostras: Samplebased geometric modeling (Dey, 2005).

Outra área na qual a reconstrução de superfícies a partir de pontos pode ser empregada é nos métodos de acompanhamento de fronteiras (front-tracking) de fluidos em ambientes de simulação computacional. Nesse contexto, existem técnicas que utilizam malhas para manter a descrição dessas fronteiras, porém há uma série de complexidades envolvidas na manutenção dessas malhas. Por essa razão, muitos autores têm considerado apenas o uso de pontos para o processo de acompanhamento da fronteira e, conseqüentemente, o uso de técnicas de representação e reconstrução de superfícies. Por exemplo, o trabalho de Gois et al. (2008) propõe o uso de técnicas baseadas em MLS (Moving Least Squares) para a representação das fronteiras de fluidos. A Figura 1.2 mostra a fronteira de um fluido sendo representada através de MLS conforme são realizadas deformações. 


\subsection{Objetivos}

A reconstrução de superfícies a partir de nuvens de pontos através de funções implícitas apresenta vantagens na representação de amostras com ruídos, já que as funções não necessariamente interpolam os dados de entrada. No entanto, um problema gerado por essa situação é o fato de que muitos dos detalhes finos subjacentes ao conjunto de pontos são perdidos. Uma forma de tratar esse problema é através do uso de abordagens adaptativas, em que regiões de maior complexidade são representadas e também poligonalizadas de maneira diferenciada. Além disso, as funções implícitas permitem a adaptação à topologia.

Outra grande vantagem do uso de métodos implícitos está no fato de que a representação da superfície é obtida através de uma função que pode ser combinada com outras funções para fins de modelagem. Essa é uma flexibilidade que não é oferecida pelos métodos baseados em conceitos de geometria computacional.

A partir desses fatos, os objetivos do presente trabalho foram definidos no sentido de aplicar técnicas adaptativas tanto na obtenção de funções implícitas a partir de nuvens de pontos quanto na poligonalização da função obtida. Além disso, foi definida como prioridade a avaliação e a definição de soluções para os problemas de robustez apresentados por outras técnicas de reconstrução similares.

Um fato conhecido a respeito das malhas geradas pelo poligonalizador baseado na triangulação $J_{1}^{a}$ (Castelo et al., 2006) é a baixa qualidade dos triângulos obtidos. Por essa razão, o desenvolvimento de maneiras de melhorar a qualidade das malhas também foi tratado como um requisito essencial.

Por fim, outro objetivo definido foi o desenvolvimento de uma espécie de modelador genérico capaz de lidar com diferentes ferramentas de modelagem geométrica, incluindo as superfícies baseadas em pontos.

\subsection{Organização da dissertação}

A dissertação é organizada da seguinte forma:

- Capítulo 2: nesse capítulo é apresentada uma introdução a respeito da reconstru- 
ção de superfícies a partir de nuvens de pontos. Inicialmente, é fornecida uma definição formal do problema e uma classificação das abordagens. Em seguida, é apresentada uma revisão bibliográfica dos métodos empregados no processo de reconstrução com particular ênfase para os métodos implícitos;

- Capítulo 3: nesse capítulo é apresentada uma revisão bibliográfica dos métodos de extração de isosuperfícies, devido ao papel dessas técnicas na geração de aproximações poligonais das funções implícitas;

- Capítulo 4: nesse capítulo são descritas todas as técnicas e algoritmos desenvolvidos incluindo a triangulação $J_{1}^{a}$, o extrator de isosuperfícies e o algoritmo de reconstrução propriamente dito;

- Capítulo 5: no capítulo final da dissertação é feita uma apreciação dos resultados obtidos e são sugeridos alguns possíveis trabalhos futuros. 


\section{Introdução}




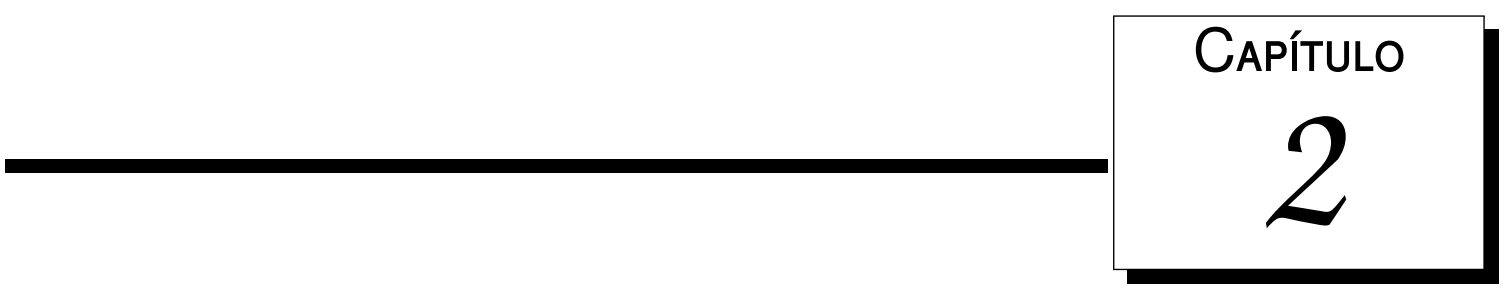

\section{Reconstrução de Superfícies a partir de} nuvens de pontos

\subsection{Considerações iniciais}

O presente capítulo introduz o assunto da reconstrução de superfícies a partir de nuvens de pontos. Na Seção 2.2 é feita a caracterização do problema de reconstrução através da definição formal e de uma visão geral dos trabalhos desenvolvidos. No restante do capítulo, são detalhados cada um dos tipos de técnicas de reconstrução de acordo com a taxonomia proposta no trabalho de Gois et al. (2004). A divisão adotada é a seguinte: métodos por esculpimento (Seção 2.3), métodos incrementais (Seção 2.4), métodos baseados em modelos deformáveis (Seção 2.5), métodos da família Crust (Seção 2.6) e métodos implícitos (Seção 2.7). O conteúdo apresentado nesse capítulo exige, para sua correta compreensão, alguns conceitos básicos de topologia e geometria computacional (Gois, 2004). 


\subsection{Caracterização do problema}

Nesta seção é fornecida uma definição matemática do problema de reconstrução e são apresentadas algumas das possíveis formas de classificação das abordagens.

\subsubsection{Definição formal do problema}

O problema da reconstrução de superfícies a partir de nuvens de pontos pode apresentar variações em que mais ou menos informações estão disponíveis sobre os dados de entrada e, por essa razão, muitos algoritmos foram construídos para instâncias particulares do problema explorando essa estrutura parcial dos dados. Por exemplo, algoritmos para reconstrução de superfícies a partir de pontos obtidos sobre contornos aproveitam, em sua concepção, essa informação topológica previamente conhecida. Hoppe et al. (1992) propôs a generalização do problema ao não assumir conhecimento de estruturas a respeito dos pontos de entrada. As vantagens advindas dessa unificação das abordagens são tanto de cunho teórico quanto prático. Pelo lado teórico, a generalização permite enxergar os aspectos críticos do problema, enquanto que, pelo lado prático, os algoritmos tornam-se robustos e capazes de trabalhar com diferentes dados de entrada.

Dentre as principais dificuldades apresentadas pelo problema geral da reconstrução de superfícies, pode-se destacar:

- Amostras com ruídos: os equipamentos de aquisição de dados apresentam erros intrínsecos ao processo de obtenção de amostras;

- Amostras com sharp features: essas características aparecem em regiões nas quais a curvatura da superfície é elevada;

- Amostras incompletas: nem sempre a amostragem é suficiente para reconstruir a superfície.

O problema alvo desse trabalho pode ser enunciado da seguinte forma: seja $S$ uma 2-variedade em $\mathbb{R}^{3}$ e um conjunto de pontos $P \subset S$, define-se uma reconstrução da superfície $S$ a partir da nuvens de pontos $P$ como uma aproximação $S^{\prime}$ tal que: 
1. $S^{\prime}$ seja topologicamente equivalente a $S$;

2. $S^{\prime}$ seja geometricamente próxima a $S$.

Essas duas condições podem ser expressas formalmente através da seguinte definição:

Definição 1 (Equivalência topológica e geométrica) Seja $S$ a superfície original e $S^{\prime}$ uma reconstrução da superfície a partir de uma amostra de pontos $P \subset S$. Diz-se que $S^{\prime}$ é topologicamente equivalente e geometricamente próxima de $S$ se existe um homeomorfismo $f: S \rightarrow S^{\prime}$ e se, dado um ponto $p \in S, d(p, f(p))<\varepsilon$, em que d é uma métrica de distância e é é um valor suficientemente pequeno.

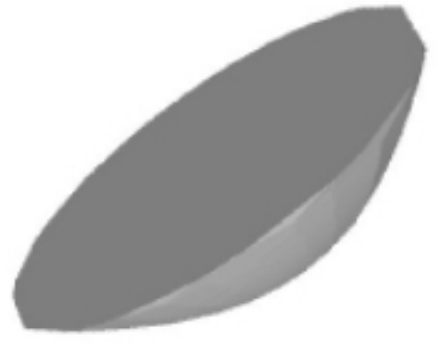

(a)

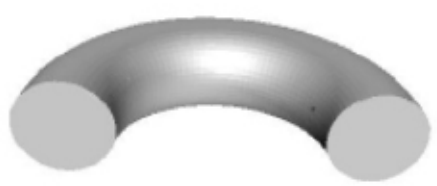

(b)

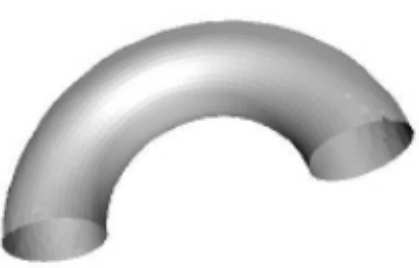

(c)

Figura 2.1: Os objetos (a) e (b) são apenas topologicamente equivalentes, enquanto que os objetos (b) e (c) são apenas geometricamente próximos

Vale reforçar que os dois critérios devem ser obedecidos para que a reconstrução possa ser considerada satisfatória. Na Figura 2.1 (Gois, 2004) vemos que os itens (a) e (b) são topologicamente equivalentes, porém não são geometricamente próximos. A situação é inversa para os itens (b) e (c) que apesar de serem similares geometricamente não são homeomorfos.

\subsubsection{Classificação dos métodos}

Ao longo dos anos, foram propostas diversas técnicas para resolver o problema da reconstrução de superfícies a partir de nuvens de pontos empregando desde conceitos de geometria computacional até modelos baseados em equações diferenciais parciais 
(E.D.P.). Como guia para a exploração dessas técnicas é necessário adotar algum tipo de classificação.

Uma grande parte dos trabalhos realiza a classificação apenas em métodos paramétricos e implícitos (Hoppe et al., 1992; Zhao et al., 2001). Huang and Menq (2002) propuseram uma classificação em métodos baseados em superfícies, em que a superfície é incrementalmente construída; métodos volumétricos, que se baseiam na remoção de simplexos da triangulação de Delaunay em 3D; e métodos implícitos, em que a superfície é representada por uma isosuperfície de uma função de distância com sinal. Mais recentemente, Boissonnat e Cazals classificaram os métodos em quatro grupos (Boissonnat and Cazals, 2002):

- Métodos baseados em projeções locais: a aproximação é realizada tratando a superfície como uma função definida em um domínio de referência local;

- Métodos deformáveis: a partir de um invólucro (membrana) inicial são aplicadas deformações no sentido de minimizar uma função de energia e obter uma aproximação para a superfície;

- Métodos combinatoriais (esculpimento): os métodos se baseiam na remoção de simplexos de um arranjo espacial, tal como a triangulação de Delaunay;

- Métodos implícitos: são os métodos já descritos no parágrafo anterior.

Em 2004, Góis et al. propuseram uma classificação mais geral baseada no funcionamento dos algoritmos e em características tais como garantias teóricas oferecidas (Gois et al., 2004). Essa classificação servirá de base para a organização das seções subseqüentes do capítulo. A taxonomia divide os métodos em cinco categorias:

- Métodos de esculpimento;

- Métodos incrementais;

- Métodos baseados em modelos deformáveis;

- Métodos da família Crust; 
- Métodos implícitos.

Todas as classificações apresentadas anteriormente baseiam-se nas características funcionais dos algoritmos, porém, outros tipos de classificação são possíveis, tais como divisões baseadas em complexidade computacional ou qualidade de amostragem exigida pelos algoritmos.

\subsection{Métodos de esculpimento}

Os métodos de esculpimento baseiam-se na obtenção da triangulação de Delaunay 3D dos pontos de entrada e na subseqüente remoção de um conjunto de simplexos da triangulação através de uma heurística de esculpimento para que, ao fim do processo, os simplexos restantes sejam uma aproximação da superfície original. O conjunto de faces que representa a superfície é uma restrição da triangulação de Delaunay e a complexidade desses algoritmos normalmente é limitada pela complexidade para a obtenção da triangulação.

O primeiro trabalho realizado no âmbito da reconstrução de superfícies (Boissonnat, 1984) introduziu dois algoritmos, sendo que um deles pode ser considerado o primeiro método de esculpimento. O algoritmo é baseado no fato de que, sob algumas restrições de amostragem, a triangulação de Delaunay 3D contém um poliedro que fornece uma aproximação coerente da superfície a ser reconstruída. A heurística de esculpimento prevê a remoção de 3-simplexos (tetraedros) enquanto a fronteira dos simplexos formar um poliedro. Os autores argumentam que qualquer superfície de genus zero, compreendida em uma triangulação de Delaunay 3D, pode ser obtida através de tal procedimento.

Outra heurística de remoção de simplexos, baseada no perímetro das faces de tetraedros, foi proposta por Rodriguez et al. (1994). O algoritmo de reconstrução funciona de forma parecida à do algoritmo descrito anteriormente, pois mantém a fronteira definida pelas faces externas dos tetraedros e, a cada passo, remove todos os 3-simplexos que possuem o perímetro da face externa menor que um limiar dado pela média dos perímetros de todas as faces externas. Tendo removido todos possíveis simplexos, um novo limiar é calculado e comparado ao valor anterior. Se esse valor 
é maior que $1 \%$, o processo é repetido. A escolha do perímetro como heurística de esculpimento em detrimento à área ou raio do circuncírculo é justificada pelos autores pelo fato de que o perímetro é calculado de forma rápida e eficiente e pelo fato de que em testes realizados, a medida apresentou os melhores resultados.

Edelsbrunner and Mücke (1994) propuseram uma generalização para o fecho convexo que pode ser usada para a reconstrução de superfícies a partir de nuvens de pontos. Essa generalização, chamada de $\alpha$-shape, é controlada pelo parâmetro $\alpha$ que indica o nível de detalhes da representação volumétrica obtida através da triangulação de Delaunay 3D, ou seja, a heurística de esculpimento é definida por esse parâmetro. Uma intuição sobre a representação obtida pelos $\alpha$-shapes é a seguinte: dada a triangulação de Delaunay, cuja fronteira representa o fecho convexo do conjunto de pontos de entrada, um simplexo (aresta, triângulo ou tetraedro) é removido se uma (ou várias) esfera de raio $\alpha$ consegue atravessá-lo sem tocar os vértices. A partir disso pode-se verificar que:

- para $\alpha=\infty$, o politopo definido pelo $\alpha$-shape corresponde ao fecho convexo dos pontos de entrada;

- para $\alpha=0$, o $\alpha$-shape corresponde apenas aos pontos de entrada, ou seja, todos os $p$-simplexos, com $p \geqslant 1$ são removidos.

$\mathrm{O}$ algoritmo $\alpha$-shape exige uma amostragem uniforme para que a reconstrução seja homeomorfa à superfície original. A amostragem uniforme é definida da seguinte forma:

Definição 2 (Amostragem uniforme) Uma amostragem é dita $\varepsilon$-uniforme se, para todo $q$ pertencente à superfície original, existe um ponto $p$ da amostra tal que $\|p-q\|<\varepsilon$.

A grande desvantagem da técnica de $\alpha$-shapes é o fato de que o parâmetro $\alpha$ deve ser ajustado manualmente, o que torna o processo de reconstrução pouco automático. A Figura 2.2 ilustra exemplos de $\alpha$-shapes para diferentes valores de $\alpha$ (Gois, 2004).

Bajaj et al. (1995) propuseram uma técnica para a reconstrução usando $\alpha$-shapes obtidos de forma automática combinados com funções implícitas (maiores detalhes na 
(a)

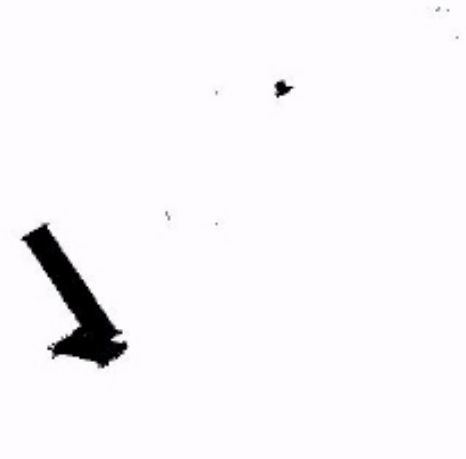

(c)

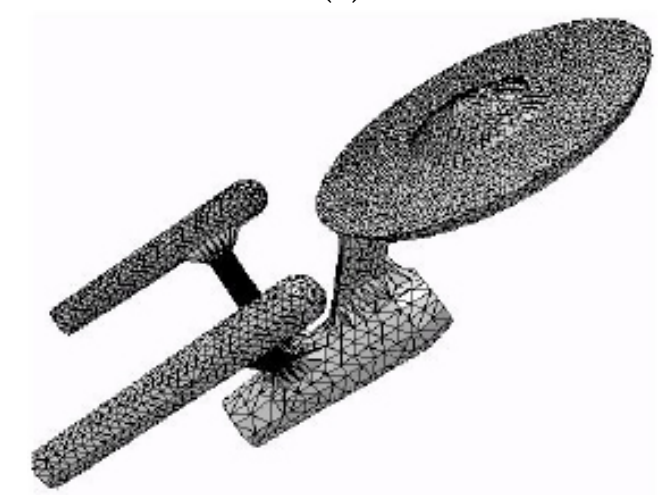

(b)

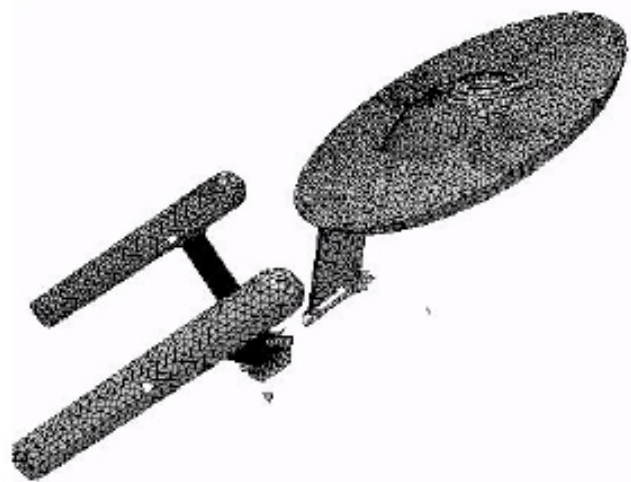

(d)

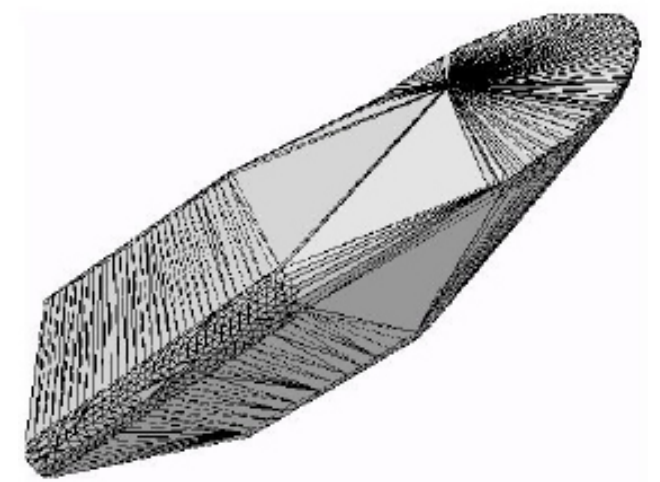

Figura 2.2: Exemplos de $\alpha$-shapes para um objeto com 11885 pontos: (a) $\alpha=10$, (b) $\alpha=$ 40, (c) $\alpha=60$ e (d) $\alpha=95$.

seção 2.7). A fim de selecionar um valor de $\alpha$ são definidos critérios a respeito das propriedades da superfície desejada e, baseado nisso, uma busca binária é realizada procurando pelo melhor parâmetro $\alpha$ que satisfaça as condições impostas (Bernardini et al., 1999a).

Bernardini and Bajaj (1997) descreveram de maneira formal as condições necessárias para que uma superfície reconstruída através de $\alpha$-shapes seja homeomorfa à superfície original. A intuição usada na demonstração é que a superfície só pode ser reconstruída se for possível caminhar pelos pontos da amostra usando uma esfera de raio $\varepsilon$. Isso implica em duas propriedades, que correspondem às propriedades de uma amostragem uniforme:

- Quaisquer dois pontos $p$ e $q$ adjacentes na superfície original devem estar a uma distância menor que $\varepsilon$ na amostra; 
- Estando em um ponto $p$, somente pontos adjacentes na superfície original devem ser alcançáveis a partir de $p$.

O trabalho de Teichmann and Capps (1998) apresenta duas extensões para os $\alpha$ shapes em que são propostas modificações para resolver o problema das falhas geradas sobre a superfície e para relaxar a exigência de uma amostra uniforme:

- A primeira extensão modifica o critério de remoção de simplexos do $\alpha$-shape através da substituição do teste da esfera pelo teste do elipsóide. O elipsóide é obtido deformando-se a esfera com relação às normais nos pontos locais. A utilização de um elipsóide para a determinação dos simplexos a serem removidos tornaria o processo muito complicado, por essa razão, ao invés de realizar uma deformação na esfera, os pontos da triangulação são mapeados para um domínio anisotrópico ${ }^{1}$ no qual o teste da esfera convencional é aplicado. A Figura 2.3(a) apresenta um simplexo e a esfera (círculo) convencional, enquanto que a Figura 2.3(b) ilustra a deformação aplicada ao círculo e a Figura 2.3(c) mostra o mapeamento dos pontos para um domínio anisotrópico;

- A segunda extensão realiza medidas locais de densidade e as emprega para redimensionar o parâmetro $\alpha$ adaptativamente. O intuito dessa modificação é tornar o processo de reconstrução menos sensível a condições de amostragem não-uniformes.

A desvantagem do método de Teichmann e Capps é a definição manual de parâmetros tanto para a determinação da escala anisotrópica quanto para o redimensionamento do parâmetro $\alpha$.

Adamy et al. (2002) apresenta um algoritmo, também baseado na triangulação de Delaunay, que escolhe uma superfície local em cada vértice na forma de um guardachuva. O processo de reconstrução, assim como do trabalho anteriormente citado, é garantido para 2D mas não apresenta as mesmas propriedades em três dimensões. Nesse último caso é necessária a realização de uma limpeza topológica como pósprocessamento na malha de triângulos.

\footnotetext{
${ }^{1}$ Domínio anisotrópico é o domínio que apresenta propriedades dependentes da direção como, por exemplo, escala.
} 


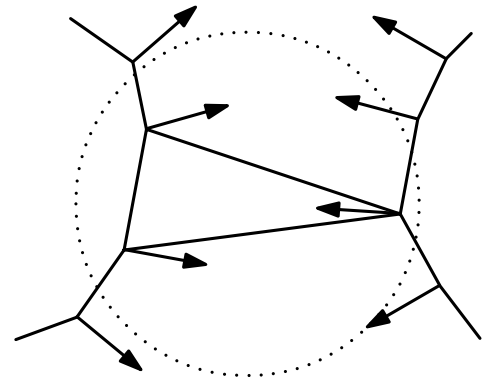

(a)

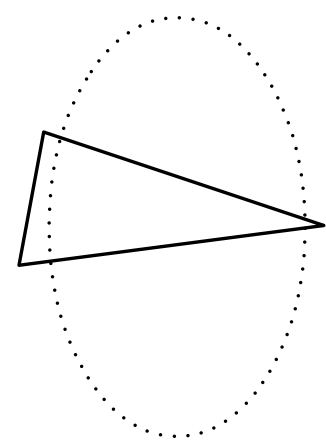

(b)

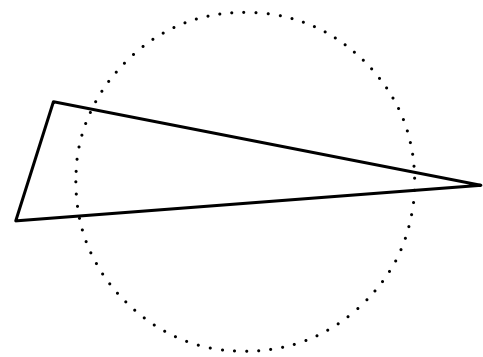

(c)

Figura 2.3: Em (a) é ilustrado o teste da esfera convencional; (b) mostra a deformação da esfera para a obtenção de uma elipse enquanto que em (c), a deformação é aplicada aos vértices do triângulo.

Edelsbrunner (2002) propôs a aplicação da teoria de Morse para a reconstrução de superfícies em um software comercial desenvolvido pela empresa Raindrop Geomagic. A idéia básica é definir uma função de Morse $\mu$ adaptada para a triangulação de Delaunay, já que a teoria de Morse se aplica a variedades diferenciáveis. Edelsbrunner estabelece uma relação de equivalência entre o fluxo gradiente de $\mu$ e os tipos de intersecção entre os simplexos e seus duais (Gois, 2004).

\subsection{Métodos incrementais}

Os métodos incrementais são baseados no avanço incremental de uma fronteira que compreende os pontos já processados. Em outras palavras: no início do algoritmo é definida uma fronteira de avanço composta por um conjunto de arestas e, conforme o algoritmo processa os dados de entrada, a fronteira é expandida até que todos os pontos sejam compreendidos. Os métodos incrementais podem ser vistos como o processo oposto ao esculpimento, ou seja, ao invés de se obter um conjunto completo de simplexos e depois esculpi-lo, a abordagem incremental gera somente os simplexos de interesse para a aproximação da superfície.

Uma etapa de pré-processamento normalmente realizada pelos algoritmos incrementais é a construção de uma árvore de busca espacial ( $k d$-tree ou quad-tree) para que, dado um conjunto de arestas da fronteira de avanço, seja possível encontrar os pontos que são candidatos a serem processados em seguida. 
O trabalho de Boissonnat (1984) apresenta uma versão baseada em avanço de fronteira para a reconstrução de superfícies que pode ser considerado o primeiro algoritmo incremental.

Como já havia sido apontado na Seção 2.3, Bernardini and Bajaj (1997) provaram algumas propriedades sobre os $\alpha$-shapes utilizando algumas observações que posteriormente originaram um algoritmo incremental conhecido como Ball Pivoting Algorithm (BPA) (Bernardini et al., 1999b).

O algoritmo funciona da seguinte maneira:

1. Dado um parâmetro $\rho$, que depende da densidade da amostra, uma bola de raio $\rho$ é definida e posicionada de forma a compreender três pontos de entrada. As três arestas geradas pelos pontos, que definem o primeiro triângulo da superfície, são inseridas em uma estrutura que mantém a fronteira de avanço;

2. Tomando uma das arestas da fronteira de avanço ainda não processadas, a bola é rotacionada em torno da aresta, sem perder contato com os vértices, até que um novo ponto da amostra seja atingido. Se isso ocorre, um novo triângulo é definido e a fronteira de avanço é atualizada;

3. Caso ainda existam arestas a serem processadas, o passo 2 deve ser executado. Se não há arestas na fronteira de avanço que ainda não foram processadas e o conjunto de pontos de entrada já foi todo processado, o algoritmo termina. Caso contrário, uma novo triângulo inicial é definido e o passo 2 é executado.

Segundo os autores, o algoritmo Ball Pivoting gera uma aproximação simplicial que é um subconjunto dos $\alpha$-shapes e, portanto, possui as mesmas garantias de reconstrução dadas as condições de amostragem uniforme. A vantagem do algoritmo é eliminar a necessidade do cálculo da triangulação de Delaunay, que corresponde ao maior custo associado aos algoritmos de esculpimento.

Um dos problemas apresentados pelo algoritmo Ball pivoting é a definição manual do parâmetro $\rho$. Se esse valor for muito pequeno, pontos da amostra não são alcançáveis e, caso contrário, áreas com curvatura acentuada não são atingidas. A Figura 2.4 ilustra, em duas dimensões, as relações entre a curva reconstruída e o parâmetro $\rho$. 
(a) Valor adequado de $\rho$

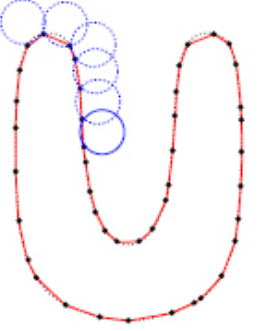

(b) Valor de $\rho$ excessivo

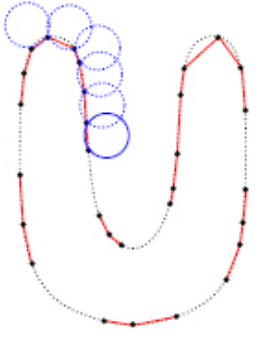

(c) Valor de $\rho$ insuficiente

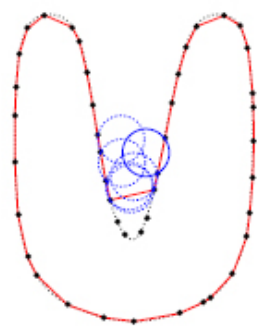

Figura 2.4: A figura (a) mostra um valor adequado para $\rho$, enquanto que (b) mostra um valor muito grande e (c) um valor muito reduzido.

Gopi et al. (2000) apresentam um algoritmo que é baseado no cálculo de triangulações de Delaunay locais. A idéia geral é projetar cada ponto da amostra sobre um plano tangente local juntamente com seus vizinhos prováveis. Em seguida, a triangulação de Delaunay é calculada para cada um dos planos locais e, por fim, algumas heurísticas para a conexão dessas triangulações locais são empregadas e geram a superfície.

Petitjean and Boyer. (2001) apresentam um método de reconstrução que oferece garantias de reconstrução baseadas apenas na densidade da amostragem, sem a necessidade de conhecimento sobre a forma da superfície a ser reconstruída. Os autores argumentam que o conhecimento prévio da forma do objeto não é necessário, pois as conexões entre os pontos são mais dependentes de propriedades locais do que globais. O funcionamento desse algoritmo depende de conceitos tais como grafo de Gabriel (2D) e hipergrafo estendido de Gabriel (3D) e não será detalhado.

Mederos et al. (2003) propõe uma técnica que se baseia no agrupamento de pontos do conjunto de amostras e escolha de pontos representativos para cada cluster. Uma triangulação é gerada a partir do grafo de k-vizinhos mais próximos para os pontos representativos.

Freedman (2007) propõe um algoritmo incremental também baseado em triangulações locais, porém, a diferença é que ao invés de calcular todos os trechos de triangulação (Gopi et al., 2000) e depois combiná-los, o algoritmo gera os triângulos de forma realmente incremental. 


\subsection{Métodos baseados em modelos deformáveis}

Os métodos baseados em modelos deformáveis constituem um grupo mais reduzido de algoritmos cujo funcionamento consiste em obter um modelo inicial que aproxime o conjunto de pontos e em deformar essa aproximação até que a superfície se ajuste ao conjunto de pontos. Esses métodos são rápidos, mas dependem de uma boa aproximação inicial derivada de algum conhecimento prévio sobre o formato do objeto a ser reconstruído.

Os algoritmos dessa classe podem ser subdivididos em duas categorias:

- Métodos baseados em Equações Diferenciais Parciais:: são métodos que empregam equações diferenciais parciais para a deformação dos modelos iniciais (Zhao et al., 2000). Apesar de produzirem bons resultados, essas técnicas dependem de discretizações e de resoluções de grandes sistemas lineares;

- Métodos baseados em funções paramétricas: esses métodos realizam deformações na superfície através da variação de parâmetros. A partir disso surgem dois problemas principais nesse tipo de abordagem: a necessidade de se conhecer como a alteração de parâmetros influencia a deformação e a dificuldade de representar detalhes finos.

Bardinet et al. (1998) apresentam um trabalho baseado em superquádricas. A vantagem do emprego de superquádricas, que são generalizações de quádricas, está no número reduzido de parâmetros. No entanto, isso se torna uma desvantagem ao passo que a técnica é incapaz de representar detalhes finos. Para tratar esse problema, uma etapa final de pós-processamento, chamada Free Form Deformation, deve ser aplicada.

\subsection{Métodos da família Crust}

Essa classe de algoritmos foi inicialmente proposta por Amenta et al. (1998a) e tem como principal característica o emprego das propriedades e relacionamentos entre o diagrama de Voronoi, a triangulação de Delaunay e o eixo medial para definir métodos de reconstrução com garantias teóricas. No entanto, tais garantias dependem 
de condições de amostragem bem específicas que são definidas a seguir, logo após as definições de eixo medial e Local Feature Size:

Definição 3 (Eixo medial) Define-se como eixo medial de uma superfície $M$ o conjunto de pontos que definem os centros de esferas que tangenciam $M$ em ao menos dois pontos.

Definição 4 (Local Feature Size) A Local Feature Size é a distância de um ponto na superfície até o eixo medial.

Definição 5 ( $\varepsilon$-amostragem) Uma $\varepsilon$-amostragem é definida a partir do local-feature size $f(x)$ da seguinte forma: seja um ponto $x$ sobre a superfície original, sempre deve existir um ponto $p$ na amostragem tal que $\|p-x\| \leq \varepsilon f(x)$, ou seja, para cada ponto da superfície deve existir um ponto na amostra a uma distância proporcional ao local-feature size

O algoritmo Crust, que deu início a toda a família de algoritmos (Amenta et al., 1998a), é discutido com maiores detalhes a seguir, sendo que inicia-se a discussão com o algoritmo Crust em 2D e, em seguida, estende-se o algoritmo para três dimensões.

O desenvolvimento do algoritmo Crust partiu de dois resultados da geometria computacional:

- Dados uma $\varepsilon$-amostragem de uma curva e dois pontos, $p$, q, não consecutivos da curva, não existe um circuncírculo contendo a aresta com extremos $p$ e $q$ livre de outros pontos da amostra e livre de pontos do eixo medial;

- Os vértices do diagrama de Voronoi fornecem uma boa aproximação do eixo medial desde que a amostragem seja suficientemente densa.

A partir dessas observações, pode-se inferir que quando é feita uma triangulação de Delaunay sobre os pontos da amostra unidos aos vértices do diagrama de Voronoi, obtém-se arestas que possuem o circuncírculo livre tanto de outros pontos da amostra quanto de pontos do eixo medial. Com base nisso, pode-se afirmar que uma aproximação da curva pode ser feita através das arestas que possuem pontos da amostra como seus dois extremos. Essa noção intuitiva dá origem ao algoritmo Crust: 
(a)

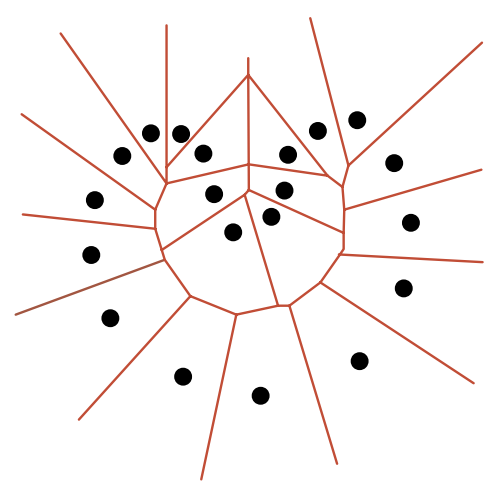

(b)

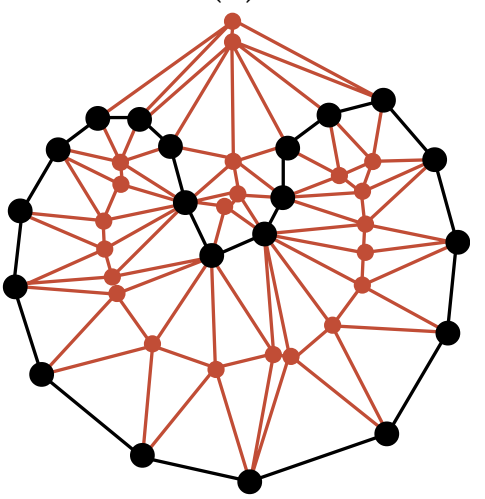

Figura 2.5: (a) Diagrama de Voronoi do conjunto de pontos. (b) A triangulação de Delaunay a partir dos pontos da amostra (preto) e dos vértices de Voronoi (vermelho). As arestas em preto constituem a reconstrução da curva (crust).

1. Calcula-se o diagrama de Voronoi de $S$, em que $S$ é o conjunto de pontos da amostra;

2. Sendo $V$ o conjunto de vértices do diagrama de Voronoi calculado em (1), calculase a triangulação de Delaunay do conjunto $S \cup V$;

3. Define-se a aproximação da curva - chamada de crust - como o conjunto de arestas da triangulação que possuem os dois extremos $p$ e $q$ tais que $p \in S$ e $q \in S$,

A Figura 2.5 fornece elementos gráficos do funcionamento do algoritmo crust em duas dimensões. A Figura 2.5(a) ilustra o diagrama de Voronoi do conjunto de pontos da amostra $S$, enquanto que a Figura 2.5(b) traz a triangulação de Delaunay de $V \cup S$ em que $V$ são os vértices de Voronoi da Figura 2.5(a). A curva reconstruída é representada pelo conjunto das arestas em preto.

A extensão desse algoritmo para três dimensões não é direta, pois a propriedade de que os vértices de Voronoi aproximam o eixo medial não é válida em $\mathbb{R}^{3}$. Na Figura 2.6 pode-se observar um exemplo de um vértice de Voronoi que não fornece uma aproximação para o eixo medial.

Diante disso, Amenta et al. (1998b) sugerem que podem ser usados dois vértices de cada célula de Voronoi como aproximação do eixo medial. Dado um ponto da amostra $p$ e sua correspondente célula de Voronoi $V_{p}$, os vértices que aproximam o eixo medial 


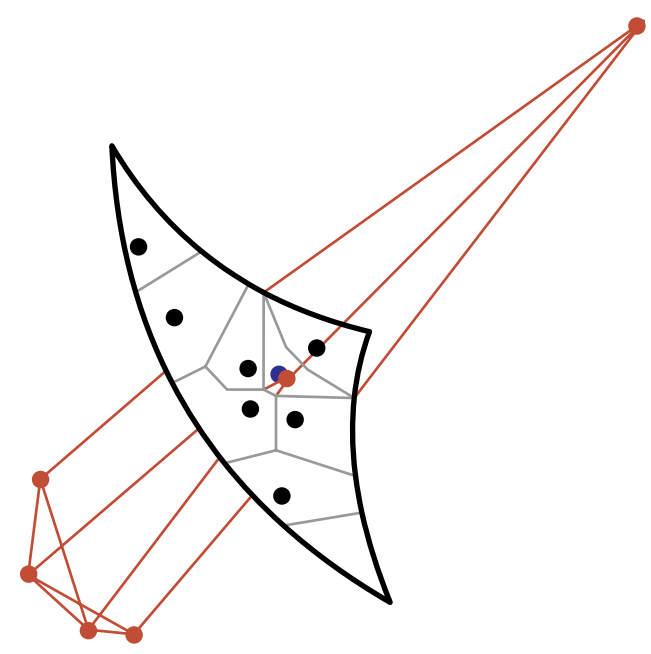

Figura 2.6: Célula de Voronoi, em vermelho, para o ponto da amostra em azul. Pode-se verificar a existência de um vértice da célula próximo à superfície que não pode ser usado como aproximação do eixo medial.

são os vértices de $V_{p}$ mais distantes do ponto $p$ que estão em lados opostos da superfície. Tais vértices, chamados pólos $p^{+}$e $p^{-}$, geram uma aproximação para o diagrama de Voronoi e são usados no algoritmo estendido para três dimensões:

1. Calcula-se o diagrama de Voronoi para o conjunto de pontos amostrados $S$;

2. Determina-se o conjunto $P$ como contendo os pólos $\left(p^{+}\right.$e $\left.p^{-}\right)$de todas as células de Voronoi calculadas em (1);

3. Calcula-se a triangulação de Delaunay para o conjunto $P \cup S$;

4. Define-se a aproximação da superfície como o subconjunto de triângulos da triangulação obtida em (3) tais que cada triângulo possua todos os seus vértices em $S$.

As principais vantagens do algoritmo Crust são as garantias teóricas oferecidas, no entanto, tais garantias só se aplicam a superfícies suaves e corretamente amostradas. Além disso, como o algoritmo exige o cálculo de um diagrama de Voronoi e de uma triangulação de Delaunay, esse é suscetível a ruídos.

A partir desse trabalho pioneiro de Amenta et al., toda uma família de algoritmos com garantias teóricas de reconstrução tem sido proposta. Gois (2004) apresenta uma 
revisão extensa de todos esses métodos que não serão discutidos nesse trabalho. Uma lista dos principais algoritmos da família é fornecida a seguir:

- Crust (Amenta et al., 1998b)

- Power Crust (Mederos et al., 2005)

- Cocone (Amenta et al., 2000)

- Tight Cocone(Dey and Goswami, 2002)

- Robust Cocone(Dey and Goswami., 2004)

- Eigencrust (Kolluri et al., 2003)

\subsection{Métodos implícitos}

Os métodos implícitos são baseados na definição de uma função de distância com sinal $f$ e na realização de uma aproximação simplicial (triangulação) da isosuperfície $f(x)=c$. Tal processo de aproximação da função $f$ é realizado através de técnicas de extração de isosuperfícies, que são descritas em maiores detalhes no Capítulo 3. Portanto, a presente seção dedica-se a expor como a função $f$ é definida a partir da nuvem de pontos.

Dentre as vantagens dos métodos implícitos, pode-se destacar a menor sensibilidade a ruídos e a facilidade de se combinar funções implícitas para fins de modelagem. No entanto, as mesmas características que tornam os métodos implícitos robustos com relação a dados ruidosos e incompletos podem produzir suavizações indesejáveis nas superfícies. Além disso, normalmente é difícil conseguir controle local sobre as funções de distância.

Nos parágrafos subseqüentes é feita uma revisão a respeito dos principais métodos de reconstrução de superfícies que empregam funções implícitas, seguindo uma divisão entre métodos iniciais, métodos baseados em Partição da Unidade, métodos baseados em RBFs e métodos baseados em MLS.

Em 1982, Blinn (Blinn, 1982) propôs uma nova técnica para a modelagem de superfícies implícitas - conhecida como modelo Blobby - através da combinação de funções 
primitivas tais como esferas ou superquádricas. Esse modelo serviu de ponto de partida para uma das primeiras técnicas de reconstrução de nuvens de pontos usando funções implícitas (Muraki, 1991). A técnica proposta por Muraki consiste na definição de um conjunto de blobbies que, combinados, aproximam a superfície subjacente à nuvem de pontos. O algoritmo funciona de forma a minimizar uma função de energia que mede a distância entre a superfície gerada e a nuvem de pontos, e também a diferença entre a normal da superfície (assumida como conhecida) e o gradiente sobre a superfície. Inicialmente a aproximação é dada por apenas um blobby que é subdividido sucessivamente com o intuito de minimizar a função de energia.

O trabalho de Hoppe et al. (1992) é um dos mais citados na área de reconstrução, pois algumas das técnicas e idéias introduzidas são aplicadas ainda hoje.

Antes da descrição do algoritmo são feitas duas definições sobre a qualidade de amostragem assumida pelo algoritmo.

Definição 6 (Amostra $\delta$-ruidosa e Amostra $\rho$-densa) Seja $X=\left\{x_{0} \ldots x_{n}\right\}$ uma amostra obtida sobre uma superfície $S$. Considerando $x_{i}=y_{i}+e_{i}$, em que $y_{i}$ é a medida exata e $e_{i}$ o erro cometido, X é dita $\delta$-ruidosa seja para qualquer $i$, tal que $e_{i}<\delta$. Uma amostra é dita $\rho$-densa se para qualquer $y_{i}$ existe pelo menos uma amostra $y_{j}$ tal que $\left\|y_{i}-y_{j}\right\|<\rho$.

Considerando uma superfície $S$ e a amostragem $X \rho$-densa e $\delta$-ruidosa, a idéia básica do algoritmo pode ser resumida em dois passos principais:

- Para cada ponto $x_{i}$ da amostra $X$ é definido um plano de referência local representado por uma origem $o_{i}$ e por uma normal $\vec{n}_{i}$;

- Uma função de distância com sinal é definida a partir dos planos de referência, ou seja, a distância de um ponto $p$ qualquer é calculada como a distância de $p$ ao plano de referência local cuja origem $o_{i}$ está mais próxima de $p$.

A definição dos planos locais de referência é realizada através do cálculo das origens, do cálculo das direções dos vetores normais e de uma orientação consistente das normais. 
Dado um ponto da amostra $x_{i}$, um plano associado $T_{x_{i}}$, uma $k$-vizinhança $\operatorname{Viz}\left(x_{i}\right)$ composta pelos $k$ pontos mais próximos a $x_{i}$ e um ponto qualquer $q$ define-se a distância entre $p$ e $T_{x_{i}}$ como:

$$
f(p)=\left(p-o_{i}\right) \cdot \overrightarrow{n_{i}}
$$

Os cálculos do centro $o_{i}$ e do vetor normal $\overrightarrow{n_{i}}$ são realizados de forma que o plano seja aquele melhor se aproxime à vizinhança $V i z\left(x_{i}\right)$. Para tanto, o centro $o_{i}$ é definido como o centróide de $\operatorname{Viz}\left(x_{i}\right)$ e a direção normal é determinada pela análise da direção principal da matriz de co-variância:

$$
M C=\sum_{y \in V i z\left(x_{i}\right)}\left(y-o_{i}\right) \otimes\left(y-o_{i}\right)
$$

em que $\otimes$ é o operador de produto externo. ${ }^{2}$

Após o cálculo dos autovalores $\lambda_{i}^{1}>\lambda_{i}^{2}>\lambda_{i}^{3}$ da matriz $M C$, o autovetor $v_{i}^{3}$, associado ao autovalor $\lambda_{3}$, é definido como a direção do vetor normal $n_{i}$.

Para finalizar o processo, ainda resta realizar a orientação consistente dos vetores normais $n_{i}$. Considerando que dois vetores unitários vizinhos $n_{i}$ e $n_{j}$ devem ser aproximadamente paralelos, uma orientação consistente faz com que o produto interno de dois vetores vizinhos $n_{i}$ e $n_{j}$ seja aproximadamente 1 . A abordagem empregada consiste em escolher um ponto extremo, por exemplo, o ponto $x_{k} \operatorname{com}$ maior coordenada $z$, orientá-lo e propagar a orientação para o restante dos pontos. Essa abordagem ainda é largamente empregada para a orientação de vetores normais pelos bons resultados que apresenta.

Depois que todos os planos de referência foram calculados, a função de distância é dada pela Equação 2.1 em que $o_{i}$ é o centróide mais próximo de $p$.

Os autores ainda argumentam que a função $f$ funciona bem para uma superfície sem bordo, no entanto, para uma superfícies com bordo, a projeção de um ponto sobre o plano de referência pode estar fora da superfície e, para esses casos, a distância é indefinida. Para detectar se a projeção $z$ de um ponto $p$ está fora da superfície basta

\footnotetext{
${ }^{2} \mathrm{O}$ produto externo $m=a \otimes b$ é tal que $m_{i, j}=a_{i} \cdot b_{j}$
} 
(a) Modelo original

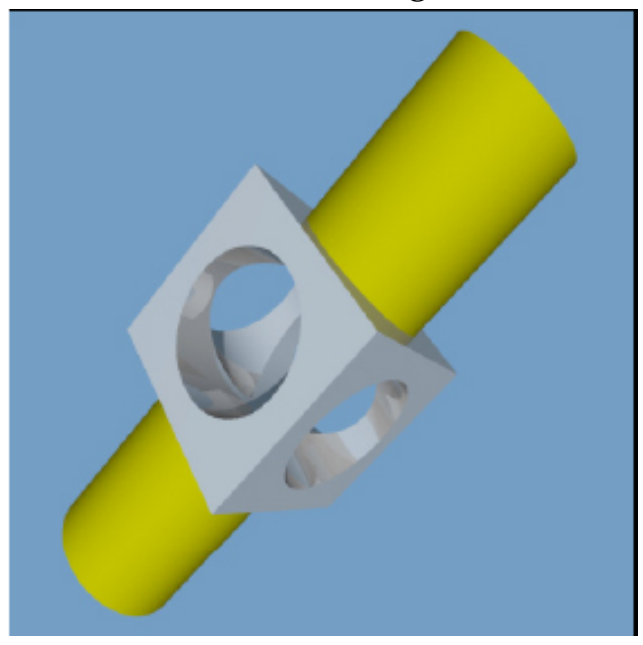

(c) Planos de referência

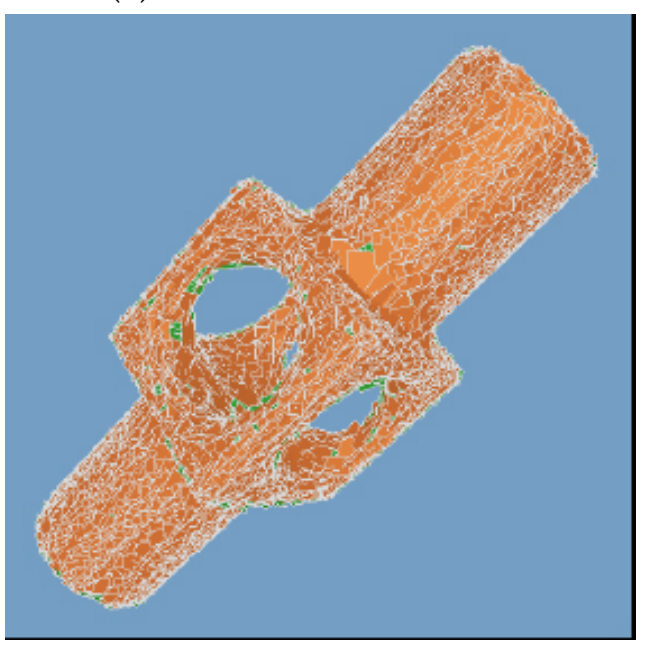

(b) Pontos da amostra

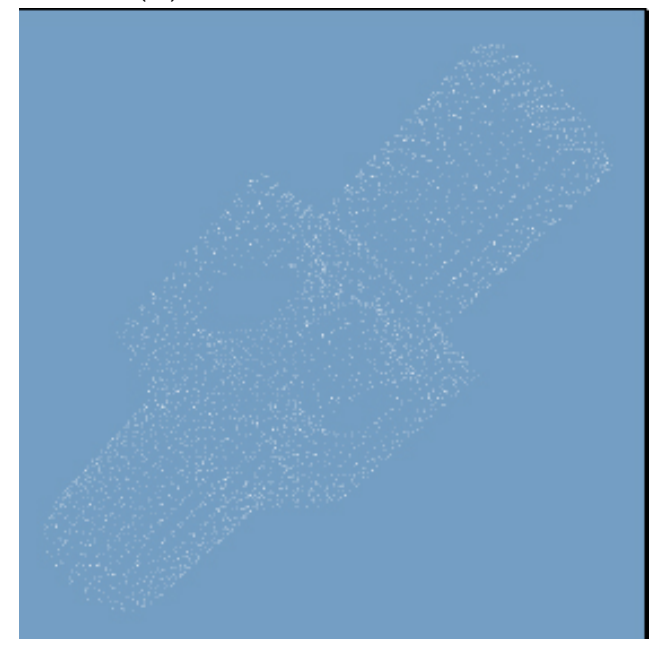

(d) Superfície reconstruída

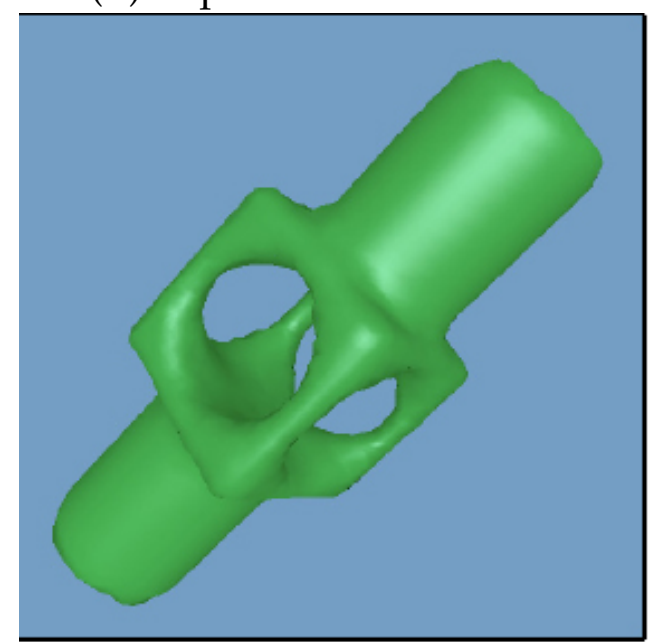

Figura 2.7: Método de reconstrução da superfície (Hoppe et al., 1992).

verificar se a distância entre $z$ e o ponto $x_{i}$ mais próximo de $z$ é maior que $\rho+\delta$, já que o algoritmo assume que a amostragem $X$ é $\rho$-densa e $\delta$-ruidosa.

A Figura 2.7 ilustra o processo de reconstrução através do algoritmo proposto por Hoppe et al. (1992).

Hoppe et al. (1994) estenderam o trabalho descrito anteriormente através da adoção de funções suaves para realizar a aproximação local. Uma técnica conhecida como superfícies de subdivisão é empregada, na qual funções suaves são aproximadas pela combinação de patches definidos por um número reduzido de parâmetros irrestritos. Essa técnica apresenta vantagens sobre o uso de patches NURBS, pois esses últimos 
apresentam um grande número de parâmetros (coeficientes das B-Splines) restritos por condições de continuidade.

O método descrito no trabalho pode ser dividido em 3 passos:

1. Geração de uma malha inicial que aproxime o objeto usando a técnica descrita em Hoppe et al. (1992);

2. Simplificação da malha;

3. Uso da superfície de subdivisão para aproximar regiões locais. O esquema de subdivisão proposto é capaz de detectar e representar sharp edges e sharp vertices.

Bajaj et al. (1995) fazem uso de conceitos de $\alpha$-shapes, introduzidos na Seção 2.3, para a definição de uma função de distância aproximada e da subseqüente definição de uma função final baseada na combinação de aproximações suaves locais usando polinômios de Bernstein-Bèzier.

Para a definição da função de distância aproximada, é calculada uma aproximação para a superfície usando $\alpha$-shapes. O valor de $\alpha$ é selecionado através de uma busca binária que procura pelo valor que produza as condições exigidas para a superfície. Durante o cálculo do $\alpha$-shape, a triangulação de Delaunay e, conseqüentemente, o diagrama de Voronoi também são obtidos sendo que, paralelamente, um procedimento simples realiza a classificação dos tetraedros da triangulação de Delaunay em internos ou externos. A função de distância para um ponto qualquer $p$ é definida como $f(p)=$ s. $\left\|p-x_{i}\right\|$ em que $\mathrm{s}$ é +1 se o tetraedro no qual $p$ se encontra é externo ou -1 se o tetraedro é interno e $x_{i}$ é o ponto da amostra mais próximo a $p$ calculado através do diagrama de Voronoi.

Após a definição da função de distância, uma aproximação usando polinômios de Bernstein-Bèzier é feita para cada tetraedro que possua uma face contida no $\alpha$-shape. O valor do erro de aproximação global em relação aos pontos da amostra é calculado e, enquanto esse erro é maior que um dado limiar, os tetraedros são subdivididos através da inserção de novos pontos. Por fazer uso dos $\alpha$-shapes, o algoritmo exige uma nuvem de pontos uniformemente amostrada. 


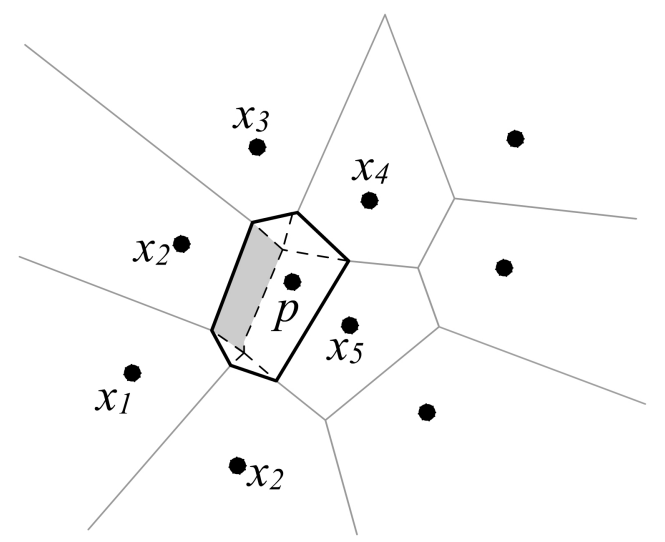

Figura 2.8: Ilustração da vizinhança natural de $p$. A área hachurada representa o valor de $\lambda_{x_{2}}(p)$.

Outro trabalho (Bernardini et al.,1999a) também faz uso de $\alpha$-shapes e de polinômios de Bernstein-Bèzier com a diferença de que um passo de simplificação da triangulação é aplicado antes da definição dos polinômios.

Boissonnat and Cazals (2002) propõem uma função de distância baseada na interpolação de vizinhos naturais. Sejam $h_{x_{i}}(p)$ e $\lambda_{x_{i}}(p)$, respectivamente, uma função de distância e uma função peso associadas ao ponto $x_{i}$ da amostra $X$. A distância de um ponto $p$ à superfície $S$ subjacente à nuvem de pontos é dada por:

$$
f(p)=\sum_{p \in X} \lambda_{x_{i}}(p) \cdot h_{x_{i}}(p)
$$

A função $h_{x_{i}}(p)$ empregada é a mesma definida por Hoppe et al. (1992) e função peso $\lambda_{x_{i}}(p)$ é dada pela relação de vizinhança natural.

Definição 7 (Vizinhança natural) Sejam $X=\left\{x_{0} \ldots x_{n}\right\}$ uma amostra obtida sobre uma superfície S e p um ponto qualquer. A vizinhança natural de pé dada pelos pontos interligados a p na triangulação de Delaunay de X $\cup p$.

De maneira equivalente, a vizinhança natural de $p$ pode ser definida, em termos do diagrama de Voronoi, como o conjunto de pontos $\left\{x_{i}\right\}$ que tem suas células afetadas pela inserção de $p$ no diagrama. Essa situação pode ser visualizada na Figura 2.8.

Logo, uma forma de definir a função de peso $\lambda_{x_{i}}(p)$ para um ponto da amostra $x_{i}$ é através da medida da intersecção entre a célula de $x_{i}$ no diagrama de Voronoi de $X$ e a 
célula de $p$ no diagrama de Voronoi de $X \cup\{p\}$. Na Figura 2.8 está representado o valor de $\lambda_{x_{2}}(p)$.

Além da definição da função de distância, Boissonnat and Cazals (2002) aproveitam os dados calculados em um processo de extração de isosuperfícies baseado na dualidade do diagrama de Voronoi e da triangulação de Delaunay. Esse processo apresenta vantagens em relação a outros métodos, pois a o diagrama de Voronoi é adaptado à geometria da superfície e os pontos da amostra $X$ encontram-se sobre a superfície. A poligonalização é realizada aproveitando a relação de dualidade entre arestas de Voronoi e faces da triangulação Delaunay 3D, bastando avaliar a função nas extremidades de uma aresta de Voronoi e, se os valores possuírem sinais opostos, incluir a face dual na triangulação.

Os trabalhos citados até o momento consistem de aproximações da superfície usando planos de referência locais. A principal desvantagem dessa abordagem é não empregar partição espacial e, portanto, desconsiderar o uso de refinamentos para representar regiões mais complexas da superfície. Os trabalhos descritos nessa seção, a partir de agora, fazem uso de partição espacial.

Em 2003, Ohtake et al. propuseram um método conhecido como Multi-Level Partition of Unity (MPU) que emprega decomposição espacial baseada em octree (Ohtake et al., 2003). De maneira geral, o método funciona estabelecendo uma partição do domínio em regiões que correspondem aos nós de uma octree. Em seguida, são calculadas aproximações locais para cada uma das regiões e é feita a combinação das funções locais a fim de definir uma função global. O algoritmo desenvolvido assume que os pontos de entrada estão equipados com vetores normais e é descrito a seguir:

1. Criar uma octree com um único nó folha que corresponda a um cubo que contenha todos os pontos de entrada (bounding box);

2. Para cada nó folha, criar uma aproximação local para os pontos contidos nesse nó. Se a aproximação gerar um erro acima de um limiar fixado, subdividir o nó e recalcular as aproximações para os novos 8 nós folha;

3. Combinar todas as aproximações locais em uma função global através da técnica 
de partição da unidade.

A técnica de partição de unidade é tipicamente utilizada na integração de aproximantes locais em uma aproximação global. A idéia básica é separar o domínio em várias partes, aproximar os dados em cada subdomínio separadamente e combinar as soluções locais através de pesos locais e suaves que, se somados em cada ponto do domínio, são iguais a um. Antes de descrever em maiores detalhes o procedimento da partição da unidade, são feitas algumas definições:

Definição 8 (Suporte) Definimos como suporte de uma função $f$, denotado supp $(f)$, como o fecho do conjunto $\{x: f(x) \neq 0\}$.

Definição 9 (Conjunto compacto) No espaço euclidiano, um conjunto compacto é definido como um conjunto fechado e limitado.

Definição 10 (Suporte compacto) Uma função f possui suporte compacto se supp $(f)$ é um conjunto compacto.

Considerando um domínio $\Omega$ em um espaço euclidiano (no caso, o espaço tridimensional) e um conjunto de funções de suporte compacto não-negativas $\left\{\varphi_{i}\right\}$ tais que:

$$
\sum_{i} \varphi_{i}=1
$$

Seja $V_{i}$ um conjunto de funções aproximantes locais com domínio $\operatorname{supp}\left(\varphi_{i}\right)$, a função de aproximação global em $\Omega$ é escrita na forma:

$$
f(x) \approx \sum_{i} \varphi_{i}(x) Q_{i}(x)
$$

onde $Q_{i} \in V_{i}$. Dado um conjunto de funções de suporte compacto $\left\{w_{i}(x)\right\}$ tais que

$$
\Omega \subset \bigcup_{i} \operatorname{supp}\left(w_{i}\right)
$$

o conjunto de funções de partição de unidade $\left\{\varphi_{i}(x)\right\}$ pode ser gerado por: 


$$
\varphi_{i}(x)=\frac{w_{i}(x)}{\sum_{j=1}^{n} w_{j}(x)}
$$

O conjunto de funções $\left\{w_{i}(x)\right\}$ pode ser definido para fins de aproximação ou de interpolação. Para a aproximação é usada a função B-spline quadrática $b(t)$ centrada em $c_{i}$ com suporte esférico de raio $R_{i}$ :

$$
w_{i}(x)=b\left(\frac{3\left|x-c_{i}\right|}{2 R_{i}}\right)
$$

As funções do conjunto $\left\{V_{i}\right\}$, utilizadas na aproximação local dos conjuntos de pontos, podem ser de três tipos:

1. Quádrica 3D: utilizada para aproximar grandes partes da superfície;

2. Polinômio de grau 2 em sistema de coordenadas locais: empregado na aproximação de regiões suaves

3. Superfícies de grau 2 por partes: utilizada para aproximar arestas e vértices afiados

Algumas heurísticas são aplicadas para determinar qual o tipo de função que deve ser aplicado. Por exemplo, o tipo 3 é empregado se, para quaisquer dois pontos $i$ e $j$ no domínio local, $\min _{i, j}\left|n_{i} . n_{j}\right|>0.7$.

Dentre as principais vantagens do algoritmo de Ohtake et al. (2003) pode-se destacar a capacidade de lidar com grandes conjuntos de dados e a reconstrução precisa de características afiadas (vértices e arestas).

Recentemente, o uso de funções de base radial (RBFs) tem se tornado freqüente nos métodos de reconstrução de superfícies usando funções implícitas, portanto, tais técnicas serão exploradas a seguir, logo após uma definição de RBFs:

Definição 11 (Funções de Base Radial) Uma função de base radial é uma função simétrica em relação à vizinhança radial de um ponto (centro).

Carr et al. (2001) fazem uso de funções de base radial na aproximação de um conjunto de pontos equipados com normais orientadas. Dada uma função de base 
radial apropriada, no caso $\phi(x)=|x|$, a função de interpolação para um conjunto de amostras $S$ é da forma

$$
f(x)=\sum_{j=1}^{N} \lambda_{j} \phi\left(x-s_{j}\right)+P(x),
$$

em que $N$ é o tamanho da amostra, $\lambda_{j}$ são os pesos e $P(x)$ é um polinômio de grau $m$.

Uma restrição colocada sobre os coeficientes é:

$$
\sum_{i=0}^{N} \lambda_{i} P\left(x_{i}\right)=0 .
$$

Sejam $\left\{p_{1}, \ldots, p_{l}\right\}$ uma base de polinômios $p_{i}$ de grau no máximo $\mathrm{m}$ e $\left\{c_{1}, \ldots, c_{l}\right\}$ os coeficientes que descrevem $P$ na base, as equações 2.9 e 2.10 podem ser escritas através do sistema linear

$$
\left(\begin{array}{ll}
A & P \\
P^{T} & 0
\end{array}\right)\left(\begin{array}{l}
\lambda \\
c
\end{array}\right)=\left(\begin{array}{l}
f \\
0
\end{array}\right),
$$

em que $f$ é o valor da função a ser determinada nos pontos da amostra.

Como todos os pontos da amostra $S$ estão localizados sobre a superfície e, portanto, apresentam $f\left(x_{i}\right)=0$, é necessária a adição de novos pontos ao sistema para evitar a solução trivial $\lambda_{i}=0$ para qualquer $i$. Esses pontos são gerados a partir de cada ponto $x_{i}$ caminhando-se na direção do vetor normal.

Carr et al. (2001) argumentam que, pelo fato de depender da resolução de um sistema linear, a abordagem não pode lidar com um número muito grande de pontos de entrada e por isso propõem duas otimizações:

- Uso de um método para a rápida avaliação das RBFs que se baseia em relaxar critérios de precisão a fim de aumentar o desempenho sem comprometer o resultado;

- Uso de um algoritmo guloso para utilizar apenas um subconjunto dos pontos de entrada no processo de interpolação. Essa técnica escolhe um subconjunto qualquer de pontos, realiza a interpolação e, em seguida, calcula os resíduos. 
Se o erro estiver fora de um limiar definido, novos pontos são adicionados e a interpolação é re-calculada.

O trabalho de Turk and O'brien (2002) também utiliza RBFs, no entanto, o foco do trabalho está na modelagem e não no processo de reconstrução. A função de base radial utilizada nesse trabalho é $\phi(x)=\left|x^{3}\right|$.

Dentre as vantagens dos métodos baseados em RBFs, pode-se destacar a capacidade de lidar com dados incompletos e ruidosos, porém, tais métodos apresentam uma desvantagem quanto ao número de pontos que podem ser tratados devido à complexidade de resolução do sistema linear. Por essa razão, alguns trabalhos têm explorado o emprego de funções de base radial de suporte compacto que tornam os sistemas esparsos e aceleram a resolução. No entanto, esse tipo de função apresenta alta sensibilidade a ruídos e densidade de amostragem. Em um tentativa de unir o melhor oferecido pelas duas frentes, Ohtake et al. (2004) propuseram um método hierárquico que faz uso de RBFs de suporte compacto.

Dada uma amostragem $S$, o método funciona definindo uma hierarquia de pontos:

$$
\left\{S^{1}, \ldots, S^{n}=S\right\},
$$

em que $S^{k}$ é uma simplificação de $S^{k+1}$.

O processo de interpolação (ou aproximação) emprega uma abordagem bottom-up através da construção de funções implícitas $f^{k}$ que interpolam (aproximam) $S^{k}$ para $k=1, \ldots, n$.

O processo de construção das funções funciona da seguinte forma: dada uma aproximação $f^{k}(x)$, a aproximação $f^{k+1}(x)$ é dada pela soma da função $f^{k}(x)$, de uma partição de unidade para $S^{k+1}$ e da aproximação obtida pelas RBFs de suporte compacto.

Os autores argumentam que o método resultante é mais eficiente que o método de Carr et al. (2001) e que também é capaz de lidar com dados incompletos. Na maioria dos casos, o método apresentou bons resultados práticos, no entanto, houve casos em que superfícies extra foram geradas.

O trabalho de Co et al. (2004) propõe o uso de RBFs para geração de aproximantes locais que são combinados através de Partição da Unidade. A maior contribuição do 
(a) Pontos orientados

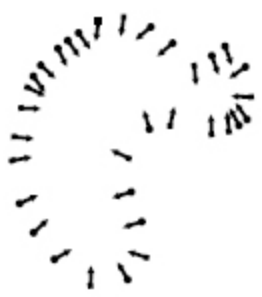

(c) Função indicadora

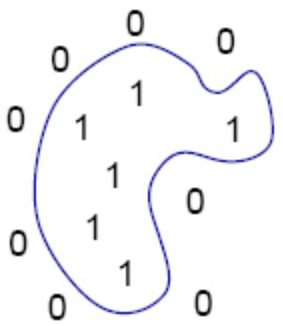

(b) Gradiente da função indicadora

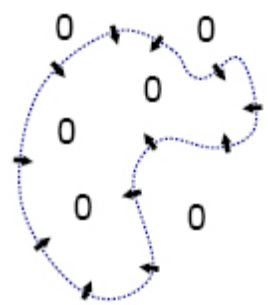

(d) Curva reconstruída

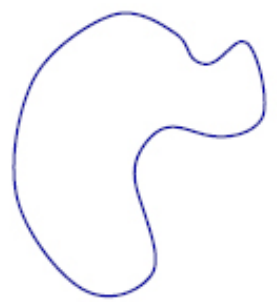

Figura 2.9: Relação entre gradiente da função indicadora e amostra de pontos

trabalho, segundo os autores, é a capacidade de lidar com amostras de pontos vindas de diversos tipos de grids, que podem ser até não alinhados. Os autores também argumentam que um ponto que merece investigação é a melhoria da eficiência da avaliação da função, que depende diretamente da facilidade em se avaliar os interpolantes locais.

O trabalho de Kazhdan et al. (2006) propõe uma abordagem diferente de todas já apresentadas nessa seção. A observação chave feita pelos autores é relacionar os pontos orientados (pontos equipados de vetores normais apontando para o interior da superfície) com o gradiente de uma função indicadora.

Uma função indicadora é simplesmente uma função que possui valor zero para pontos externos à superfície e valor um para pontos internos. Isso significa que o gradiente da função indicadora é zero em todo o domínio exceto sobre a superfície, onde é representado por um campo de vetores apontando para o interior da mesma. Portanto, os pontos amostrados podem ser considerados uma amostragem do gradiente da função indicadora, o que reduz o problema da reconstrução a encontrar a função cujo gradiente corresponde aos pontos de entrada. Os autores argumentam que esse problema pode ser transformado em um problema de Poisson. A Figura 2.9 ilustra a situação descrita no parágrafo anterior no caso bidimensional. 
Shen et al. (2004) propõe um método de reconstrução a partir de funções implícitas que recebe como entrada uma sopa de polígonos, ou seja, uma triangulação incompleta que pode ter sido gerada por qualquer método de reconstrução, e produz como saída uma superfície suave.

Outro tipo de abordagem implícita faz uso de Moving Least-Squares (MLS, Mínimos quadrados móveis) em um processo de aproximação da superfície baseado em propriedades estritamente locais. O operador de projeção MLS, se baseia em resultados da geometria diferencial e consiste na definição de um sistema de coordenadas locais e aproximação de um polinômio nesse sistema. Dessa forma, a superfície é definida apenas localmente nos pontos em que é necessária a avaliação.

Adamson and Alexa (2003) propuseram um algoritmo de ray tracing em que é empregada uma função implícita inspirada no mecanismo de projeção MLS. A função de distância é expressa pela seguinte equação:

$$
f(x)=n(x) \cdot(a(x)-x)
$$

em que $n(x)$ é a normal calculada em relação ao ponto $x$ e $a(x)$ corresponde à média ponderada dos pontos na vizinhança de $x$.

Essa função de distância é igual à definida por Hoppe et al. (1992), com a diferença de que no cálculo de $a(x)$ e $n(x)$ é empregada uma função de peso $\theta$, que é utilizada no operador de projeção MLS. O emprego dessa função peso tem a finalidade de tentar garantir a continuidade da função, que é definida apenas localmente.

Sejam $p_{0}, \ldots, p_{N-1}, N$ pontos de entrada e $\theta_{i}(x)=\theta\left(\left\|p_{i}-x\right\|\right)$ a função peso que especifica a influência do ponto $p_{i}$ em relação a $x$, a média ponderada dos pontos na vizinhança de $x$ é dada por:

$$
a(x)=\frac{\sum_{i=0}^{N-1} \theta_{i}(x) p_{i}}{\sum_{i=0}^{N-1} \theta_{i} x}
$$

e a co-variância ponderada em $x$ na direção $n$ descreve o quão bem o plano $n \cdot(x-p)=0$ aproxima os pontos da amostra de entrada: 


$$
\sigma_{n}^{2}(x)=\frac{\left.\sum_{i=0}^{N-1} \theta_{i}(x)\left(n \cdot\left(x-p_{i}\right)\right) .\right)^{2}}{\sum_{i=0}^{N-1} \theta_{i} x}
$$

Seja $\sigma(x)$ o vetor das co-variâncias nas direções da base canônica:

$$
\sigma(x)=\left(\begin{array}{c}
\sigma_{1,0,0}(x) \\
\sigma_{0,1,0}(x) \\
\sigma_{0,0,1}(x)
\end{array}\right) .
$$

A matriz $\Sigma(x)$ é definida de forma que as direções de maior e menor covariância sejam acessíveis através dos auto-vetores:

$$
\Sigma(x)=\sigma(x) \sigma(x)^{T}
$$

A direção $n(x)$ é dada pelo auto-vetor da matriz $\Sigma(x)$ associado ao menor autovalor, sendo que o vetor $n(x)$ só é bem definido se o menor autovalor é único.

Em um passo posterior, a função de distância pode ser ajustada através da aproximação de um polinômio nas coordenadas locais dadas pelo plano de referência.

Em outro trabalho, Kolluri (2005) também propôs um método de reconstrução definindo uma função implícita a partir de MLS e provou propriedades de correta reconstrução para amostragens proporcionais ao local feature size.

\subsection{Considerações finais}

O presente capítulo introduziu o problema da reconstrução de superfícies a partir de nuvens de pontos e apresentou uma revisão dos principais métodos empregados. Dentre os tipos de algoritmos introduzidos foi enfatizada a classe dos métodos implícitos, já que esse é o foco principal do presente trabalho. No capítulo seguinte será feita um revisão dos métodos de extração de isosuperfícies, já que os mesmos são utilizados na poligonalização das superfícies obtidas através de funções implícitas. 
Reconstrução de Superfícies a partir de nuvens de pontos 


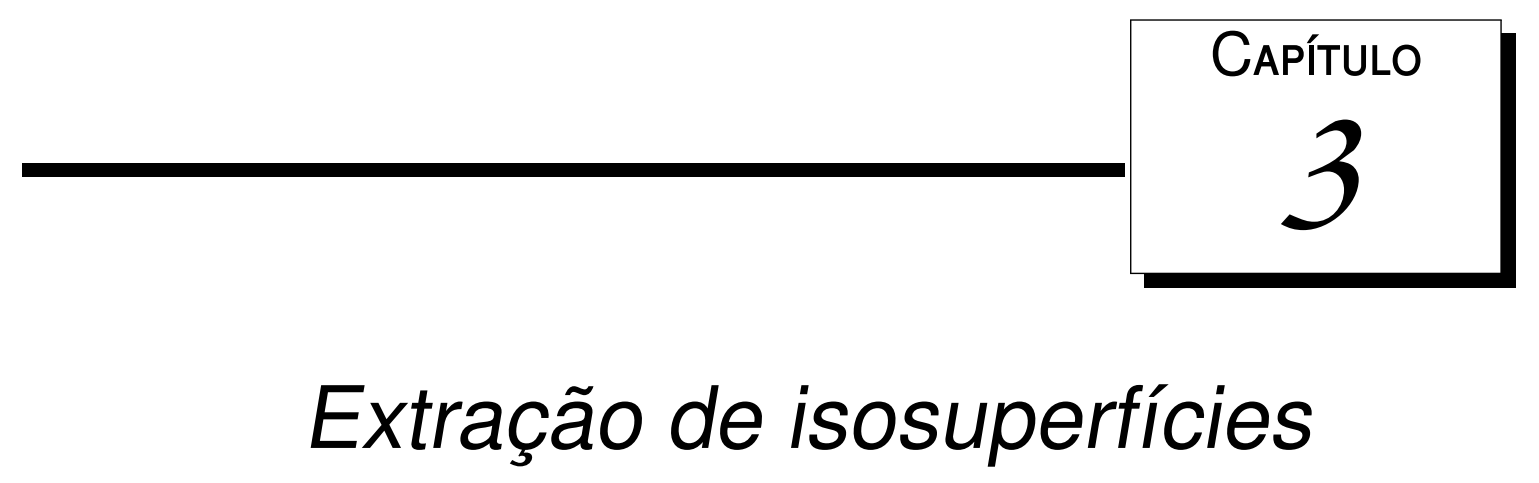

\subsection{Considerações iniciais}

No presente capítulo é feita uma revisão a respeito dos métodos de extração de isosuperfícies, que são particularmente importantes para a geração de aproximações simpliciais das funções implícitas obtidas a partir das nuvens de pontos. Na Seção 3.2, o problema da extração de isosuperfícies é enunciado e, em seguida, na Seção 3.3, é apresentada uma revisão dos principais métodos no contexto de computação gráfica e visualização. Por fim são feitas algumas considerações finais (Seção 3.4).

\subsection{Definição do problema}

Seja $f: A \subset \mathbb{R}^{3} \rightarrow \mathbb{R}$ uma função qualquer em que $A$ é um conjunto compacto, definimos a imagem inversa $F^{-1}$ da função $f \operatorname{como} F^{-1}(a)=\{x \mid f(x)=a\}$, ou seja, o conjunto de pontos para os quais a função $f$ assume o valor $a$. O objetivo da extração de isosuperfícies é obter uma aproximação simplicial para a imagem inversa de uma função $f$ para um dado nível $a$. A função $f$ pode ser contínua ou consistir de dados discretos amostrados em uma grade regular. No caso contínuo, a função pode ser avaliada em quaisquer pontos, enquanto que no caso discreto, deve-se empregar 


\section{Extração de isosuperfícies}

interpolação para a avaliação da função em pontos longe da amostra.

\subsection{Revisão dos métodos}

A revisão dos métodos de extração de isosuperfícies é organizada em duas seções, sendo que na primeira são apresentados os métodos baseados em grades regulares, enquanto que na segunda, são apresentados os métodos que não são baseados nessas estruturas, que consistem basicamente de algoritmos incrementais e dos que utilizam estruturas não-regulares.

\subsubsection{Métodos baseados em grades regulares}

Um dos mais citados métodos de extração de isosuperfícies foi proposto por Lorensen and Cline (1987) e é conhecido como marching cubes. O funcionamento do método pode ser resumido da seguinte forma, em que $a$ é o nível da isosuperfície a ser reconstruída:

- Definição de uma grade regular sobre um dado domínio;

- Avaliação da função nos vértices de um cubo e geração de codificação de 8 bits, um para cada vértice, da seguinte forma:

- Se $f(x)$ no vértice é maior que $a$, o valor do bit é 1

- Se $f(x)$ no vértice é menor que $a$, o valor do bit é 0

- Acesso a uma tabela de casos usando a codificação gerada a fim de definir a forma da superfície para cada cubo.

A Figura 3.1 mostra os 15 possíveis casos de codificação dos vértices que são obtidos excluindo-se casos simétricos de um conjunto de 256 casos possíveis. Esses casos são guardados em uma tabela onde o algoritmo encontra informações sobre quais arestas sofrem intersecção pela superfície.

Duas das principais desvantagens do algoritmo marching cubes são o fato de que a superfície gerada não é necessariamente topologicamente coerente e o fato de que o método não é adaptativo, ou seja, não permite um refinamento maior em regiões de alta complexidade da superfície. 


\section{Extração de isosuperfícies}
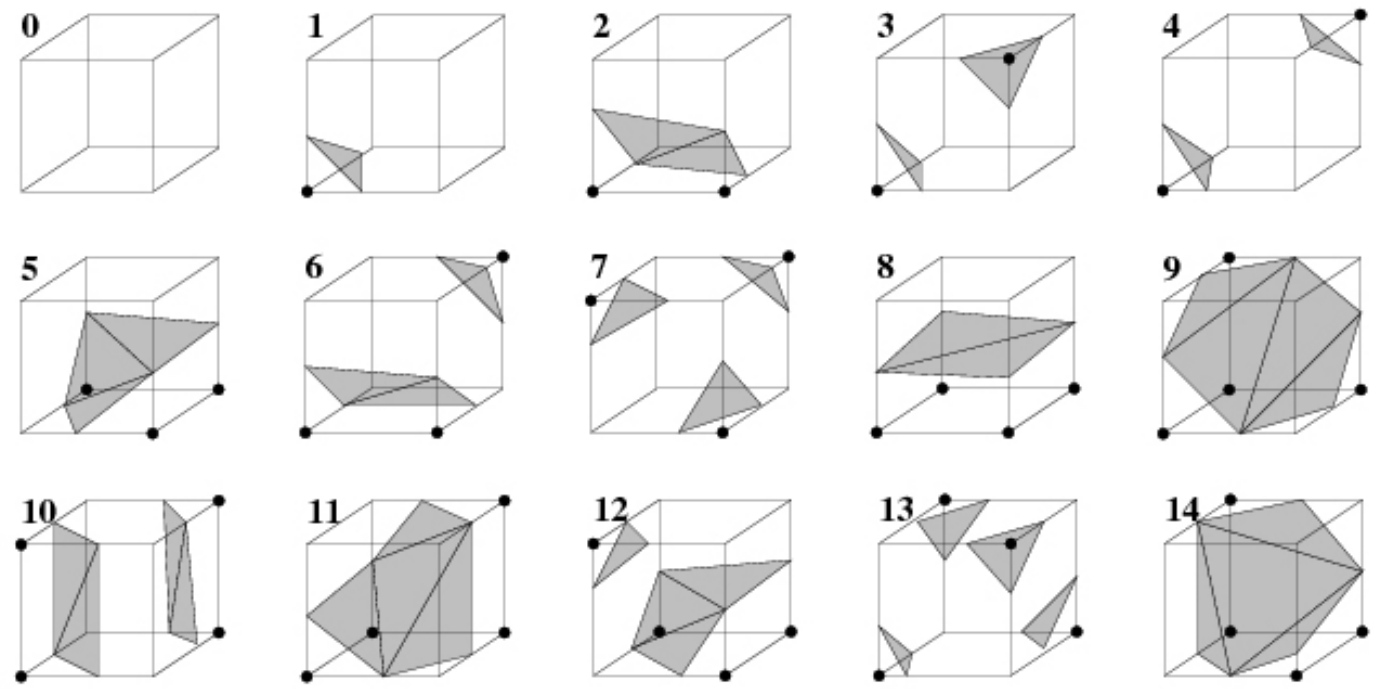

Figura 3.1: Tabela de casos do algoritmo marching cubes

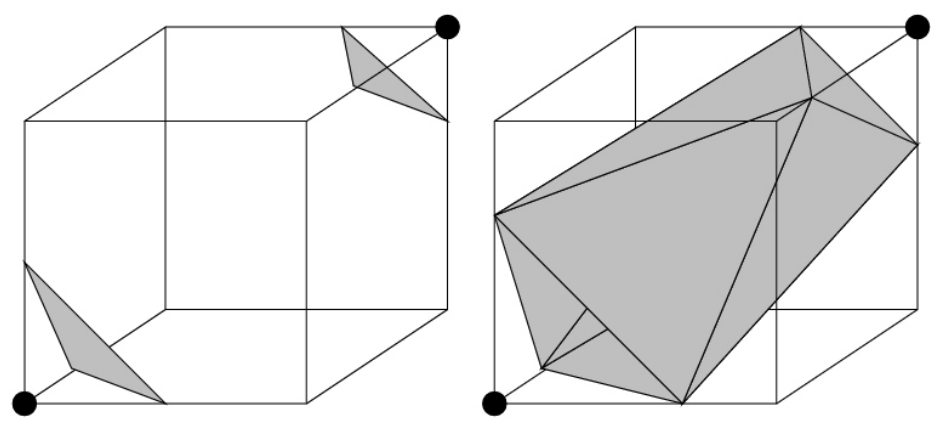

Figura 3.2: Nessa figura é mostrada a ambigüidade que pode ocorrer ao avaliar os casos de intersecção, já que em ambas as situações a codificação dos vértices é a mesma, mas a forma da superfície é diferente. 


\section{Extração de isosuperfícies}

A Figura 3.2 ilustra um dos casos ambíguos que pode acontecer na aproximação de uma superfície obtida pelo algoritmo marching cubes e que pode gerar superfícies com falhas.

Em trabalhos subseqüentes, dois tipos de abordagens procuram tratar o problema das superfícies não topologicamente coerentes, a saber: uso de malhas tetraedrais e extensões da tabela da busca do algoritmo marching cubes.

O uso de tetraedros na poligonalização de superfícies resulta em superfícies topologicamente corretas, mas, por outro lado, geram malhas que normalmente apresentam triângulos de baixa qualidade, isto é, triângulos que apresentam alta razão de aspecto. A razão de aspecto de um triângulo é a razão entre o raio do circuncírculo e o raio de um círculo inscrito. Os primeiros trabalhos que empregaram malhas tetraedrais funcionavam dividindo os cubos em cinco tetraedros e percorrendo o domínio de maneira similar ao marching cubes (Payne and Toga, 1990), dando origem ao termo marching tetrahedra. A Figura 3.3 (a) apresenta a subdivisão mencionada.

(a)

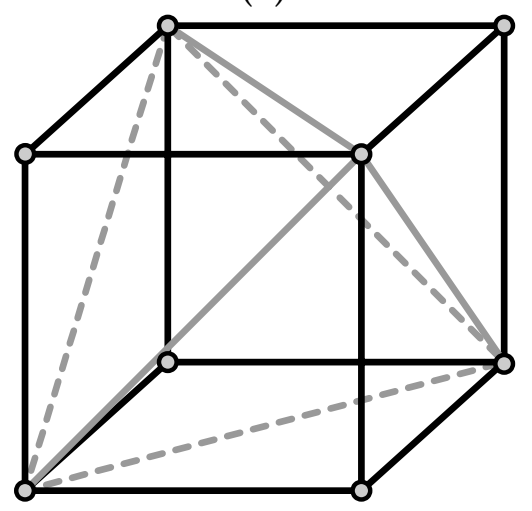

(b)

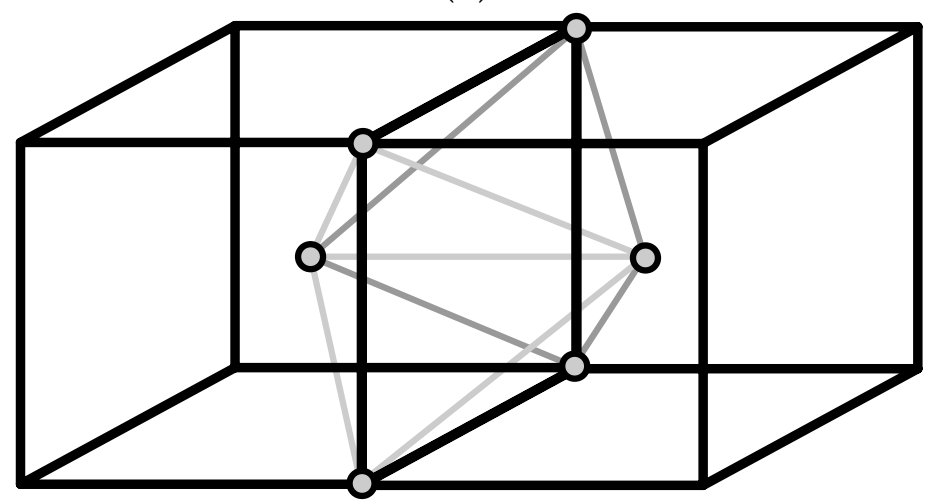

Figura 3.3: (a) Subdivisão de um cubo em 5 tetraedros. (b) Subdivisão de um cubo através dos centros.

O trabalho de Hall and Warren (1990) faz uso de uma decomposição tetraedral em que a qualidade dos triângulos é melhorada através de uma heurística que permite a movimentação dos vértices e promove a remoção de triângulos ruins. A técnica melhora a razão de aspecto dos triângulos da malha resultante, porém não apresenta nenhuma garantia a respeito dessa propriedade. 


\section{Extração de isosuperfícies}

Também com o intuito de reduzir o número de triângulos ruins, alguns trabalhos tentam produzir decomposições formadas por tetraedros mais regulares. Chan and Purisima (1998) propõem uma decomposição espacial em tetraedros aproximadamente regulares através da inserção do centróide de cada cubo e da conexão desses novos vértices a cada um dos vértices do cubo e aos centróides vizinhos. Essa decomposição faz com que cada tetraedro seja transversal a mais de um cubo. A Figura 3.3 (b) ilustra a decomposição proposta.

O trabalho de Treece et al. (1999) faz uso da decomposição descrita anteriormente e propõe um algoritmo chamado regularised marching tetrahedra. A idéia principal é a de combinar o algoritmo de extração de isosuperfícies com um algoritmo de simplificação de malhas por clusterização. O algoritmo funciona em três passagens, sendo que na primeira, cada vértice da malha de tetraedros recebe uma marcação relativa à sua proximidade da superfície, em seguida, verifica-se quais conjuntos de vértices podem ser agrupados e transformados em um único vértice e, por fim, a superfície é poligonalizada.

Dentre os trabalhos que tratam as ambigüidades do algoritmo marching cubes através da extensão da tabela de casos, destacam-se os trabalhos de Montani et al. (1994) e Chernyaev (1995). Chernyaev (1995) verificou as ambigüidades existentes nos casos do marching cubes e as classificou como ambigüidades de face ou ambigüidades internas. A ambigüidade de face, que já havia sido detectada por Nielson and Hamann (1991), ocorre quando apenas dois vértices de uma face estão marcados e encontram-se sobre uma diagonal da face. Esse caso é ilustrado na Figura 3.4, na qual fica claro que existem duas formas de poligonalizar a face. A ambigüidade interna ocorre quando apenas dois vértices opostos com relação a uma diagonal do cubo estão marcados, conforme ilustrado na Figura 3.2. Chernyaev (1995) sugere o uso de testes adicionais para ambas as ambigüidades. Ainda nessa mesma linha, Lopes and Brodlie (2003) propuseram soluções para alguns problemas nos testes adicionais do marching cubes, citados acima, que são gerados pela interpolação dos valores da função obtida nos vértices do cubo.

Recentemente, o trabalho Lewiner et al. (2003) completou os casos de ambigüidades interna destacados por Chernyaev (1995) e propôs uma implementação eficiente do 

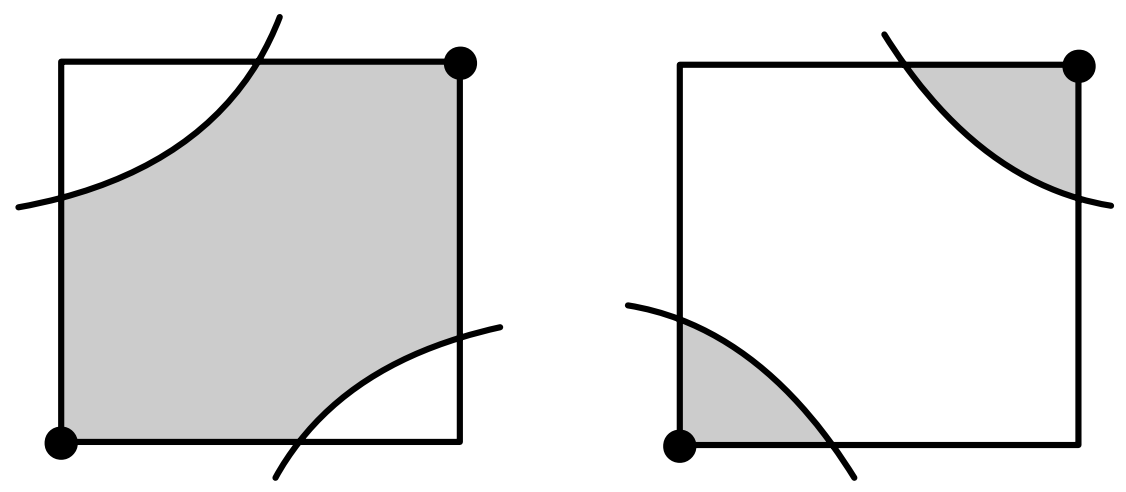

Figura 3.4: Exemplo de ambigüidade de face encontrada no algoritmo marching cubes.

algoritmo marching cubes com garantias topológicas.

A abordagem proposta por Bloomenthal (1994) procura unir a qualidade da malha gerada pelo marching cubes com a corretude proporcionada pelo uso de tetraedros. Nessa abordagem híbrida, o poligonalizador funciona ou através do cálculo da intersecção entre os cubos e a superfície ou através da interseção entre a superfície e tetraedros oriundos da subdivisão do cubo. Tal subdivisão permite um nível maior de refinamento e ocorre sempre que um caso ambíguo do algoritmo marching cubes é encontrado.

Agora que já foram discutidas algumas abordagens a respeito da geração de superfícies topologicamente coerentes, serão revistos alguns trabalhos que propõe mecanismos adaptativos para a reconstrução de superfícies.

O trabalho de Bloomenthal (1988) baseia-se na subdivisão do domínio através de uma octree e da poligonalização dos cubos referentes aos nós folhas da árvore. Uma dificuldade que surge nesse contexto é realizar a conexão das superfícies de cubos de diferentes tamanhos evitando rachaduras (Figura 3.5(a)). Para corrigir tais falhas, são enumeradas as possíveis situações que gerem rachaduras e, para cada caso, é especificada uma poligonalização. Porém, a adaptatividade baseada em octree também apresenta problemas quanto à escolha dos cubos a serem refinados, já que em alguns casos o refinamento pode gerar falhas que não são contornáveis e, portanto, devem ser feitos testes que determinem quais cubos da vizinhança também devem ser refinados. Especificamente, na Figura 3.5(b) são ilustrados dois casos em que o refinamento de 


\section{Extração de isosuperfícies}

vizinhos torna-se necessário, pois quando a superfície intercepta duas vezes a mesma aresta, é como se não houvesse intersecção. No primeiro caso, todos os cubos que compartilham a aresta interceptada devem ser refinados enquanto que, no segundo caso, apenas o cubo que compartilha a face deve ser refinado. Uma abordagem semelhante à de Bloomenthal (1988) é proposta por Shu et al. (1995) e é denominada adaptive marching cubes.

(a)

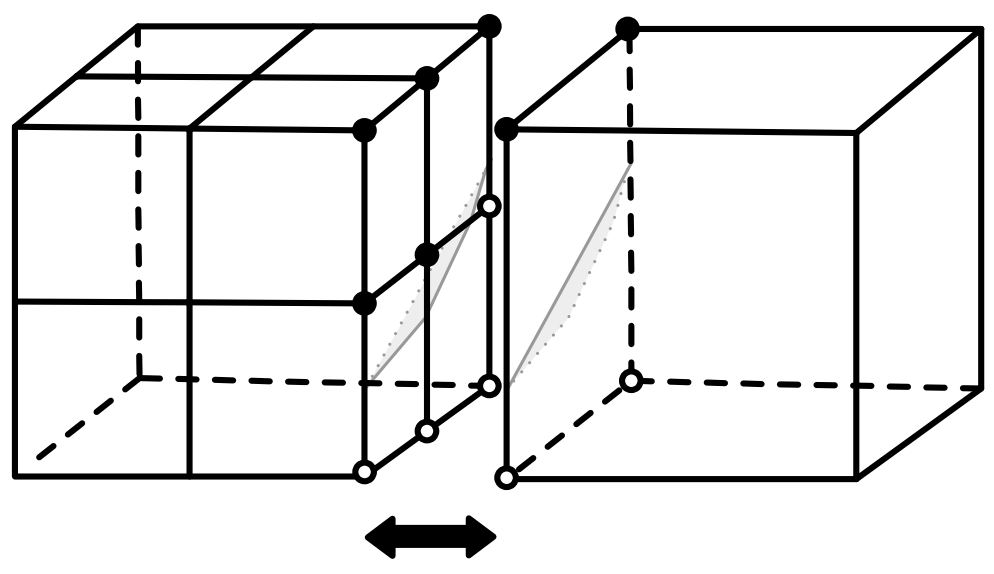

(b)

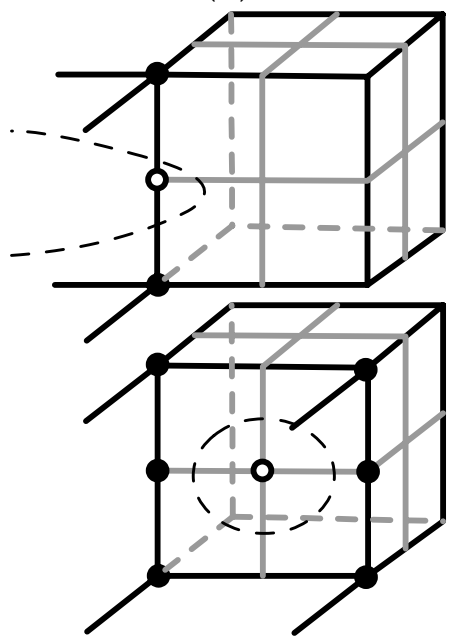

Figura 3.5: Os pontos sólidos representam pontos dentro da superfície enquanto que os demais pontos representam pontos fora da superfície. (a) A área em cinza claro representa uma rachadura que ocorre na junção de blocos de diferentes tamanhos. (b) Duas situações que não podem ser corrigidas através das heurísticas para remoção de rachaduras.

Devido aos problemas gerados pela adaptatividade baseada em octree, Hall and Warren (1990) desenvolveram uma técnica baseada em malhas tetraedrais adaptativas. O princípio básico da abordagem adotada é definir um esquema de subdivisão de tetraedros e empregar tetraedros de transição que realizam a conexão entre diferentes níveis de refinamento mantendo a propriedade de complexo celular. Tal fato impede a aparição de rachaduras, já que a propriedade de complexo celular significa que dois tetraedros quaisquer ou possuem intersecção vazia ou compartilham uma face (vértice, aresta ou face).

Recentemente, foi proposto por Paiva et al. (2006) outro método baseado na decomposição espacial do domínio através de octree. A construção da octree é feita definindo 


\section{Extração de isosuperfícies}

um bounding box da superfície e refinando qualquer nó folha que não satisfaça critérios topológicos e geométricos. A diferença dessa abordagem em relação às citadas anteriormente é que a poligonalização não é feita diretamente sobre a octree, o que leva ao problema das rachaduras, e sim sobre o dual geométrico da octree. O dual geométrico é construído de forma que cada face $k$-dimensional da octree é associada a uma face (3-k)-dimensional no dual, ou seja, um cubo é associado a um vértice, a face a uma aresta e um vértice a uma célula dual. A vantagem no uso do dual é que a conexão entre cubos de diferentes graus de refinamento é feita de forma natural. A Figura 3.6(a) ilustra o dual geométrico de uma quadtree, enquanto que a Figura 3.6(b) ilustra uma célula dual que conecta dois blocos da octree com diferentes graus de refinamento.

(a)

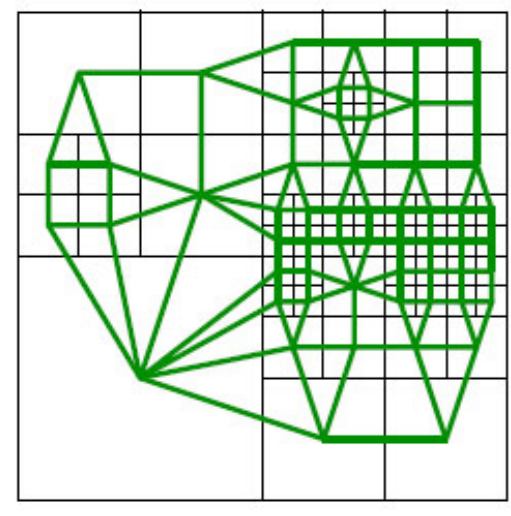

(b)

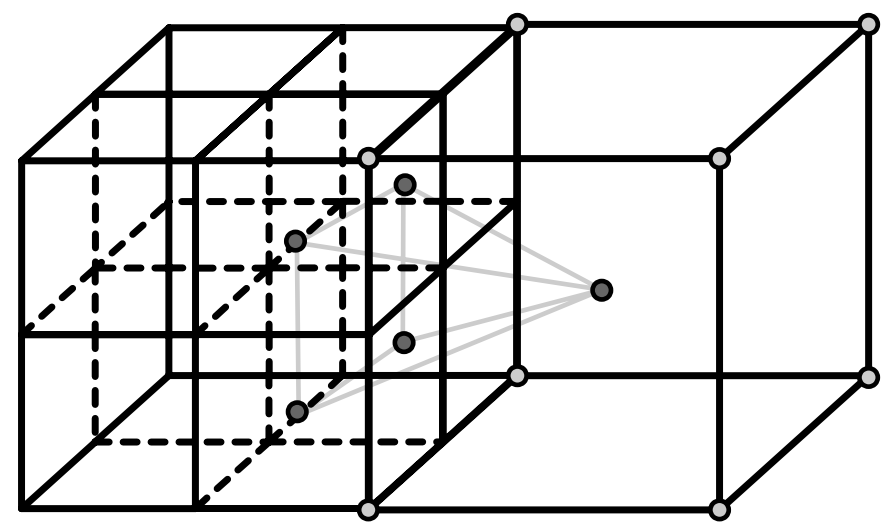

Figura 3.6: (a) Representação do dual de uma quad-tree. (b) Representação de uma célula dual de uma octree que liga cubos com níveis de refinamento diferentes.

Além das questões já exploradas, Kobbelt et al. (2001) observaram que um outro problema do algoritmo marching cubes é a dificuldade em se representar sharp features, pois essas características não estão, necessariamente, alinhadas com a grade e os vértices da aproximação simplicial são definidos apenas sobre arestas da grade. Em duas dimensões, a abordagem proposta realiza o cálculo de retas tangentes (ou planos, no caso 3D) sobre os pontos de intersecção e calcula um ponto (ou aresta) de intersecção interno. É a partir desse novo elemento que a aproximação da curva (ou superfície) é construída, como pode ser verificado na Figura 3.7. 


\section{Extração de isosuperfícies}
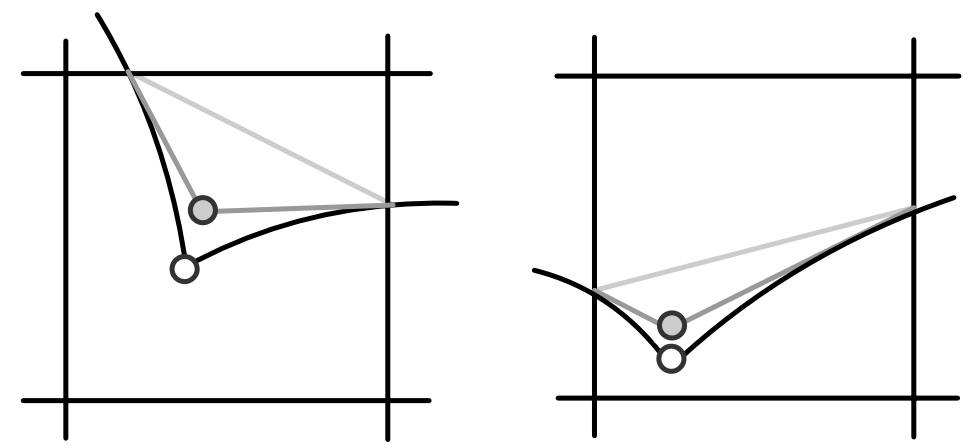

Figura 3.7: Na figura da direita, curva original está em preto, a linha cinza representa a aproximação do marching cubes e a linha cinza escura representa aproximação proposta por Kobbelt et al. (2001)

Os algoritmos citados acima estão definidos para a extração de 2-variedades imersas em $\mathbb{R}^{3}$, no entanto, a maioria deles não pode ser generalizado para $\mathbb{R}^{n}$ devido a restrições teóricas ou de implementação. No caso do marching cubes, o fator proibitivo está no número de configurações possíveis quando a dimensão aumenta e também nas inconsistências, que já existem em $\mathbb{R}^{3}$, e podem aumentar em $\mathbb{R}^{n}$. Tal fato sugere que a melhor forma de evitar as inconsistências é trabalhar com complexos simpliciais, ou seja, hipertetraedros.

Weigle and Banks (1996) propuseram um esquema de triangulação que divide um hipercubo em $2^{(n-1)} n$ ! hipertetraedros através de um algoritmo recursivo. Por exemplo, dado um quadrado, a triangulação é feita através da inserção de um ponto na face do quadrado e da ligação desse ponto aos vértices do quadrado. No caso do cubo, um ponto é inserido no centróide do cubo e conectado aos vértices, em seguida, é feita a divisão das faces da mesma maneira que é feita para o quadrado. Exemplos das decomposições para duas e três dimensões são apresentados na Figura 3.8.

Ainda que a maioria dos trabalhos extensíveis para $\mathbb{R}^{n}$ trabalhem com hipertetraedros, Bhaniramka et al. (2004) utiliza decomposição em cubos para definir um algoritmo em qualquer dimensão, mesmo que na prática, o algoritmo só seja viável para $\mathbb{R}^{3}$ e $\mathbb{R}^{4}$. A idéia do algoritmo é empregar o cálculo da envoltória convexa para decidir sobre a topologia da poligonalização final. O algoritmo pode ser resumido nos seguintes passos que estão ilustrados na Figura 3.9: 
(a)

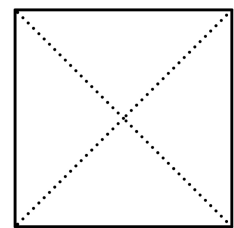

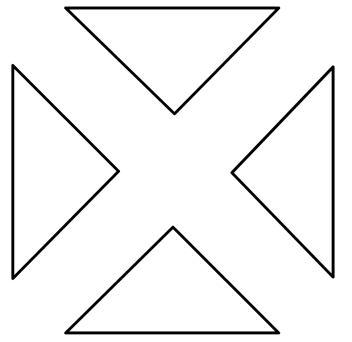

(b)

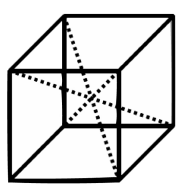

Figura 3.8: (a) Divisão em 2D. (b) Divisão em 3D.

(a)

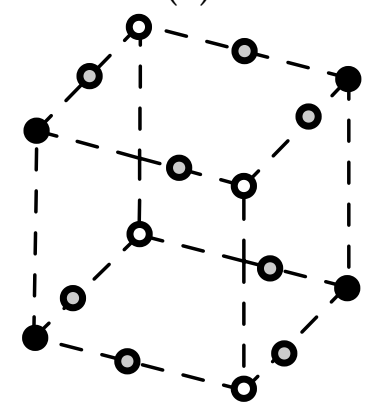

(b)

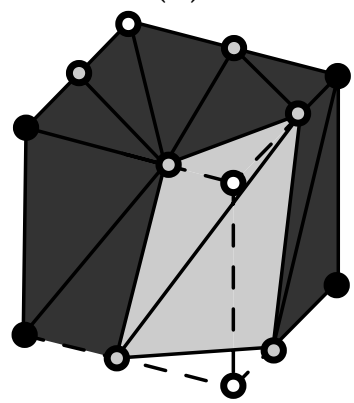

(c)

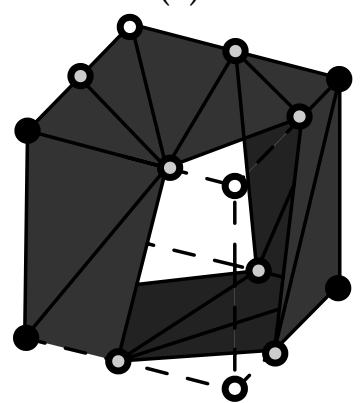

(d)

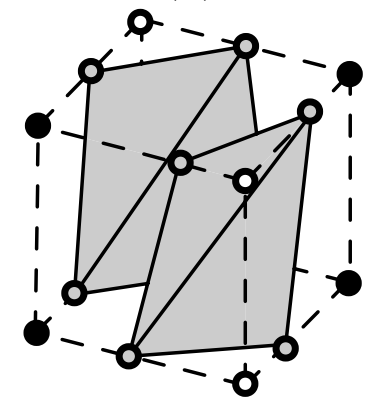

Figura 3.9: (a) Os pontos em preto estão fora, os brancos dentro e os cinza sobre a superfície. (b) Envoltória convexa dos pontos fora e sobre a superfície. (c) Simplexos que possuem faces sobre o cubo. (d) Aproximação final.

1. A envoltória convexa da união dos vértices que estão fora da superfície e dos pontos de interseção é calculada;

2. Os simplexos que possuem faces sobre o cubo são removidos.

O autor afirma que o algoritmo garantidamente gera uma aproximação que é uma 2-variedade, no entanto, o algoritmo não é capaz de resolver as ambigüidades internas corretamente, pois ainda que não haja buracos na superfície, a mesma não possui necessariamente a topologia correta.

O último algoritmo discutido nessa seção foi proposto por Castelo et al. (2006) a partir da triangulação $J_{1}^{a}$. Esse algoritmo possui muitas das características desejáveis em um extrator de isosuperfícies, a saber:

- Gera superfícies topologicamente coerentes, ou seja, a superfície é sempre homeomorfa a um disco ou a uma esfera; 


\section{Extração de isosuperfícies}

- Possui mecanismo adaptativo;

- Extensível para extração de variedades em $\mathbb{R}^{n}$.

Porém, a principal desvantagem do uso da triangulação $J_{1}^{a}$, que será discutida no próximo capítulo, é a geração de triângulos com alta razão de aspecto.

\subsubsection{Métodos não baseados em grades regulares}

Na seção anterior, foram citados trabalhos que fazem uso de decomposições do domínio através de grades regulares para a realização da poligonalização, porém existe outra classe de algoritmos de poligonalização na qual a superfície é construída incrementalmente. Nesses algoritmos o processo, normalmente se inicia a partir de um vértice sobre a superfície e novos vértices são inseridos, juntamente com novas arestas, de forma a se obter uma superfície topologicamente correta e que satisfaça algum critério de qualidade.

No trabalho de Boissonnat and Oudot (2003), o percurso é realizado sobre a superfície a partir de um ponto inicial utilizando um técnica que faz uso de propriedades da triangulação de Delaunay restrita, originalmente proposta para o refinamento de malhas. A conectividade da malha pode ser construída respeitando-se critérios mínimos de qualidade como, por exemplo, razão de aspecto e tamanho de arestas. A principal desvantagem do trabalho está na necessidade em se obter uma aproximação para o eixo medial, o que pode ser uma computação custosa. Nesse sentido, o trabalho de Cheng et al. (2004) propõe um melhoramento da técnica ao substituir o cálculo aproximado do eixo medial por cálculos de pontos críticos e silhuetas. Além disso, diferentemente do algoritmo de Boissonnat and Oudot (2003) em que a aproximação do eixo medial deve ser calculada em todos os pontos durante a geração da malha, na técnica proposta por Cheng et al. (2004), o cálculo da silhueta e de pontos críticos é feito apenas em locais específicos. Os autores argumentam que a técnica gera malhas com qualidade provada para superfícies suaves, mas não fornecem resultados semelhantes para superfícies não suaves. Além disso, ainda que o cálculo de pontos críticos e de silhueta sejam menos custosos que o cálculo do eixo medial, tais cálculos ainda envolvem um custo computacional considerável. 


\section{Extração de isosuperfícies}

Um trabalho mais recente de avanço de fronteiras foi proposto por Schreiner et al. (2006) e baseia-se na definição de um campo de direcionamento (guidance field) de forma a garantir a topologia da superfície e a qualidade dos triângulos gerados. A malha resultante também é adaptativa com relação à curvatura da superfície. Um dos principais problemas dessa técnica, bem como das técnicas incrementais citadas anteriormente, é o custo computacional elevado para o cálculo do guidance field.

O algoritmo proposto por Gavriliu et al. (2001) não é um algoritmo incremental, porém não é dependente de uma grade de poligonalização fixa, portanto, está em uma classificação à parte. Nesse trabalho, é empregada uma idéia similar à do algoritmo marching cubes, que se baseia no uso de um conjunto de casos de intersecção de uma superfície com um cubo. Porém, no algoritmo proposto a superfície é coberta por um conjunto de mapas que são homeomorfos a discos planares e, a partir desses mapas, uma versão grosseira da malha é gerada em que condições de razão de aspecto e tamanho das arestas são preservadas. Em seguida, há uma etapa de refinamento da malha, em que os triângulos são sucessivamente refinados até que um critério de erro definido pelo usuário seja satisfeito. As malhas geradas por essa técnica são adaptativas e possuem certa qualidade assegurada, segundo os autores.

O trabalho de Figueiredo et al. (1992) também não se encaixa na categoria das grades regulares e consiste de um dos primeiros algoritmos de extração de isosuperfícies no qual a qualidade dos triângulos gerados era buscada objetivamente. Dois esquemas de poligonalização baseados em propriedades físicas são propostas para a geração de malhas quasi-regulares, ou seja, malhas com triângulos aproximadamente eqüiláteros e que podem ser utilizados no âmbito de simulações ou aplicações gráficas. O primeiro é baseado em sistemas de partículas e define uma maneira de se posicionar um conjunto de partículas sobre a superfície. Como tais partículas tendem a se acumular nos pontos de alta curvatura, um processo de relaxação deve ser aplicado para tornar os pontos aproximadamente igualmente espaçados de forma que a malha gerada seja quasiregular. Outro esquema é proposto baseado em sistemas massa-mola, na qual uma grade inicial é definida e é deformada para que seus vértices se posicionem de forma a gerar uma boa aproximação da superfície. O algoritmo de melhoramento de malha 


\section{Extração de isosuperfícies}

proposto na presente dissertação baseia-se em um conceito parecido de movimentação de vértices.

\subsubsection{Resumo das características dos algoritmos}

Nesta seção é feito um resumo das características dos algoritmos apresentados nas duas seções anteriores. A Tabela 3.1 sumariza as características das técnicas de acordo com 6 critérios:

(i) Tipo de célula usada na poligonalização;

(ii) Método adaptativo;

(iii) Método com garantias topológicas;

(iv) Método extensível a $\mathbb{R}^{n}$;

(v) Método com melhoramento de malha;

(vi) Método com tratamento de sharp features.

Vale ressaltar que, nos itens (v) e (vi), não são levados em conta pós-processamentos e, sim, características intrínsecas aos algoritmos.

\subsection{Considerações Finais}

Muitas técnicas de extração de isosuperfícies foram propostas nas últimas décadas e, desses trabalhos, surgiram novos requisitos para o processo de geração das isosuperfícies, dentre os quais se pode destacar: adaptatividade, geração de superfícies topologicamente coerentes, com qualidade de malha e extensíveis para dimensões superiores. No capítulo seguinte será descrito o poligonalizador desenvolvido que procura atender aos requisitos enumerados. 
Tabela 3.1: Resumo das propriedades dos métodos de extração de isosuperfícies de acordo com os seis critérios enumerados anteriormente.

\begin{tabular}{|c|c|c|c|c|c|c|}
\hline Métodos Critérios & (i) & (ii) & (iii) & (iv) & (v) & (vi) \\
\hline Lorensen and Cline (1987) & Cubo & Não & Não & Não & Não & Não \\
\hline Bloomenthal (1988) & Cubo & Sim & Não & Não & Não & Não \\
\hline Hall and Warren (1990) & Tetraedro & Sim & Sim & Não & Sim & Não \\
\hline Payne and Toga (1990) & Tetraedro & Não & Sim & Não & Não & Não \\
\hline Nielson and Hamann (1991) & Cubo & Não & Parcial & Não & Não & Não \\
\hline Figueiredo et al. (1992) & Cubo e sem malha & Não & Sim & Não & Sim & Não \\
\hline Bloomenthal (1994) & Cubo e tetraedro & Não & Parcial & Não & Sim & Não \\
\hline Montani et al. (1994) & Cubo & Não & Parcial & Não & Não & Não \\
\hline Chernyaev (1995) & Cubo & Não & Parcial & Não & Não & Não \\
\hline Shu et al. (1995) & Cubo & Sim & Não & Não & Não & Não \\
\hline Weigle and Banks (1996) & Tetraedro & Não & Sim & Sim & Não & Não \\
\hline Chan and Purisima (1998) & Tetraedro & Não & Sim & Não & Sim & Não \\
\hline Treece et al. (1999) & Tetraedro & Não & Sim & Não & Sim & Não \\
\hline Gavriliu et al. (2001) & -Mapas- & Sim & Sim & Não & Sim & Não \\
\hline Kobbelt et al. (2001) & Cubo & Não & Não & Não & Não & Sim \\
\hline Boissonnat and Oudot (2003) & -Incremental- & Sim & Sim & Não & Sim & Não \\
\hline Lewiner et al. (2003) & Cubo & Não & Sim & Não & Não & Não \\
\hline Lopes and Brodlie (2003) & Cubo & Não & Sim & Não & Não & Não \\
\hline Bhaniramka et al. (2004) & Cubo & Não & Não & Sim & Não & Não \\
\hline Cheng et al. (2004) & -Incremental- & Sim & Sim & Não & Sim & Não \\
\hline Castelo et al. (2006) & Tetraedro & Sim & Sim & Sim & Não & Não \\
\hline Paiva et al. (2006) & Cubo & Sim & Sim & Não & Não & Não \\
\hline Schreiner et al. (2006) & -Incremental- & Sim & Sim & Não & Sim & Não \\
\hline
\end{tabular}




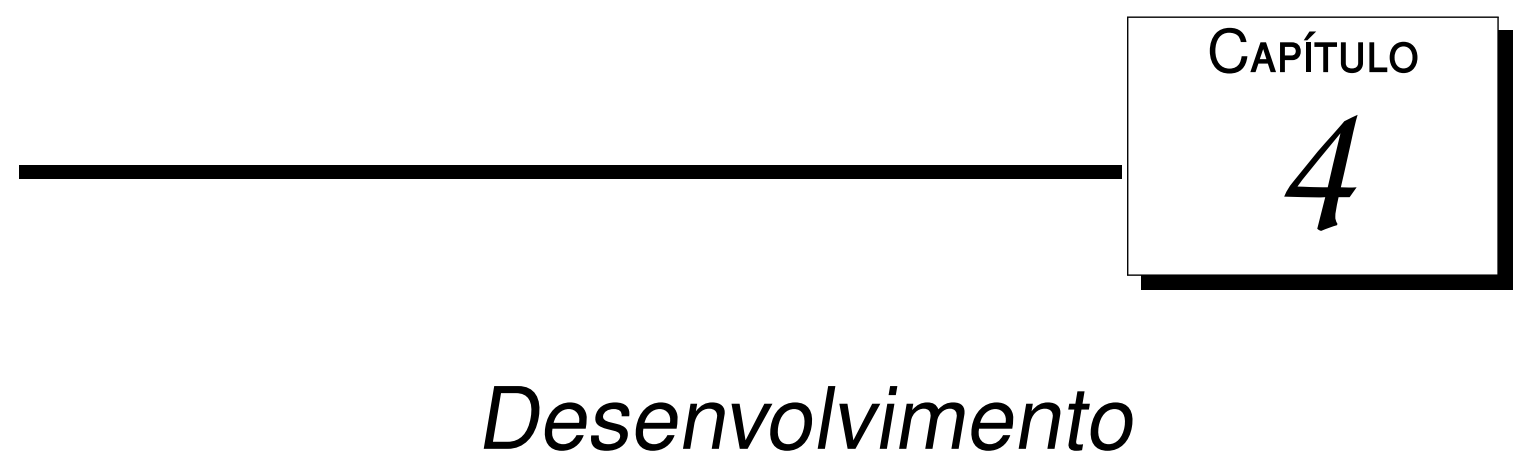

\subsection{Considerações iniciais}

No presente capítulo o trabalho desenvolvido é dividido em quatro partes, às quais são devotadas seções separadas, a saber: triangulação $J_{1}^{a}$, extração de isosuperfícies com melhoramento de malha, reconstrução de superfícies e modelador genérico. Em cada seção são feitas considerações de cunho teórico e de implementação. Ao final desse capítulo, são delineadas algumas considerações finais a respeito do projeto como um todo.

\subsection{Triangulação $J_{1}^{a}$}

A triangulação $J_{1}^{a}$ (Castelo et al., 2006) é uma estrutura definida algebricamente que pode ser construída em qualquer dimensão e é capaz de lidar com refinamentos usados para representar características locais. A principal vantagem da $J_{1}^{a}$ é a existência de regras algébricas usadas para percorrer a malha, que eliminam a necessidade de armazenar informações topológicas e, conseqüentemente, tornam o armazenamento muito eficiente.

As características principais da triangulação $J_{1}^{a}$ são um mecanismo capaz de iden- 
tificar cada simplexo dentro da triangulação e, como já citada, a existência de regras algébricas para percorrer os simplexos. A seguir, ambas as propriedades serão descritas em detalhes, bem como alguns aspectos de implementação importantes.

\subsubsection{Identificação de simplexos}

A triangulação $J_{1}^{a}$ em $\mathbb{R}^{n}$ consiste de uma grade no qual o elemento básico é um hipercubo $n$-dimensional. Cada hipercubo é dividido em $2^{n} n$ ! $n$-simplexos de forma que cada um deles possa ser descrito algebricamente através de uma sêxtupla $S=$ $(g, r, \pi, s, t, h)$. No contexto da $J_{1}^{a}$, os hipercubos são chamados de blocos.

Os dois primeiros elementos de $S$ definem em qual bloco o simplexo está contido, sendo que o vetor $n$-dimensional $g$ especifica as coordenadas do bloco na grade de refinamento $r$. A idéia dos graus de refinamento pode ser entendida como se a grade da triangulação $J_{1}^{a}$ fosse uma superposição de diversas camadas de grades de diferentes resoluções, em que cada bloco está em camada particular. Esse conceito está ilustrado na Figura 4.1, em que são representados três grades de resoluções diferentes originadas por subdivisões binárias sucessivas de cada coordenada. A Figura 4.2 (a) ilustra uma triangulação $J_{1}^{a}$ bidimensional enquanto que a Figura 4.2 (b) destaca um bloco de refinamento $r=0$ e coordenadas da grade $(3,1)$. Também na Figura 4.2, os blocos em cinza escuro apresentam nível de refinamento $r=1$ e fazem parte de uma grade de maior resolução.

Uma vez que o simplexo foi localizado na grade, deve existir uma forma de especificar a posição do simplexo dentro de um bloco específico. No entanto, antes de abordar essa questão, é necessário observar como a triangulação $J_{1}^{a}$ em $\mathbb{R}^{n}$ trata refinamentos.

Quando um $i$-bloco da triangulação $J_{1}^{a}$ em $\mathbb{R}^{n}$ é refinado, o mesmo deixa de existir e é substituído por $2^{n}(i+1)$-blocos através da partição binária de cada um dos eixos coordenados. Tal processo também desencadeia uma série de modificações locais na grade para que os blocos recém-criados sejam acomodados. As modificações dão origem ao bloco de transição, que é um tipo diferente de bloco daqueles já tratados até o momento. Esses últimos, a partir de agora, serão chamados de blocos básicos.

A triangulação $J_{1}^{a}$ proíbe situações nas quais vizinhos apresentem diferença maior que um entre seus níveis de refinamento e impõe que, sempre que blocos com diferentes 

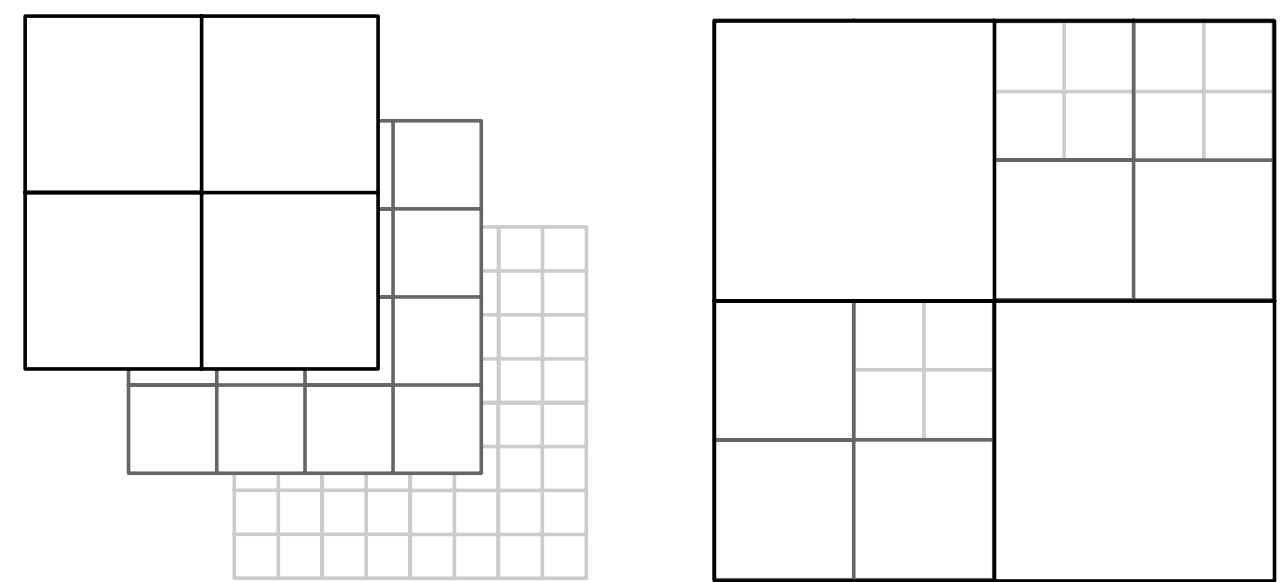

Figura 4.1: À esquerda, três blocos com diferentes resoluções em que a grade imediatamente abaixo é obtido pela subdivisão binária de cada uma das coordenadas. À direita, encontra-se uma grade da $J_{1}^{a}$.

níveis de refinamento tornem-se vizinhos, aquele com menor nível de refinamento deve ser transformado em um bloco de transição. Obloco de transição é aquele que apresenta apenas algumas de suas faces $k$-dimensionais $(0<k<n)$ refinadas com o intuito de manter a conectividade da triangulação. Isso é mais bem ilustrado pela Figura 4.2, na qual 0-blocos básicos receberam cor branca, 1-blocos, a cor cinza escuro e 0-blocos de transição a cor cinza claro. Em particular, o bloco de transição destacado possui apenas a aresta superior refinada.

A representação de simplexos é baseada no fato de que todos os simplexos compartilham, pelo menos, o vértice $v_{0}$, que está posicionado no centro do hipercubo. Começando em $v_{0}$, o próximo passo para traçar o simplexo é dado na direção positiva ou negativa de um eixo coordenado escolhido. Isso produzirá $v_{1}$ que figura no centro de uma face $(n-1)$-dimensional e, conforme o processo continua, os vértices $v_{2}, \ldots, v_{n}$ serão definidos como centros das faces de dimensão $(n-1), \ldots, 0$, respectivamente. Em outras palavras, simplexos podem ser representados univocamente pelo caminho percorrido de $v_{0}$ a $v_{n}$, que corresponde exatamente à informação armazenada nos vetores $\pi$ es.

O vetor $\pi$ guarda uma permutação de $n$ inteiros de 1 a $n$ que correspondem a cada um dos eixos coordenados, enquanto $s$ representa a direção, positiva ou negativa, que deve ser seguida em cada um dos eixos, ou seja, $s_{1}=-1$ significa que deve-se tomar 

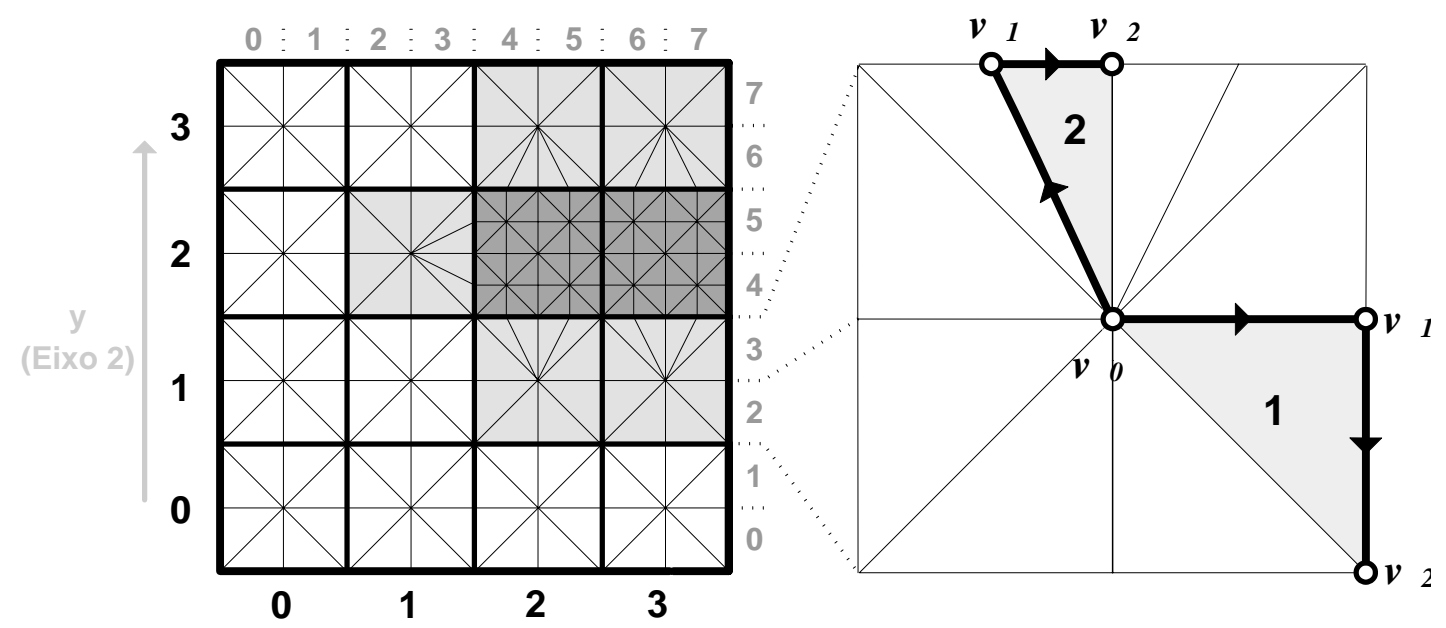

Figura 4.2: À esquerda, a representação de uma triangulação $J_{1}^{a}$ em 2D. À direita, a representação do bloco $g=(3,1), r=0$ e dois caminhos traçando simplexos.

a direção negativa ao se percorrer a direção do eixo 1. Por exemplo, na Figura 4.2, o simplexo 1 é representado por $\pi=(1,2)$ e $s=(1,-1)$, o que significa que, primeiro, $o$ eixo $\pi_{1}$ é percorrido na direção $s_{\pi_{1}}$ e, em seguida, o eixo $\pi_{2}$ é percorrido na direção $s_{\pi_{2}}$. O cálculo de rótulos para os vetores $\pi$ e $s$ é feito através da enumeração das possíveis combinações.

No caso de simplexos pertencentes a blocos básicos e simplexos que não alcançam nenhuma face refinada dentro de blocos de transição, a informação fornecida por $\pi$ e $s$ é suficiente, implicando em $h=0$ e $t=(0,0,0)$. Entretanto, nos casos restantes informações adicionais são necessárias, pois, quando uma face $k$-dimensional é alcançada, não há apenas um centro e $\operatorname{sim} 2^{k}$ centros. Nesse sentido, o escalar $h$ é definido como o número de passos dados até que uma face refinada seja alcançada, enquanto que o vetor $t$ define sinais extras para os eixos $\pi_{h+1}, \ldots, \pi_{n}$ que devem ser percorridos após atingir uma face refinada a fim de selecionar apenas um centro dentre todas as possibilidades. Por exemplo, na Figura 4.2, o simplexo 2 é representado por $\pi=(1,0), s=(1,1)$, $h=1$ e $t=(-1,0)$, porque apenas um passo é dado antes que uma aresta refinada seja alcançada e o vetor $t$ contém a informação necessária para determinar qual dos dois centros deve ser escolhido. No caso do exemplo, o vértice $v_{1}$ é posicionado na direção 
negativa de $\pi_{h+1}$.

O processo de representação de simplexos pode ser formalizado através das seguintes expressões, em que os simplexos de uma triangulação em $\mathbb{R}^{n}$ encontram-se dentro de um hipercubo centrado na origem $(0, \ldots, 0)$ com arestas de comprimento 2 :

$$
\left\{\begin{array}{l}
v_{0}=(0, \ldots, 0) \\
v_{i}=v_{i-1}+e_{\pi_{i}} s_{\pi_{i}}, \text { para } 1 \leq i<h \\
v_{h}=v_{h-1}+e_{\pi_{h}} s_{\pi_{h}}+\frac{1}{2} \sum_{k=h+1}^{n} e_{\pi_{k}} t_{\pi_{k}} \\
v_{i}=v_{i-1}+\frac{1}{2} e_{\pi_{i}} s_{\pi_{i}}, \text { para } h<i \leq n,
\end{array}\right.
$$

em que $e_{i}$ é um vetor $n$-dimensional com valor 1 na posição $i$ e 0 nas posições restantes, ou seja, é um dos vetores da base canônica em $\mathbb{R}^{n}$.

Como cada simplexo da triangulação pode ser representado algebricamente, as únicas informações armazenadas sobre a triangulação correspondem a quais blocos e faces foram refinadas. Isso torna o armazenamento de uma triangulação $J_{1}^{a}$ extremamente eficiente, ao passo que uma triangulação não refinada não requer o armazenamento de qualquer tipo informações. Para ilustrar esse fato, a seguir estão descritas as informações mínimas que precisam ser armazenadas para a triangulação da Figura 4.2:

- $\operatorname{Bloco}(2,1), r=0$ : aresta superior refinada;

- $\operatorname{Bloco}(3,1), r=0$ : aresta superior refinada;

- Bloco $(1,2), r=0$ : aresta direita refinada;

- Bloco $(2,2), r=0$ : bloco refinado;

- $\operatorname{Bloco}(3,2), r=0$ : bloco refinado;

- Bloco $(2,3), r=0$ : aresta inferior refinada;

- $\operatorname{Bloco}(3,3), r=0$ : aresta inferior refinada.

\subsubsection{Pivoteamento}

Além de descrever simplexos algebricamente, a triangulação $J_{1}^{a}$ também define regras de pivoteamento que permitem percorrer a triangulação sem usar estruturas de 


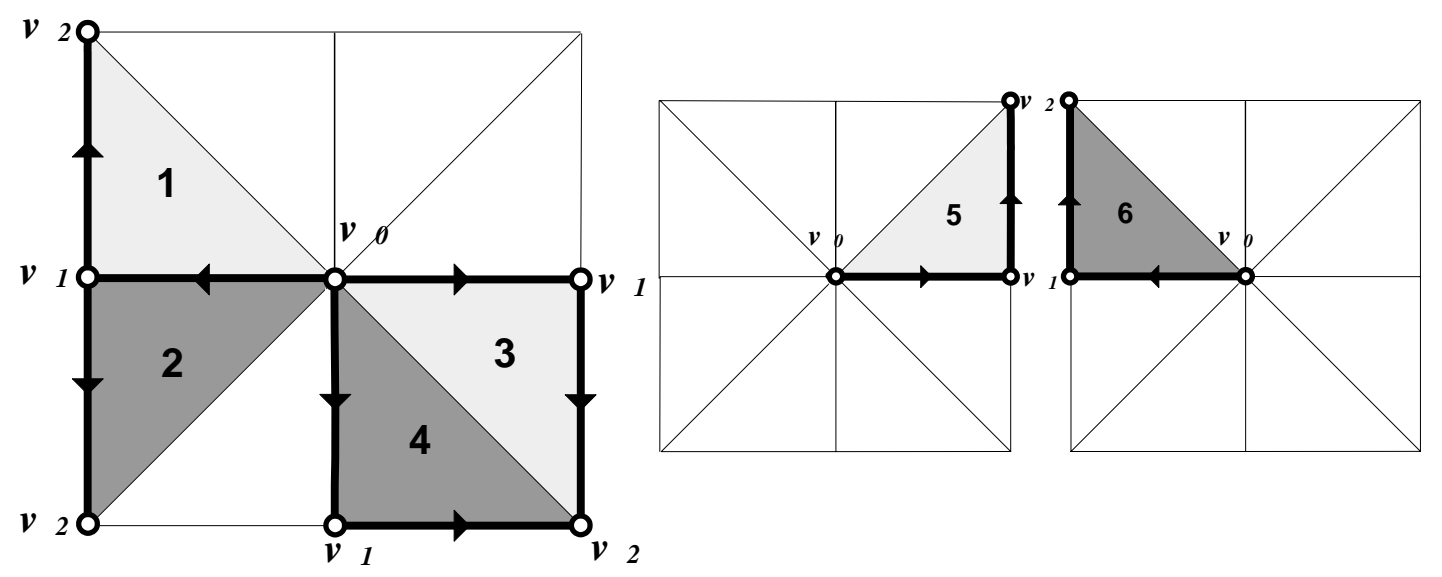

Figura 4.3: Exemplo de operações de pivoteamento na triangulação $J_{1}^{a}$

dados topológicas auxiliares. Antes da descrição das operações de pivoteamento na $J_{1^{\prime}}^{a}$ é feita a definição de pivoteado de um simplexo.

Definição 12 (Pivoteado de um simplexo) Dado um complexo simplicial C e um simplexo $s=\left[v_{1}, \ldots, v_{k-1}, v_{k}, v_{k+1} \ldots, v_{n}\right] \in C$, em que $[V]$ representa ofecho convexo do conjunto de vértices $V$. O pivoteado de s com relação ao vertice $v_{k}$, ésimplexo $s^{\prime}=\left[v_{1}, \ldots, v_{k-1}, v_{k^{\prime}}^{\prime} v_{k+1}, \ldots, v_{n}\right] \in$ C.

As operações de pivoteamento na triangulação $J_{1}^{a}$ são definidas a partir de regras que levam em consideração, além do simplexo em questão e do pivô, as características locais da triangulação. Para os casos envolvendo apenas blocos básicos há poucas regras, enquanto que para casos envolvendo blocos de transição, um número maior de regras é necessário. A descrição completa das regras de pivoteamento pode ser encontrada no artigo de Castelo et al. (2006). A fim de ilustrar o funcionamento das operações de pivoteamento, a Figura 4.3 mostra três operações de pivoteamento:

- O pivoteado do simplexo 1 em relação ao vértice $v_{2}$ é o simplexo 2;

- O pivoteado do simplexo 3 em relação ao vértice $v_{1}$ é o simplexo 4 ;

- O pivoteado do simplexo 5 em relação ao vértice $v_{0}$ é o simplexo 6 .

Algumas propriedades interessantes sobre as operações de pivoteamento podem ser observadas nos exemplos da Figura 4.3: 
1. O pivoteamento de um simplexo com relação a um vértice $v_{k}$ faz com que o vértice $v_{k^{\prime}}^{\prime}$ pertencente ao pivoteado, mude de face $(n-k)$-dimensional dentro da grade. Por exemplo, na Figura 4.3, quando o simplexo 1 é pivoteado em relação a $v_{2}$, o novo vértice $v_{2}$ muda de face 0 -dimensional, ou seja, o novo vértice $v_{2}$ está no mesmo bloco, na mesma aresta, mas em um vértice diferente. Quando, o simplexo 3 é pivoteado em relação a $v_{1}$, o novo vértice muda de face 1-dimensional, ou seja, muda de aresta, mas continua no mesmo bloco. De forma análoga, o pivoteado de 5 em relação a $v_{0}$ provoca uma mudança de bloco;

2. Seja $s=\left[v_{1}, \ldots, v_{n}\right]$ um simplexo e $F$ uma face de $s$, pode-se girar em torno de $F$ realizando seguidos pivoteamentos em relação aos vértices de $s$ não pertencentes a F. De forma concreta, seja o simplexo 1 da Figura 4.3, para girar em torno do vértice $v_{0}$, basta alternar seguidos pivoteamentos em relação aos vértices 1 e 2 . Se a seqüência for iniciada com 1, o sentido da rotação será horário, caso contrário, a rotação será no sentido anti-horário;

A propriedade (2) pode ser empregada para realizar percursos em torno de vértices e arestas.

\subsubsection{Rotulagem}

Algumas operações, tal como a geração de um índice para acesso de uma tabela hash, podem exigir a transformação dos vetores da triangulação $J_{1}^{a}$ em valores inteiros. Essa operação é denominada rotulagem e, nessa seção, é definida para cada um dos vetores que identificam um simplexo.

A conversão de $g$ em um rótulo $l(g)$ é dado pela seguinte fórmula:

$$
l(g)=\sum_{i=1}^{m} b_{i} g_{i}
$$

em que $m$ é a dimensão da triangulação, $g_{i}$ é a $i$-ésima componente de $g, b_{1}=1$, $b_{j}=b_{j-1} 2^{r} d_{j}, r$ é o nível de refinamento do bloco e $d$ é um vetor $n$-dimensional que representa o número de 0-blocos (blocos no nível de refinamento zero) presentes em cada eixo coordenado de $g$. 
Um esquema de rotulagem também deve definir como recuperar o vetor a partir de um rótulo. No caso dos rótulos $l(g)$, a função inversa só é definida se for conhecido o valor de $r$. A Equação 4.3 ilustra a conversão da dupla $(l(g), r)$ no vetor $g$.

$$
\left\{\begin{array}{l}
g_{i}=\left\lfloor\frac{l(g)}{b_{i}}\right\rfloor \\
l(g) \rightarrow l(g) \bmod \left(b_{j}\right), j=m-1, \ldots, 0 .
\end{array}\right.
$$

De maneira similar, os vetores $\pi$, s e $t$ são convertidos em rótulos $l(\pi), l(s)$ e $l(t)$ através das operações descritas na Equação 4.4 .

$$
\begin{aligned}
& l(\pi)=\sum_{i=1}^{m} m^{(m-i)}\left(\pi_{i}-1\right) \\
& l(s)=\sum_{i=1}^{m} 2^{(m-i)}\left(s_{i}+1\right) / 2 \\
& l(t)=\sum_{i=1}^{m} 3^{(m-i)}\left(t_{i}+1\right)
\end{aligned}
$$

em que $m$ é a dimensão da triangulação.

É possível verificar na Equação 4.4 que a operação é muito similar para os três vetores, sendo que apenas a base $(m, 2$ ou 3$)$ e os deslocamentos realizados diferem. Conseqüentemente, a operação inversa é realizada de maneira similar para os três vetores sendo necessário o deslocamento final dos valores obtidos. Para ilustrar a situação, a Equação 4.5 descreve a conversão de $l(\pi)$ em $\pi$.

$$
\left\{\begin{array}{l}
\pi_{i}=\left\lfloor\frac{l(\pi)}{m^{(m-i)}}\right\rfloor \\
l(\pi) \rightarrow l(\pi) \bmod \left(m^{(m-i)}\right), i=1, \ldots, m
\end{array}\right.
$$

\subsubsection{Gerenciamento de blocos}

Ainda que a triangulação $J_{1}^{a}$ possa ser implementada de forma a se armazenar a menor quantidade de informações possível, tal abordagem resulta em um maior custo computacional durante a utilização da estrutura, já que muitos dados sobre a triangulação estão implícitos e devem ser calculados de maneira ad hoc. Por esse motivo, a implementação da $J_{1}^{a}$ empregada no projeto realiza o armazenamento de todos os blocos da estrutura. Com os blocos, também estão informações a respeito de faces refinadas, ponteiros da octree subjacente à estrutura, e os vértices dos blocos que podem ser pré-calculados. Esse último dado torna a estrutura muito mais eficiente, já 

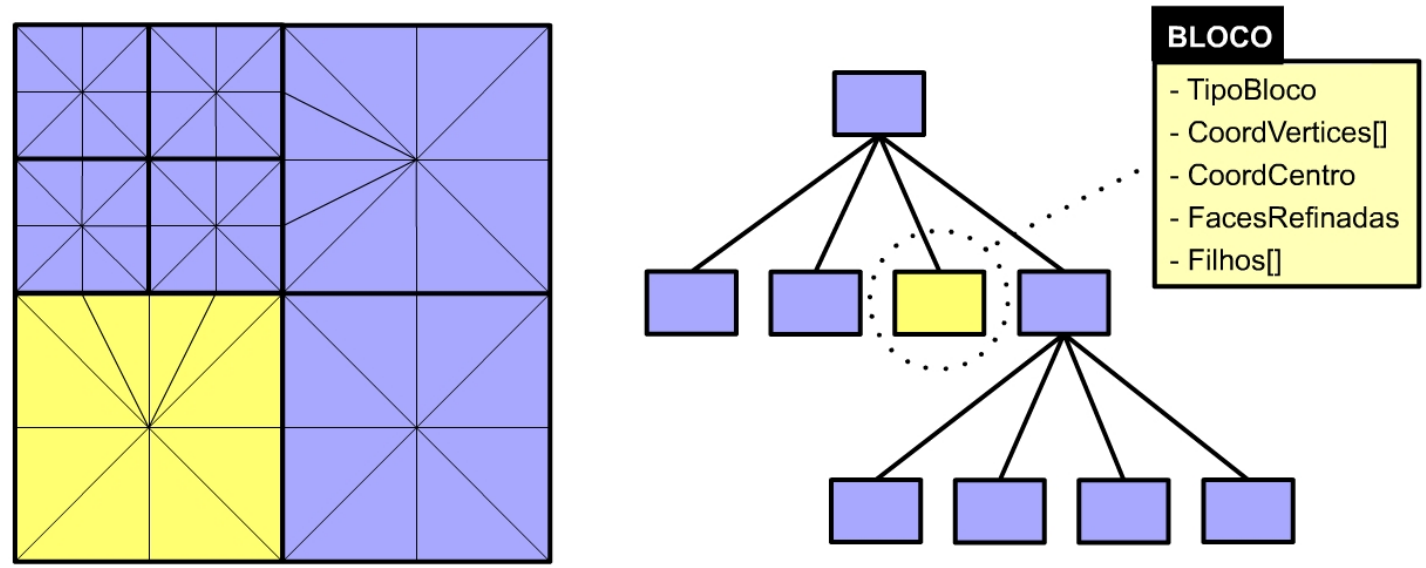

Figura 4.4: Estrutura de dados para os blocos da triangulação $J_{1}^{a}$. À esquerda, uma triangulação $J_{1}^{a}$ em duas dimensões. Ao centro, a estrutura de quad tree e à direita, as informações armazenadas em cada bloco.

que as coordenadas geométricas dos blocos originam as coordenadas dos simplexos e o recálculo dessas informações é evitado. A Figura 4.4 ilustra uma estrutura de dados para a $J_{1}^{a}$ em $2 \mathrm{D}$.

No exemplo da Figura 4.4, a triangulação em questão possui uma grade inicial $1 \times 1 \times 1$, porém, para resoluções maiores, cada bloco de nível zero será a raiz de uma árvore separada. Por esse motivo, além das árvores, é armazenada uma tabela que contém os ponteiros para cada um dos blocos de nível zero, para que o acesso às árvores seja direto.

Agora que já foi esclarecida a forma como os bloco da triangulação $J_{1}^{a}$ são armazenados, é necessário descrever como um bloco é acessado a partir de uma posição no grid $g$ e um nível de refinamento $r$.

A busca dos blocos é feita através da estrutura subjacente e de alguns poucos cálculos, o que torna o processo bastante eficiente. A idéia parte do princípio de que o bloco da triangulação $J_{1}^{a}(g, r)$, possui como pai o bloco $\left(g^{\prime}, r-1\right)$, em que $g_{i}^{\prime}=\left\lfloor\frac{g_{i}}{2}\right\rfloor$. Com isso, é possível obter, através de sucessivas divisões, o caminho até um bloco de nível zero e armazenar tal caminho em uma pilha. A descrição de um caminho nada mais é que a utilização de códigos que identifiquem quais filhos devem ser escolhidos sucessivamente, a partir da raiz, para se alcançar um determinado bloco. É possível estabelecer esse caminho, pois cada filho recebe uma numeração de acordo com sua 
posição em relação aos eixos $(x, y, z)$. Por exemplo, o filho voltado às direções negativas de $x$ e $y$, e à direção positiva de $z$, recebe o código $(0,0,1)$. Estando em um bloco de nível zero, basta acessar o ponteiro da árvore correspondente e seguir os códigos armazenados na pilha até o bloco desejado. Essa procedimento é esclarecido através do Algoritmo 1.

\section{Algoritmo 1}

Entrada: seja $(g, r)$ o bloco que se deseja buscar e res o vetor com a resolução do grid.

Saída: seja $b$ o bloco buscado

1. ( ${ }^{*}$ Determina o caminho *)

2. Inicialize pilha $P$

3. enquanto $r>0$

4. faça para $i=1$ até 3

5. $\quad$ faça $c_{i}=g_{i} \% 2$

6. $\quad g_{i}=$ floor $\left(g_{i} / 2\right)$

7. $\mathrm{r}=\mathrm{r}-1$

8. $\quad$ Empilhe $c$ em $P$

9. $\quad$ se $g \notin\left\{\left(0, \ldots, r e s_{x}\right) \times\left(0, \ldots, r e s_{y}\right) \times\left(0, \ldots, r e s_{z}\right)\right\}$

10. então Sinalize erro

11. Obtenha o bloco $b$ a partir de $(g, 0)$

12. enquanto $P \neq \emptyset$

13. faça Desempilhe $c$

14. $\quad b=b \rightarrow$ obterFilho(c)

Na linha 11 do Algoritmo 1 o bloco de nível zero é obtido a partir da tabela hash que contém o endereço para o respectivo bloco.

\subsubsection{Utilização da estrutura}

Para finalizar a descrição da triangulação $J_{1}^{a}$, deve-se discutir como a estrutura é utilizada. A triangulação possui algumas peculiaridades, sendo a principal delas o fato de os simplexos serem representados implicitamente, ou seja, não são armazenados como estruturas permanentes. Por essa razão, foram desenvolvidas duas formas de 

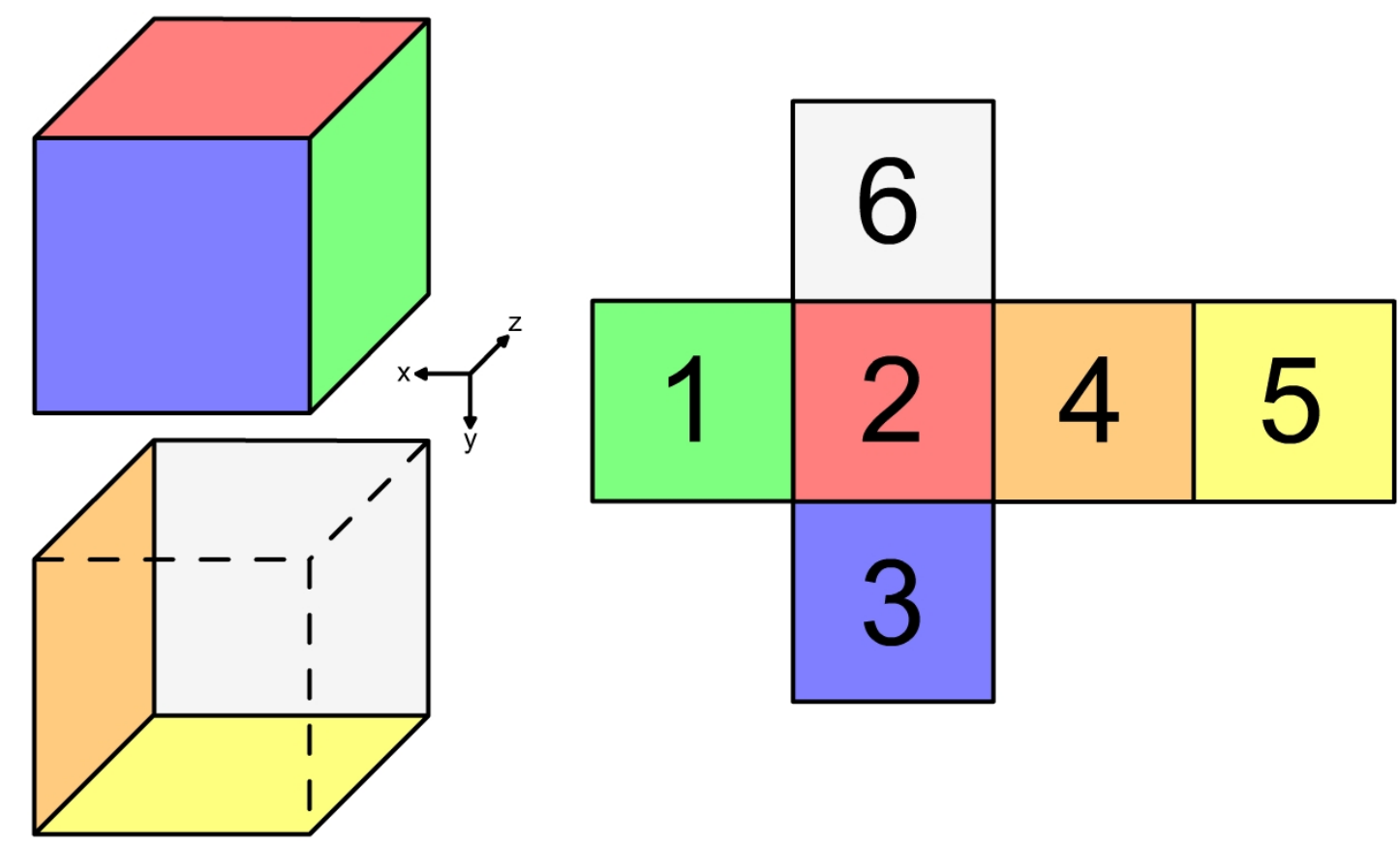

Figura 4.5: Ordem em que são percorridas as faces de um bloco.

transitar pela triangulação através de iteradores.

O primeiro iterador descrito nessa seção é o iterador de blocos que, para sua inicialização, requer uma dupla $(g, r)$ que especifique um bloco qualquer dentro da triangulação. No caso de o bloco não ser refinado, o iterador percorre todos os simplexos do bloco especificado, caso contrário, o iterador percorre todos os simplexos de todos os descendentes do bloco especificado. O primeiro simplexo também pode ser definido, mas normalmente é o simplexo com a primeira permutação de $\pi$ e com todos os sinais negativos em $s$ e nas posições existentes em $t$.

No caso de blocos básicos, cada uma das faces é percorrida sendo que a ordem de iteração seguida determina que o iterador percorra todos os simplexos na ordem horária (definida quando se olha diretamente para a face) através do pivoteamento alternado em relação aos vértices 2 e 3 . A ordem para percorrer as faces é ilustrada na Figura 4.5 e segue o princípio de visitar as faces na ordem $(-x,-y,-z,+x,+y,+z)$ para que a próxima face a ser visitada seja sempre adjacente à anterior.

No caso de blocos de transição, podem ocorrer tanto arestas quanto faces refinadas. No caso de arestas refinadas, o algoritmo usado para circular pelos simplexos da face funciona sem nenhuma alteração, já que os pivoteamentos alternados completam o 


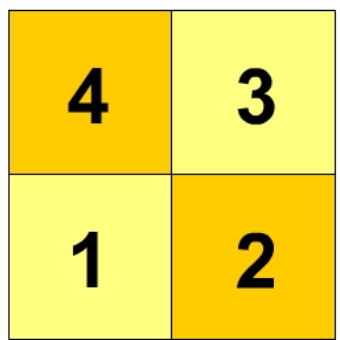

Face 2
Face 1

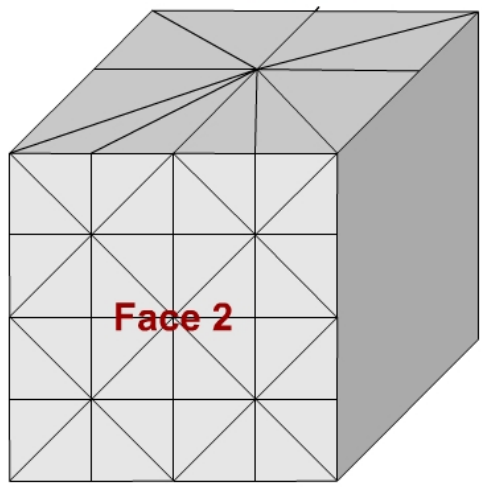

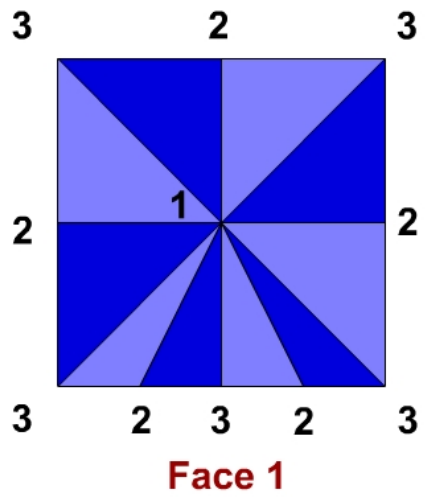

Figura 4.6: À esquerda, está ilustrado o caso de uma face refinada, para a qual basta visitar cada subface de maneira convencional. À direta, uma face com uma aresta refinada deixa claro que os pivoteamentos alternados dos vértices 3 e 2 promovem o efeito de circular a face no sentido anti-horário.

circuito na ordem desejada, conforme ilustra a Figura 4.6 à direita. Porém, para as faces refinadas, deve-se realizar uma modificação significativa, que é a de realizar o percurso em cada uma das 4 subface antes de seguir para a próxima face. Também na Figura 4.6, esse último fato também pode ser verificado.

Outra forma de iteragir com a triangulação é através da operação de pivoteamento. Para esse caso, foi criado o iterador de pivoteamento que permite a especificação de um simplexo particular na triangulação e, a partir desse, percorrer os simplexos desejados. Esse iterador pode ser utilizado como base para o desenvolvimento de outros iteradores que realizem percursos típicos de estruturas de dados topológicas, tais como o percurso da estrela de vértices ou arestas.

\subsection{Reconstrução da superfície}

Depois de uma revisão dos métodos de reconstrução de superfícies existentes, a construção de superfícies implícitas por Partição da Unidade (Ohtake et al., 2003) destacou-se como uma abordagem interessante, ao passo que dá origem à métodos eficientes e que permitem o controle local da superfície. Dessa forma, ao invés de propor uma abordagem implícita híbrida (Ohtake et al., 2004) ou outro esquema matematicamente carregado, foi decidido que a técnica de reconstrução proposta deveria tratar de algumas deficiências apresentadas pelos métodos de Implícitas de Partição da Unidade 
(IPU) sem se desfazer de suas principais vantagens, a saber, simplicidade e eficiência.

Eu outras abordagens de IPU, as informações obtidas durante a aproximação da função são, geralmente, desconsideradas. Portanto, uma das características da nova abordagem é o uso de tais informações para condicionar uma poligonalização adaptativa através do uso da estrutura octree restrita subjacente à triangulação $J_{1}^{a}$ tanto para propósitos de aproximação, quanto para propósitos de poligonalização. Outros elementos chaves da abordagem incluem o uso de polinômios ortogonais recursivamente definidos nas aproximações locais, que proporciona uma adaptatividade de duas vias e evita a solução de sistemas lineares; e o desenvolvimento de um critério de robustez, que ajuda a prevenir o aparecimento de superfícies espúrias e artefatos.

É importante ressaltar que o algoritmo proposto funciona em duas etapas bem definidas, sendo que a primeira consiste no cálculo de aproximações locais e a segunda, na avaliação da função, que pode ser necessária para o processo de poligonalização ou de ray tracing.

Nas seções seguintes, além de alguns fundamentos importantes, é descrita a forma como as aproximações locais são obtidas, bem como o esquema de avaliação da função e algumas características importantes do algoritmo, tais como o suporte à sharp features e o esquema de edição interativa de função.

\subsubsection{Superfícies Implícitas de Partição da Unidade Multinível}

Como em outros métodos de aproximação por superfícies implícitas, no método proposto a IPU é definida como o conjunto zero de uma função $\mathcal{F}$. O elemento chave na definição da aproximação global $\mathcal{F}$ em um domínio finito $\Omega$ é a combinação linear de aproximações locais usando pesos. Para esse propósito, um conjunto de funções pesos não-negativas de suporte compacto $\Phi=\left\{\phi_{1}, \ldots, \phi_{n}\right\}$ satisfazendo $\sum_{i=0}^{n} \phi_{i}(x) \equiv 1, x \in \Omega$; e um conjunto $\mathbb{F}=\left\{f_{1}, \ldots, f_{n}\right\}$ de funções de distância locais com sinal $f_{i}$ devem ser definidas em $\Omega$, através da partição do domínio em blocos com suportes esféricos. Dado o conjunto $\mathbb{F}$ e $\Phi$, a função $\mathcal{F}: \mathbb{R}^{3} \rightarrow \mathbb{R}$ é dada pela Equação 4.6.

$$
\mathcal{F}(x) \equiv \sum_{i=0}^{n} f_{i}(x) \phi_{i}(x), \quad x \in \Omega
$$




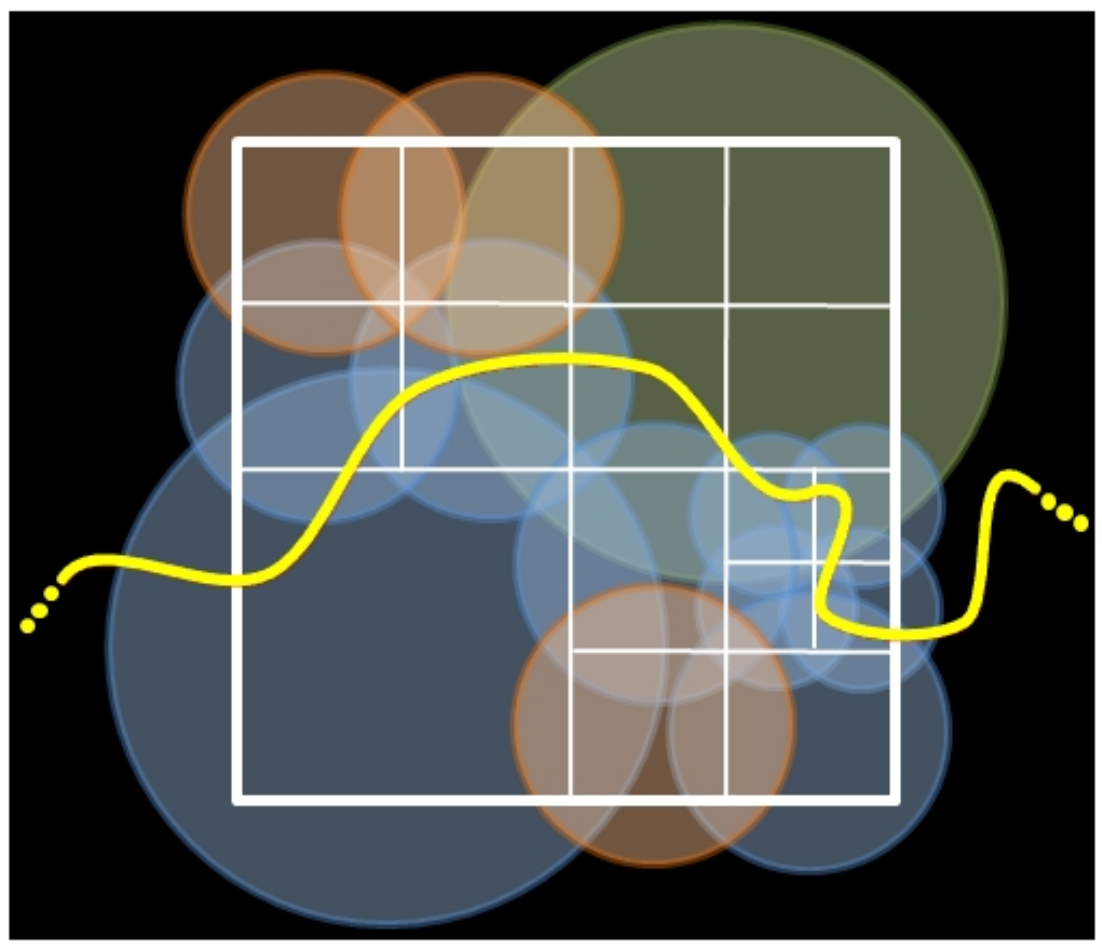

Figura 4.7: Comportamento da triangulação $J_{1}^{a}$ durante a aproximação da função.

Um conjunto de funções de suporte compacto $\Theta=\left\{\theta_{1}, \ldots, \theta_{n}\right\}$ produz a partição da unidade como:

$$
\phi_{i}(x)=\frac{\theta_{i}\left(\left\|x-c_{i}\right\| / R_{i}\right)}{\sum_{k=1}^{n} \theta_{k}\left(\left\|x-c_{i}\right\| / R_{i}\right)}
$$

em que $c_{i}$ e $R_{i}$ são o centro e o raio do suporte de $\phi_{i}$, respectivamente.

A Figura 4.7 ilustra um exemplo bidimensional no qual o domínio $\Omega$ é coberto por um conjunto de círculos - suportes- e a função global é representada pela linha em amarelo.

\subsubsection{Cálculo de aproximações locais}

As aproximações locais $f_{i}: \mathbb{R}^{3} \rightarrow \mathbb{R}$ são geradas sobre os suportes esféricos das funções de peso $\phi_{i}$, que são definidas como as circunsferas dos blocos aumentadas por um fator maior que um (o padrão utilizado é 1.5).

A função $f_{i}$ em cada bloco é computada utilizando o conjunto de pontos envolvidos por seus respectivos suportes. Inicialmente, é definido um sistema de coordenadas locais $(\xi, \eta, v)$ no centro do suporte, em que $(\xi, \eta)$ definem o plano local (domínio), e $v$ 
coincide com a direção ortogonal (imagem). Em seguida, é realizada a aproximação da função $g_{i}$ sobre o plano de referência local. Logo, $f_{i}$ é definida como $f_{i}(x)=w-$ $g_{i}(u, v)$, em que $(u, v, w)$ corresponde à representação de $x$ na base $(\xi, \eta, v)$. É importante notar que esse método requer pontos equipados consistentemente com vetores normais orientados.

No método proposto, as funções locais são obtidas por meio de aproximações polinomiais através de mínimos quadrados. Entretanto, ao invés de utilizar a base canônica $\left\{u^{i} v^{j}: i, j \in \mathbb{N}\right\}$, é escolhida uma base de polinômios ortogonais com relação ao produto interno induzido pelas equações normais. Dessa maneira, não é necessário resolver sistemas de equações. Para encontrar a base, é utilizado o método de Bartels and Jezioranski (1985). As vantagens de tal método, de acordo com os autores, são a estabilidade e a eficiência computacional.

Portanto, dado um conjunto de polinômios ortogonais $\Psi=\left\{\psi_{1}, \ldots, \psi_{l}\right\}$, a aproximação polinomial nas coordenadas locais pode ser computada conforme a Equação 4.7.

$$
g_{i}(u, v)=\sum_{\psi_{j} \in \Psi} \psi_{l}(u, v) \frac{\sum_{i=1}^{m} w_{i} \psi_{j}\left(u_{i}, v_{i}\right)}{\sum_{i=1}^{m} \psi_{j}\left(u_{i}, v_{i}\right) \psi_{j}\left(u_{i}, v_{i}\right)},
$$

em que $g_{i}$ é a função $g$ sujeita a $\left.\min _{g} \sum_{\left(u_{i}, v_{i}\right)}\left(g\left(u_{i}, v_{i}\right)-w_{i}\right)\right)^{2}$.

A maior motivação para a utilização de tais polinômios ortogonais é sua habilidade de gerar aproximações de ordem mais alta a partir de aproximações de baixa ordem previamente calculadas sem um esforço computacional significativo. Essa propriedade permite a definição de um método que não é apenas adaptativo na subdivisão espacial, mas também nos graus das aproximações locais. Entretanto, uma desvantagem do emprego de aproximações de alto grau como soluções locais é o fato de que tais funções poderem apresentar um comportamento oscilatório e, ainda que apresentem um pequeno erro de mínimos quadrados, possam constituir aproximações ruins dentro da região de interesse. Por exemplo, na Figura 4.8 à esquerda, o polinômio representado passa próximo às amostras de pontos dentro do suporte, mas os sinais obtidos quando a função é avaliada nos vértices da triangulação $J_{1}^{a}$ não são corretos. Portanto, dependendo das soluções nas vizinhanças, essa situação pode levar ao aparecimento de folhas extras ou artefatos na superfície. 

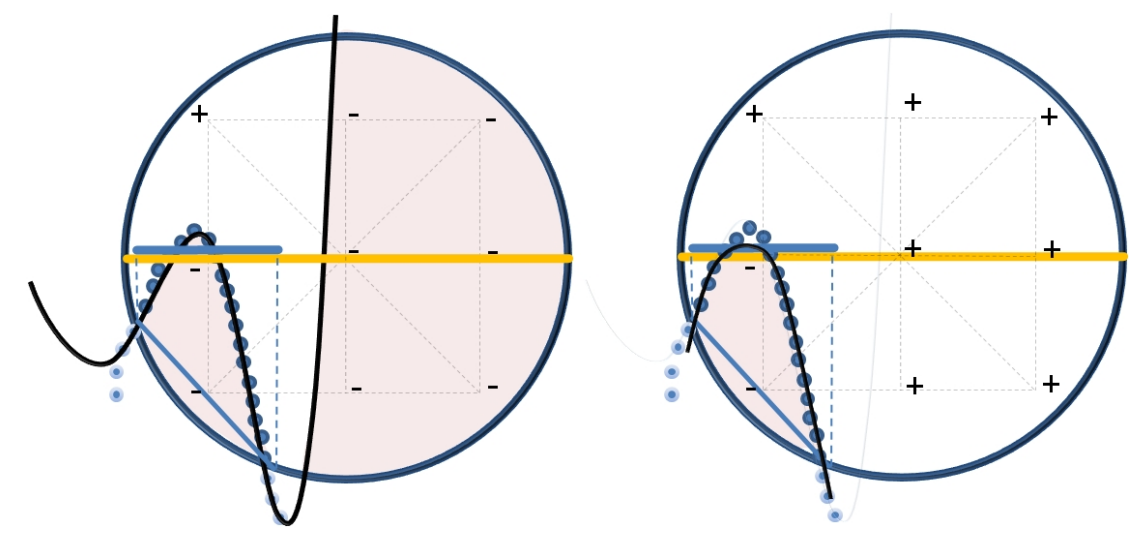

Figura 4.8: Ilustração da cobertura do domínio: note que aumentar o grau do polinômio de forma indiscriminada pode causar soluções locais inadequadas.

O aparecimento desse problema decorre do fato de que, ainda que polinômios de alto grau possam aproximar os pontos de entrada de forma correta próxima, eles também podem oscilar significativamente em locais nos quais não há muitos pontos para restringir a solução, como ilustrado no lado esquerdo da Figura 4.8. Baseado nesse fato, pode-se observar que a distribuição de pontos dentro dos suportes é tão importante para a geração de uma boa aproximação, quanto é o número de pontos utilizado na aproximação da função.

Portanto, foi proposta uma forma aproximada, porém computacionalmente eficiente, de avaliar a qualidade da distribuição de pontos dentro de um suporte. Como no método proposto os domínios locais são na verdade planos, deve-se determinar qual extensão dos planos que é coberta com pontos. Para isso, calcula-se a razão $(k)$ entre a projeção do suporte do bloco e a projeção do bounding box do conjunto de pontos sobre o plano de referência. A partir disso, foi criado um critério de cobertura para polinômios através da definição de um valor mínimo $k$ exigido para cada grau de polinômio (por exemplo, 0.4, 0.8, 0.85 são os valores padrão para polinômios de segundo, terceiro e quarto graus). Na Figura 4.8, está ilustrada a importância da cobertura para a escolha correta da função. No exemplo, uma aproximação de grau menor (à direita) é mais adequada que a aproximação de maior grau (à esquerda), justamente porque a cobertura do plano é pequena.

Como já foi mencionado, além do critério de cobertura, também deve ser levado em conta o número mínimo de pontos que deve ser empregado para cada grau de 


\section{Desenvolvimento}

polinômio (o padrão é duas vezes o número de bases polinomiais para cada grau). A união de ambos os critérios, cobertura e mínimo de pontos, constitui o Teste de Robustez usada no algoritmo de reconstrução.

Um fato imediato que surge do teste de mínimo de pontos é que nem todo bloco no domínio contém pontos suficientes para realizar a aproximação polinomial. Logo, foi criada uma estratégia para lidar com blocos que contenham poucos pontos ou nenhum ponto. Essa estratégia difere de trabalhos anteriores porque, ao invés de crescer o suporte iterativamente até alcançar o mínimo número de pontos (Ohtake et al., 2003) - que pode fazer com que uma aproximação local influencie uma grande parte do domínio - ou de usar a aproximação do bloco pai (Mederos et al., 2006) - que pode ser uma aproximação pobre - no método proposto a situação é contornada através da aproximação linear do cluster de pontos mais próximo ao centro do bloco.

A determinação do cluster de pontos é realizada buscando-se o ponto da amostra $r$ mais próximo do centro do bloco, obtendo-se pontos suficientes em torno de $r$ (o padrão é 20 pontos), e realizando-se a aproximação de um plano por mínimos quadrados. Porém, dependendo da distribuição de pontos, o plano obtido pode estar em uma posição aproximadamente ortogonal ao que era esperado (Amenta and Kil, 2004). Essa situação é detectada através da comparação do vetor normal do plano com a média dos vetores normais dos vizinhos de $r$. Se o ângulo for maior que $\pi / 6$, a função obtida por mínimos quadrados é substituída pelo plano cujo vetor normal é igual à média das normais e cuja origem está posicionada sobre o centro de massa dos vizinhos. Esse último teste é considerado a terceira condição de robustez do método.

Nos parágrafos anteriores, alguns conceitos da abordagem proposta foram esclarecidos e nos parágrafos seguintes será fornecida uma descrição algorítmica do método, que é resumido em alto nível no Algoritmo 2.

\section{Algoritmo 2}

Entrada: Sejam MAXPONTOS e MINPONTOS o número máximo e mínimo de pontos admitidos para realizar a aproximação, MAXNÍVEL o maior nível de refinamento definido pelo usuário, e LIMERRO o limite de erro

1. repita 
2. Seja o bloco $B$

3. Obtenha o conjunto de pontos $P(B)$ no suporte de $B$

4. $\quad$ se quantidade $(P(B))>$ MAXPONTOS e nível $(B)<$ MAXNÍVEL

5. então $(*$ Caso $($ iii $) *)$

6. $\quad$ Refine $B$ e recomece o processo com os filhos de $B$

7. $\quad$ se quantidade $(P(B))<$ MINPONTOS

8. $\quad$ então $(*$ Caso $(i i) *)$

9. Aproxime $B$ com um plano usando o cluster de pontos mais próximos senão

10.

$(*$ Caso $(i) *)$

11.

se numFolhaSuperficie ()$>1$

12. então Refine $B$ e recomece o processo com os filhos de $B$

13. Aproxime o polinômio de grau um $\operatorname{Pol}(B)$

14. $(* g$ representa o grau do polinômio $*)$

15. $g=1$

16. enquanto $\operatorname{ErroPol}(B)<$ LIMERRO e $g<4$ e robustez $(P(B), g)=$ OK 17. faça Aumente o grau de $\operatorname{Pol}(B)$

18. até que não existam blocos sem aproximação

Depois de definir uma configuração da triangulação $J_{1}^{a}$ inicial, para cada bloco que não possui uma aproximação definida, o número de pontos dentro do suporte do bloco é obtido e, a partir disso, três situações distintas podem surgir: (i), o número de pontos é suficiente para realizar as aproximações; (ii), o número de pontos não é suficiente, nem mesmo para um plano; e (iii), o número de pontos é maior que um limiar máximo estabelecido.

Inicialmente, no caso $(i)$, um teste que mede a variação das normais dos pontos de Ohtake et al. (2003) é empregado para determinar a presença de dois ou mais folhas da superfície dentro do mesmo suporte. Tal teste é bastante simples é consiste em se calcular a média das normais dos pontos e compará-la com cada normal da amostra através do cálculo de um produto escalar. Se o ângulo entre os vetores for maior que $90^{\circ}$, a presença das folhas múltiplas exige o refinamento do bloco. Se apenas uma 


\section{Desenvolvimento}

folha é detectada, uma aproximação de grau um é calculada e o grau é recursivamente aumentado até que o critério de erro seja satisfeito, ou até que o critério de robustez não permita aumento do grau, ou até que o grau chegue ao máximo permitido (quatro, por padrão). Se o processo anterior terminar e o erro for aceitável, a aproximação é armazenada no bloco, caso contrário, o bloco é refinado, a não ser que o suporte do bloco contenha um número crítico de pontos (menos de 100 pontos, por padrão). Nessa última situação, a subdivisão do bloco pode ser abortada se as novas aproximações dos blocos refinados fariam o erro aumentar ao invés de diminuir, devido ao fato de que os novos blocos conteriam pequenas quantidades de pontos que não permitiriam aproximações de alto grau.

Na descrição anterior, em ambas as situações em que o refinamento é sugerido, o bloco pode já estar no nível de refinamento máximo permitido pelos parâmetros definidos pelo usuário. Logo, não há outra opção a não ser utilizar a melhor aproximação que pode ser obtida até o momento.

O caso de aproximação (ii) é resolvido através da busca do cluster mais próximo de pontos e através do cálculo de uma aproximação de primeiro grau, conforme já foi explicado.

Finalmente, o caso (iii) é uma heurística empregada para evitar cálculos inúteis e custosos. É considerado um esforço desnecessário calcular minimizações para mais de mil pontos. Portanto, nesse caso a subdivisão do bloco é forçada, a não ser que o bloco esteja em seu nível máximo refinamento, situação na qual a única opção é forçar o cálculo da aproximação com muitos pontos.

Para concluir a discussão a respeito das aproximações, é importante esclarecer a diferença entre refinamentos de blocos causados por condições de aproximação e aqueles exigidos pelas restrições da triangulação $J_{1}^{a}$. Nesse último caso, novas aproximações não devem ser computadas se a aproximação para o bloco que está sendo refinado já seja adequada. A Figura 4.7 ilustra um caso no qual nem todos os blocos folhas da triangulação $J_{1}^{a}$ contém aproximações associadas. Na figura, os círculos azuis representam blocos folhas que contém aproximações e pontos, e os círculos alaranjados também são folhas que contém aproximações, mas não contém pontos. Por fim, o círculo verde 
representa um nó não-folha que contém uma aproximação e que apenas foi dividido devido a restrições da triangulação $J_{1}^{a}$.

\subsubsection{Avaliação da função implícita}

Dado um ponto $x$ pertencente ao domínio, um percurso típico de octree dos blocos da triangulação $J_{1}^{a}$ é conduzido para determinar quais blocos contém $x$ dentro de seus suportes. O valor $\mathcal{F}(x)$ é obtido como uma combinação de todas as funções locais dos suportes que contém $x$ :

$$
\mathcal{F}(x)=\frac{\sum_{i=1}^{N} f_{i}(x) \theta_{i}\left(\left\|x-c_{i}\right\| / R_{i}\right)}{\sum_{i=1}^{N} \theta_{i}\left(\left\|x-c_{i}\right\| / R_{i}\right)},
$$

em que $N$ é o número de suportes que engloba $x, f_{i}(x), c_{i}$ and $R_{i}$ são a função local com sinal, o centro e o raio do bloco $i$ respectivamente, e, finalmente, a função peso $\theta_{i}(t)=\left(1-t^{2}\right)^{4}$ que assume valor zero para $t \geq 1$.

A determinação dos blocos cujos suportes englobam um dado ponto $x$ envolve uma situação que não é encontrada no trabalho de Ohtake et al. (2003), já que no caso desse último trabalho, todos os blocos são descendentes de uma única raiz. Esse fato não é necessariamente verdade para a triangulação $J_{1}^{a}$, em que se pode definir domínios com mais de um bloco no nível zero. Por essa razão, é necessário uma forma de escolher a quais blocos de nível zero será aplicado o percurso típico de octree.

A forma escolhida consiste em realizar um pré-processamento, anterior à construção da aproximação, em que os centros dos blocos de nível zero da triangulação $J_{1}^{a}$ são inseridos em uma estrutura de busca $k$ - $d$-tree. Portanto, no momento da avaliação, quando há mais de um bloco no nível zero, antes de realizar os percursos, deve ser feita uma busca na $k$ - $d$-tree tomando como entrada o ponto $x$ e como raio de busca o raio dos suportes dos blocos de nível zero.

O Algoritmo 3 ilustra o algoritmo de avaliação da função implícita.

\section{Algoritmo 3}

Entrada: Seja $x$ o ponto a ser avaliado.

1. Obtenha, com a $k$ - $d$-tree, $R$ como o conjunto de blocos de nível zero que afetam $x$

2. $\operatorname{soma}_{w}=0$ 
3. soma $_{f w}=0$

4. para cada $r$ em $R$

5. faça Inicialize a pilha $P$

6. $\quad$ Empilhe $r$ em $P$

7. enquanto $P \neq \emptyset$

8. faça Desempilhe $r$ de $P$

9. $\quad d=\operatorname{Distancia}(\operatorname{Centro}(r), x)$

$10 . \quad$ se $d<\operatorname{Raio}(r)$

11.

então se Função $(r) \neq \emptyset$

12.

então $\operatorname{soma}_{f w}+=\operatorname{Funcao}(r)(x) * \operatorname{Peso}(x, d)$

13. $\operatorname{soma}_{w}+=\operatorname{Peso}(x, d)$

14. senão para cada filho $f_{r}$ de $r$

15. faça Empilhe $f_{r}$ em $P$

\subsubsection{Extensões ao método original}

Nas seções anteriores, foi descrito o método de reconstrução originalmente desenvolvido (Gois et al., 2007). Nessa seção, serão descritas algumas extensões que foram adicionadas ao método original.

A primeira extensão diz respeito à adição da capacidade de representar sharpfeatures, através da inserção adequada de uma técnica bem conhecida.

Outra extensãoé devida à dificuldade de lidar com inúmeros parâmetros necessários à maioria das abordagens de reconstrução. Essa dificuldade sugere que, em alguns casos, pode ser útil permitir a edição manual da superfície a fim de que o usuário possa consertar artefatos indesejáveis ou melhorar a qualidade da aproximação através da escolha de funções mais adequadas.

\section{Sharp features}

Decidir quando empregar sharp features em uma determinada região não é um problema trivial, porém a solução apresentada por Kobbelt et al. (2001) leva a bons resultados.

Dado um conjunto de $k$ pontos $P=\left\{p_{1}, \ldots, p_{k}\right\}$ associado a um conjunto de vetores 
normais $N=\left\{n_{1}, \ldots, n_{k}\right\}$, o teste consiste em calcular o co-seno do ângulo entre os vetores normais de cada par de pontos e checar se o mínimo valor associado é menor que um limiar especificado (0.7, sugerido por Kobbelt). Caso esse seja o caso, diz-se que a região avaliada contém um sharp features. Para o segundo teste, dados os dois pontos $\left\{p_{i}, p_{j}\right\}$ que representam o maior ângulo de abertura entre seus vetores normais $\left\{n_{i}, n_{j}\right\}$, um vetor ortogonal é calculado como $n^{*}=n_{i} \times n_{j} /\left\|n_{i} \times n_{j}\right\|$. Feito isso, o módulo máximo do co-seno do ângulo entre $n^{*}$ e cada vetor em $N$ é calculado. Se esse módulo é maior que um limiar especificado (0.9), o sharp feature é classificado como corner, caso contrário, é classificado como uma aresta. Na implementação realizada, tal teste é complementado por uma condição que verifica se o número de pontos é menor que um parâmetro especificado pelo usuário (30, como padrão).

A adição da capacidade de representar sharp features requereu a alteração de duas partes do algoritmo explicado na Seção 4.3.2, porque o método lida diferentemente com os casos em que uma pequena quantidade de pontos é encontrada dentro do suporte.

No caso de aproximação (i), após decidir qual polinômio oferece a melhor aproximação, os testes de sharp features são feitos e, se os teste forem bem-sucedidos, uma aproximação para representar tal formato é calculada (Ohtake et al., 2003). Se o erro de aproximação for menor que o obtido com a aproximação polinomial, a função de sharp feature é utilizada. Quanto ao caso de aproximação (ii), para os blocos que originalmente apresentaram mais de zero pontos, testa-se não apenas o polinômio de grau um, mas também as funções de sharp feature. Como nesse caso o número de pontos é pequeno, o erro de aproximação não é levado em conta, ou seja, sempre que os testes de sharp features forem bem-sucedidos, uma função de sharp feature é definida e substitui o polinômio.

\section{Edição de Função}

Para a funcionalidade de edição de função, foi explorada uma das vantagens apresentadas pelos métodos de Partição da Unidade sobre outras técnicas tais como mínimos quadrados móveis (MLS) ou RBF (Funções de Base Radial), a saber, o fato de que a função global é definida por um conjunto de funções locais independentes em seus subdomínios, i.e., mudar uma dessas funções apenas afeta a função global localmente. 
Logo, mudar características locais da função consiste apenas em localizar o bloco desejado e realizar a troca da função associada. Encontrar o bloco que contém um ponto é uma tarefa relativamente simples para se realizar na estrutura da triangulação $J_{1}^{a}$ e é descrita em maiores detalhes na Seção 4.4.3.

Na implementação atual, é disponibilizada uma ferramenta gráfica se escolher o local onde se deseja realizar a mudança. O tipo da nova função a ser utilizada pode ser um dos seguintes: função constante, polinômios e funções de sharp features.

\subsection{Extração da isosuperfície}

Inicialmente é apresentada uma visão de alto-nível do algoritmo de extração de isosuperfícies sem o algoritmo de melhoramento de malha seguida de descrições das etapas não triviais do processo. Em seguida, é introduzido o conceito de movimentação de vértices e o algoritmo de melhoramento de malhas é descrito.

\subsubsection{Visão geral}

O algoritmo de extração de isosuperfícies é baseado no conceito de marching tetrahedra, em que os simplexos de uma triangulação suporte são percorridos e, para cada tetraedro, é realizado um teste para determinar as intersecções com a isosuperfície. Como já definido na Seção 3.2, a isosuperfície é definida como o conjunto zero de uma função implícita. O algoritmo de poligonalização é descrito de maneira simplificada no Algoritmo 4.

\section{Algoritmo 4}

1. Encontre um simplexo inicial $s_{\text {ini }}$ da isosuperfície $F_{0}$

2. Adicione $s_{i n i}$ à pilha $P$

3. Inicialize a estrutura de dados $A$ para comportar simplexos processados

4. enquanto $P \neq \emptyset$

5. faça Desempilhe $s_{\text {atual }}$

6. $\quad$ se $s_{\text {atual }} \notin A$

7. $\quad$ então Teste a intersecção de $s_{\text {atual }} \operatorname{com} F_{0}$

8. Calcule o conjunto de novos vértices $V$ da nova face e crie o(s) triângulo(s) 
9.

10.

11.

12.

13.

14.
Adicione ao conjunto $C_{\text {pivos }}$ todos os vértices opostos a faces interceptadas pela superfície

para cada $v_{i}$ em $C_{\text {pivos }}$

faça Pivoteie $s_{\text {atual }}$ em relação a $v_{i}$ obtendo $s_{\text {novo }}$

se $s_{\text {novo }}$ não foi processado

então Empilhe $s_{\text {novo }}$ em $P$

Adicione $s_{\text {atual }}$ a $A$

Basicamente o algoritmo funciona mantendo uma pilha de simplexos a serem processados e uma estrutura de dados que armazena os simplexos já processados enquanto percorre a triangulação através de operações de pivoteamento. Nas seções subseqüentes são detalhadas algumas etapas não-triviais desse algoritmo como as estruturas de dados, a determinação do simplexo inicial e o cálculo de intersecções e geração da malha.

\subsubsection{Estruturas de dados}

Nessa seção é discutido um aspecto que pode parecer pouco intuitivo aos não habituados ao trabalho com a triangulação $J_{1}^{a}$ que é a representação implícita de simplexos. Essa característica significa, na prática, que apenas informações sobre blocos são armazenadas, sendo os simplexos derivados implicitamente a partir dessas informações. Portanto, um simplexo só existe como um objeto transitório e, conseqüentemente, não pode carregar consigo informações, tais como as intersecções de suas arestas com a superfície ou o fato de ter sido poligonalizado ou não. Por essa razão, faz-se necessária, para o algoritmo de extração de isosuperfícies, uma estrutura de dados capaz de armazenar de maneira persistente informações sobre simplexos processados.

A fim de utilizar uma estrutura de dados para busca, é necessário criar uma chave única capaz de identificar cada simplexo que seja fácil de comparar e estabelecer uma relação de ordem. Para esse fim, cada simplexo é representado por cinco número inteiros $(l(g), r, l(\pi), l(s), l(t))$ e a relação de ordem é estabelecida considerando os elementos mais à esquerda da 5-upla como mais significativos. O cálculo de rótulos para cada um dos vetores da triangulação $J_{1}^{a}$ é detalhado na Seção 4.2.3. 


\section{Desenvolvimento}

Tendo definida uma chave única para representar os simplexos, foi construída uma estrutura de dados que consiste em uma tabela hash na qual o tratamento de colisão é efetuado através de uma árvore AVL. Dessa forma, o tempo de acesso é limitado por $O(\log (n))$ em que $n$ é o número de simplexos armazenados, sendo, no caso de se assumir a hipótese de hashing uniforme, $O\left(\log \left(\frac{n}{N}\right)\right)$, em que $N$ é o número de posições da tabela.

\subsubsection{Determinação do simplexo inicial}

Basicamente, pode-se encarar duas situações diferentes na determinação do simplexo inicial durante o processo de extração de isosuperfícies: quando há um ponto conhecido na superfície e quando não há tal informação. Para esse último caso, algum algoritmo de força-bruta deve ser utilizado, seja através da iteração dos simplexos da triangulação, seja através do lançamento de raios sobre o domínio. Porém, no caso do presente trabalho, a superfície é advinda da aproximação de uma nuvem de pontos. Conseqüentemente, qualquer um dos pontos da nuvem, constitui um ponto potencialmente próximo à superfície, a partir do qual é possível obter um ponto sobre a mesma. Portanto, o restante da discussão dessa seção está focado no caso em que existe um ponto sobre a superfície.

Como dito anteriormente, qualquer ponto $p$ pertencente à nuvem de pontos $P$ está potencialmente próximo à superfície. No entanto, nada garante que o simplexo da triangulação $J_{1}^{a}$ que contém tal ponto tenha intersecção com a superfície, conforme está ilustrado na Figura 4.9. Por essa razão, faz-se necessário obter um ponto $p^{\prime}$ que esteja mais próximo à superfície. A obtenção de $p^{\prime}$ é realizada através da projeção de $p$ sobre a superfície em questão, $S$, já que a função implícita $f$ que descreve $S$ já está, obviamente, disponível no momento da extração de isosuperfície. A projeção é feita movendo-se o ponto na direção inversa do gradiente da função $f$, conforme define a Equação 4.8.

$$
p^{\prime}=p-\frac{\nabla f(p)(f(p))}{\|\nabla f(p)\|^{2}}
$$

De posse do ponto $p^{\prime}$, três possíveis formas de encontrar o simplexo inicial foram consideradas: 


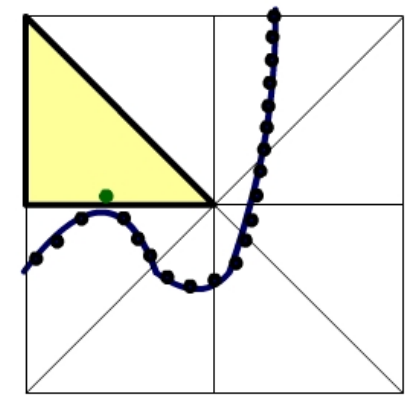

Figura 4.9: O ponto destacado na cor verde constitui um exemplo de um ponto da nuvem contido por um simplexo não interceptado pela superfície.

(i) Uso do algoritmo door-in-door-out a partir de um simplexo qualquer (TotalDido);

(ii) Uso de propriedades da triangulação $J_{1}^{a}$ para determinar o bloco inicial e iterar pelos simplexos avaliando a função(NoDido);

(iii) Uso de propriedades da triangulação $J_{1}^{a}$ para determinar o bloco inicial e uso do algoritmo door-in-door-out a partir de um simplexo qualquer desse bloco (PartialDido).

No pior caso um bloco da triangulação $J_{1}^{a}$ possui 176 simplexos, logo, pode-se intuir que o algoritmo NoDido tenha um desempenho melhor que o algoritmo TotalDido quando o custo da avaliação de função for pequeno, já que esse último exige a resolução de um sistema linear por simplexo visitado e, dependendo da escolha inicial, muitas iterações podem ser necessárias. Por outro lado, o desempenho do PartialDido será sempre comparável ou superior ao NoDido, pois o algoritmo door-in-door-out diminui consideravelmente, em média, o número de simplexos visitados de um universo já muito reduzido. A Tabela 4.1 apresenta uma comparação prática dos métodos supracitados.

Devido aos resultados obtidos, para a determinação do simplexo inicial é empregado o algoritmo PartialDido (Algoritmo 5) em que inicialmente é determinado o bloco inicial através de um cálculo relativo à grade computacional e, em seguida, é aplicado o método door-in-door-out adaptado à triangulação $J_{1}^{a}$.

\section{Algoritmo 5}


Tabela 4.1: Comparação do tempo levado pelos métodos para determinar o simplexo inicial 100 vezes em um processador Intel Core 2 Quad de 2.4Ghz. Os testes se referem ao modelo bunny de $32 \mathrm{~K}$ pontos utilizando grid inicial $3 \times 3 \times 3$ e variando o nível de refinamento máximo entre 3 e 6.

\begin{tabular}{lcccc}
\hline Refinamento Máximo & 3 & 4 & 5 & 6 \\
\hline \hline NoDido & $6 \mathrm{~ms}$ & $51 \mathrm{~ms}$ & $50 \mathrm{~ms}$ & $50 \mathrm{~ms}$ \\
\hline TotalDido & $17 \mathrm{~ms}$ & $27 \mathrm{~ms}$ & $34 \mathrm{~ms}$ & $33 \mathrm{~ms}$ \\
\hline PartialDido & $7 \mathrm{~ms}$ & $8 \mathrm{~ms}$ & $9 \mathrm{~ms}$ & $8 \mathrm{~ms}$ \\
\hline \hline
\end{tabular}

Entrada: sejam $p$ o ponto inicial, res a resolução do grid, $d_{\text {inicio }}$ o extremo inicial do bounding box e $d_{\text {fim }}$ o extremo final

Saída: seja $g$ a coordenada de grid e $r$ o nível de refinamento do bloco

1. ( ${ }^{*}$ Determinação do bloco inicial $\left.{ }^{*}\right)$

2. para $i=1$ até 3

3. $\quad$ faça $s=\left(d_{\text {fim }}^{i}-d_{\text {inicio }}^{i}\right) /\left(2^{r} *\right.$ res $\left.s^{i}\right)$

4. $\quad g^{i}=$ floor $\left(\left(p^{i}-d_{\text {inicio }}^{i}\right) / s\right)$

5. enquanto $\operatorname{Bloco}(g, r)$ não existir

6. faça $r=r-1$

7. $\quad$ para $i=1$ até 3

8. $\quad$ faça $g^{i}=g^{i} / 2$

9. ( ${ }^{*}$ Determinação do simplexo inicial $\left.{ }^{*}\right)$

10. Encontre um simplexo $s_{\text {ini }} \in \operatorname{Bloco}(g, r)$

11. repita

12. Determine as coordenadas baricêntricas $T_{p}$ de $p$ em relação a $s_{i n i}$

13. Determine a componente de menor valor $t_{\min }$ de $T_{p}$

14. Determine o vértice $v_{\text {pivo }}$ de $s_{\text {ini }}$ associado a $t_{\text {min }}$

15. se $t_{\min }<0$

16. $\quad$ então Pivoteie $s_{i n i}$ em relação a $v_{\text {pivo }}$

17. até $t_{\min } \geq 0$

Apenas por questões de completude, a Equação 4.9 apresenta o sistema linear utilizado para a determinação de coordenadas baricêntricas $\left(t_{0}, t_{1}, t_{2}, t_{3}\right)$ do ponto $p$ em relação ao simplexo de vértices $\left(v_{0}, v_{1}, v_{2}, v_{3}\right)$. 


$$
\left(\begin{array}{cccc}
1 & 1 & 1 & 1 \\
v_{0}^{x} & v_{1}^{x} & v_{2}^{x} & v_{3}^{x} \\
v_{0}^{y} & v_{1}^{y} & v_{2}^{y} & v_{3}^{y} \\
v_{0}^{z} & v_{1}^{z} & v_{2}^{z} & v_{3}^{z}
\end{array}\right)\left(\begin{array}{c}
t_{0} \\
t_{1} \\
t_{2} \\
t_{3}
\end{array}\right)=\left(\begin{array}{c}
1 \\
p_{x} \\
p_{y} \\
p_{z}
\end{array}\right)
$$

\subsubsection{Cálculos de interseção e construção da malha}

Essa seção trata de peculiaridades relativas à construção da malha a partir dos simplexos da triangulação $J_{1}^{a}$ e refere-se, especificamente, às Linhas 7, 8 e 9 do Algoritmo 4.

O teste de interseção (Linha 7) tem a função de determinar quais faces e, conseqüentemente, quais arestas são interceptadas pela superfície. Tal teste consiste na avaliação do sinal da função implícita em cada um dos quatro vértices do simplexo $\left(v_{0}, v_{1}, v_{2}, v_{3}\right)$ e na codificação dessa informação utilizando um padrão de 4 bits $\left(b_{0}, b_{1}, b_{2}, b_{3}\right)$, em que o bit $b_{i}$ assume valor 0 , caso a função seja negativa no vértice $v_{i}$, ou 1 , caso contrário. Cada um dos padrões de bits, com exceção dos padrões $(0,0,0,0)$ e $(1,1,1,1)$, apresenta uma configuração em que 3 ou 4 arestas são interceptadas, logo, através de simetrias, pode-se resumir as 14 configurações na duas representadas pela Figura 4.10.
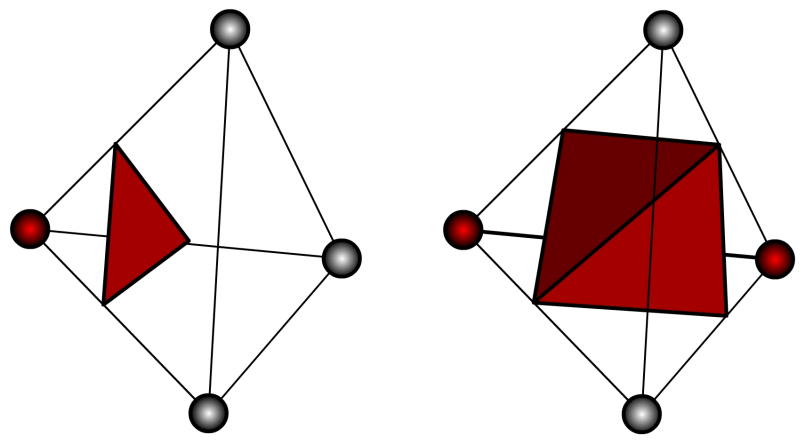

Figura 4.10: Casos de intersecção de tetraedros com a superfície.

Uma tabela com as 14 posições é acessada através do valor inteiro gerado pelo padrão de bits e contém a informação de sobre quais arestas encontram-se pontos de intersecção que darão origem aos novos polígonos da malha. De forma natural o próximo passo seria apenas calcular os 3 ou 4 novos vértices da malha. No entanto, tal abordagem geraria uma malha não consistente, já que vários vértices seriam replicados, e seria ineficiente, já que o número de avaliações de função seria muito maior que o 
mínimo necessário. Justamente por essa razão, e também para garantir que o algoritmo chegue a um fim, que deve existir uma estrutura de dados que armazene os simplexos processados, juntamente com as intersecções já calculadas.

Ao se analisar o Algoritmo 4 fica claro que, a menos do primeiro simplexo processado, todos os outros simplexos compartilham pelo menos uma face (ou 2 intersecções) com um outro simplexo já processado. Por essa razão, a pilha $P$ utilizada no algoritmo contém não apenas o simplexo a ser processado, mas também as intersecções da face compartilhada com o simplexo que o originou através da operação de pivoteamento. Isso reduz para 1 ou 2 intersecções a serem computadas, porém, como já mencionado, há a possibilidade de haver outras intersecções compartilhadas.

A solução para encontrar outras possíveis intersecções compartilhadas baseia-se em uma propriedade da triangulação $J_{1}^{a}$ que permite a obtenção da estrela de uma aresta através do pivoteamento sucessivo dos dois vértices do simplexo não pertencentes à aresta em questão. Por exemplo, dado o simplexo $\left(v_{0}, v_{1}, v_{2}, v_{3}\right)$, para encontrar a estrela da aresta $\left(v_{0}, v_{1}\right)$, basta pivotear alternadamente com relação aos vértices 2 e 3 . Na Figura 4.11 é ilustrado o início do percurso em torno da aresta $\left(v_{0}, v_{1}\right)$.
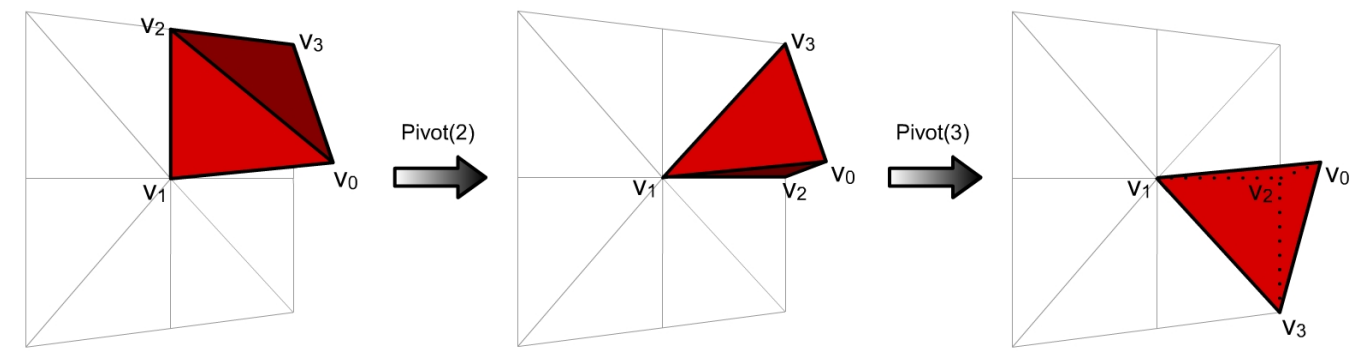

Figura 4.11: Representação do percurso da estrela de uma aresta. Da direita para a esquerda, as duas primeiras operações de pivoteamento em relação aos vértices $v_{2}$ e $v_{3}$. Os próximos simplexos são obtidos repetindo as operações com relação à $v_{2}$ e $v_{3}$.

Dessa forma, no cálculo dos novos polígonos são aproveitadas duas intersecções provenientes do simplexo anterior. Para as intersecções restantes (1 ou 2), é verificado, através do percurso da estrela das arestas correspondentes, se a intersecção já foi calculada. Somente no caso negativo, os cálculos são realizados através do algoritmo regula - falsi ou por interpolação linear, sendo esse último empregado quando se necessita favorecer a eficiência em detrimento da precisão. 


\section{Desenvolvimento}

Com todos os pontos de intersecção determinados, basta construir 1 ou 2 triângulos, dependendo da configuração do tetraedro, e adicioná-los à malha. Um último tópico que merece ser citado é a orientação da normal calculada através do produto vetorial dos vetores das faces triangulares. Tal orientação é realizada através do cálculo do produto escalar entre o vetor normal desorientado e o vetor definido pelo centro da face triangular e um dos vértices do tetraedro que se encontre fora da face (com sinal positivo). Se esse produto for positivo, a orientação do vetor normal está correta, caso contrário, o mesmo é invertido.

\subsubsection{Melhoramento da malha}

Normalmente, a qualidade da malha gerada pelo poligonalizador possui, além de uma média de razão de aspecto ruim, um desvio padrão alto, o que indica a presença de muitos pontos discrepantes. Um estudo mais detalhado sobre a qualidade das malhas e sobre a eficácia do melhoramento proposto são descritos na Seção 5.4 .

A principal causa de triângulos com razão de aspecto indesejável ocorre quando a superfície intercepta um tetraedro muito próximo a um vértice do mesmo. Tal triângulo, não necessariamente possui razão de aspecto ruim, mas forçará que seus vizinhos sejam extremamente alongados, o que contribui para a degradação da razão de aspecto. Esse fenômeno é ilustrado na Figura 4.12, em que uma malha original é comparada a uma malha melhorada.

O procedimento proposto consiste em melhorar a conformação da triangulação $J_{1}^{a}$ subjacente à superfície de forma que a interseção da superfície com os tetraedros ocorra o mais longe possível dos vértices dos mesmos. Para tal, os vértices da $J_{1}^{a}$ são movimentados de forma que sejam deslocados para longe da superfície na direção do gradiente sem invalidar a triangulação, o que significa definir uma área esférica (circular, em 2D) em torno do vértice que define o limite de movimentação do mesmo. A Figura 4.13 ilustra, além dos limites máximos para cada vértice de um bloco da $J_{1}^{a}$, o procedimento de movimentação em uma triangulação em duas dimensões.

A técnica de movimentação de vértices foi escolhida por sua simplicidade e eficiência em termos computacionais. No entanto, como os graus de liberdade oferecidos para movimentação de vértices são limitados, o melhoramento obtido também o é. 

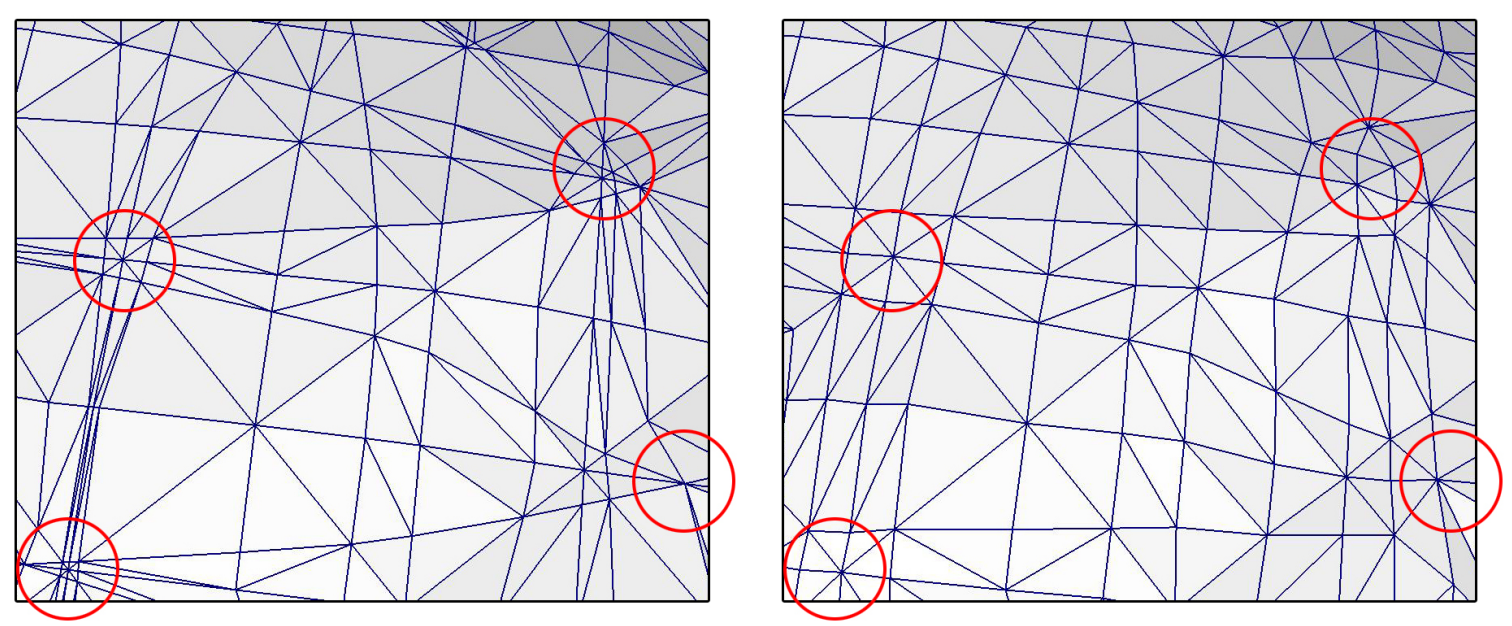

Figura 4.12: Comparação de uma malha original, à esquerda, com sua versão melhorada, à direita. Os círculos vermelhos destacam pontos em que a superfície intercepta o tetraedro da triangulação $J_{1}^{a}$ muito próximo a um vértice. A situação é corrigida através do melhoramento proposto.

A movimentação dos vértices é obtida através da Equação 4.10 e é aplicada somente aos vértices pertencentes a simplexos que interceptam a superfície durante a poligonalização. Por essa razão, não é necessário o emprego de memória extra e o esforço computacional adicional é devido ao cálculo de uma aproximação para o valor máximo da função do domínio antes do início da poligonalização, e para a avaliação do gradiente da função em cada vértice a ser movimentado. Na Equação 4.10 um vértice $x$ é levado à sua nova posição $x_{\text {nova }}$.

$$
x_{\text {nova }}=x+\left[\frac{\operatorname{sinal}(\mathcal{F}(x))}{\|\nabla \mathcal{F}\|}\left(\frac{\mathcal{F}_{\max }-\mathcal{F}(x)}{\mathcal{F}_{\max }}\right)^{2} \frac{e(l)}{4} \alpha\right] \nabla \mathcal{F}(x)
$$

em que sinal $(\mathcal{F}(x))$ representa o sinal da função, $\mathcal{F}_{\text {max }}$ é uma estimativa do valor máximo da função, $l$ é o nível de refinamento associado ao vértice, $e(l)$ é o tamanho da área no nível de refinamento $l$, e $0<\alpha<1$ determina a amplitude máxima do movimento.

Para blocos básicos, o nível de refinamento associado ao vértice $l$ é igual ao nível de refinamento do bloco $(r)$, enquanto que para os blocos de transição, $l$ é igual a $(r+1)$ para vértices pertencentes a faces refinadas, ou igual a $r$ para os vértices restantes. 
Também é interessante mencionar que $e(l) / 4$ é a máxima amplitude de movimentação - em qualquer direção - permitida pela estrutura da triangulação $J_{1}^{a}$, conforme pode ser vislumbrado na Figura 4.13.

Na prática, a Equação 4.10 significa que a movimentação ocorre na direção do gradiente, porém no sentido do sinal da função. Além disso, o termo $\left(\frac{\mathcal{F}_{\max }-\mathcal{F}(x)}{\mathcal{F}_{\max }}\right)^{2}$ funciona como um fator de normalização, enquanto que o termo $\frac{e(l)}{4} \alpha$ impõe o limite para a movimentação.
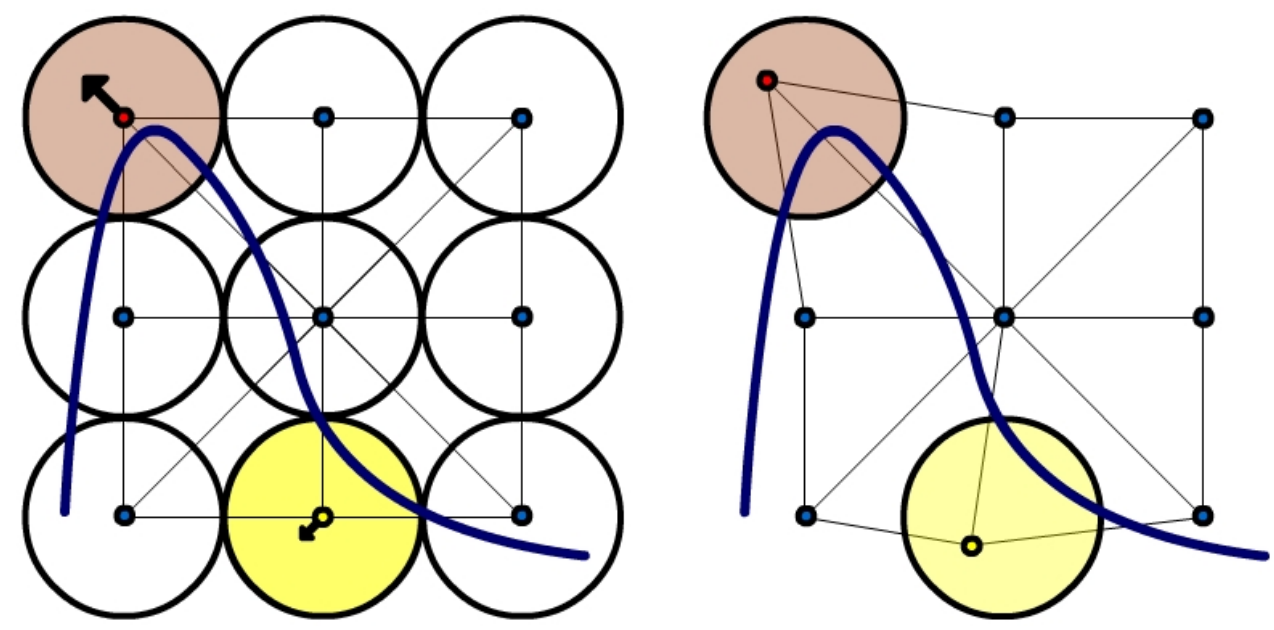

Figura 4.13: À esquerda, os limites de movimentação de cada vértice da triangulação $J_{1}^{a}$. À direita, o exemplo de movimentação de dois vértices.

Em termos de implementação, o acoplamento do algoritmo de melhoramento de malhas ao poligonalizador é bastante direto, já que não há muitas modificações a serem realizadas, com exceção do pré-cálculo da aproximação para o valor máximo da função (antes da Linha 4 do Algoritmo 4) e o deslocamento dos vértices que deve ser realizado antes do cálculo das intersecções sobre as arestas.

\subsection{Modelador genérico}

Durante as etapas de planejamento do projeto, foram feitas considerações a respeito do desenvolvimento de um modelador genérico que pudesse utilizar nuvens de pontos como um objeto de modelagem em adição aos objetos tradicionais, tais como funções paramétricas, malhas e funções implícitas. Após estudar algumas possibilidades, ficou claro que desenvolver mais um modelador a partir do nada era uma tarefa complicada e 
que poderia ter pouca aplicação prática. Por esse motivo, foi decidido que seria melhor acoplar a técnica desenvolvida à alguma ferramenta de modelagem e renderização que fosse amplamente disponível e utilizada. Para esse fim, a ferramenta POV-Ray foi escolhida e o método de reconstrução de superfícies foi acoplado ao código-fonte disponibilizado pelos desenvolvedores.

Após compreender a organização do código, foi relativamente simples concluir as implementações necessárias, que incluíram:

- Definição do tipo de dado pointset;

- Extensão da linguagem de definição de cenas do POV-Ray.

Um novo tipo de dado foi criado para representar objetos que são superfícies reconstruídas a partir de pontos de entrada. Devido ao fato de o método desenvolvido gerar uma função implícita, todos os métodos do objeto isosurface puderam ser herdados, com exceção do construtor do objeto, já que há uma série de inicializações a serem feitas para o algoritmo de reconstrução de superfícies.

O POV-Ray utiliza uma linguagem de descrição de cena, cuja especificação pode ser encontrada no website do software (PovRay, 2007). Para os fins da descrição feita nessa seção, basta saber que a linguagem permite a inserção de vários tipos de objetos em uma cena. Portanto, para que o objeto pointset possa ser incluído na cena, é necessário que a linguagem seja estendida.

Para realizar tal extensão, bastaram algumas modificações no analisador sintático da linguagem através da criação de uma nova função para realizar o parsing de um objeto do tipo pointset. Tal objeto deve respeitar a seguinte sintaxe:

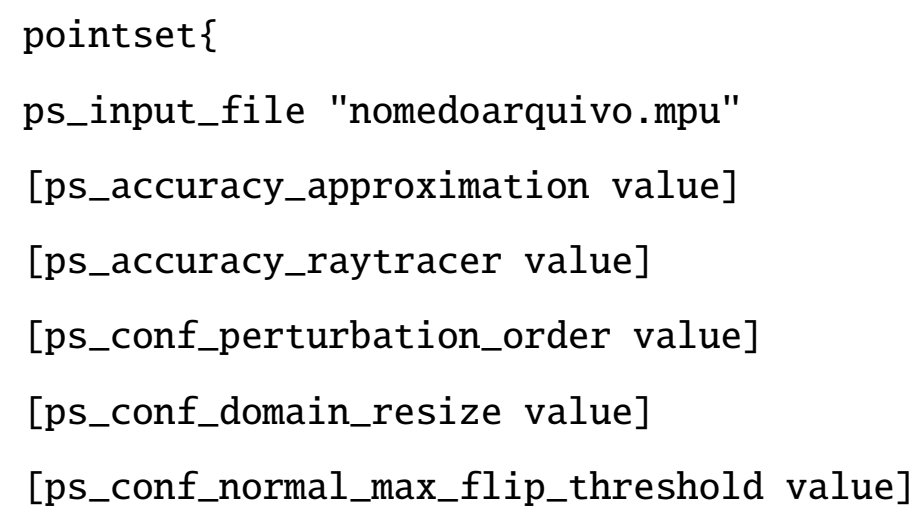




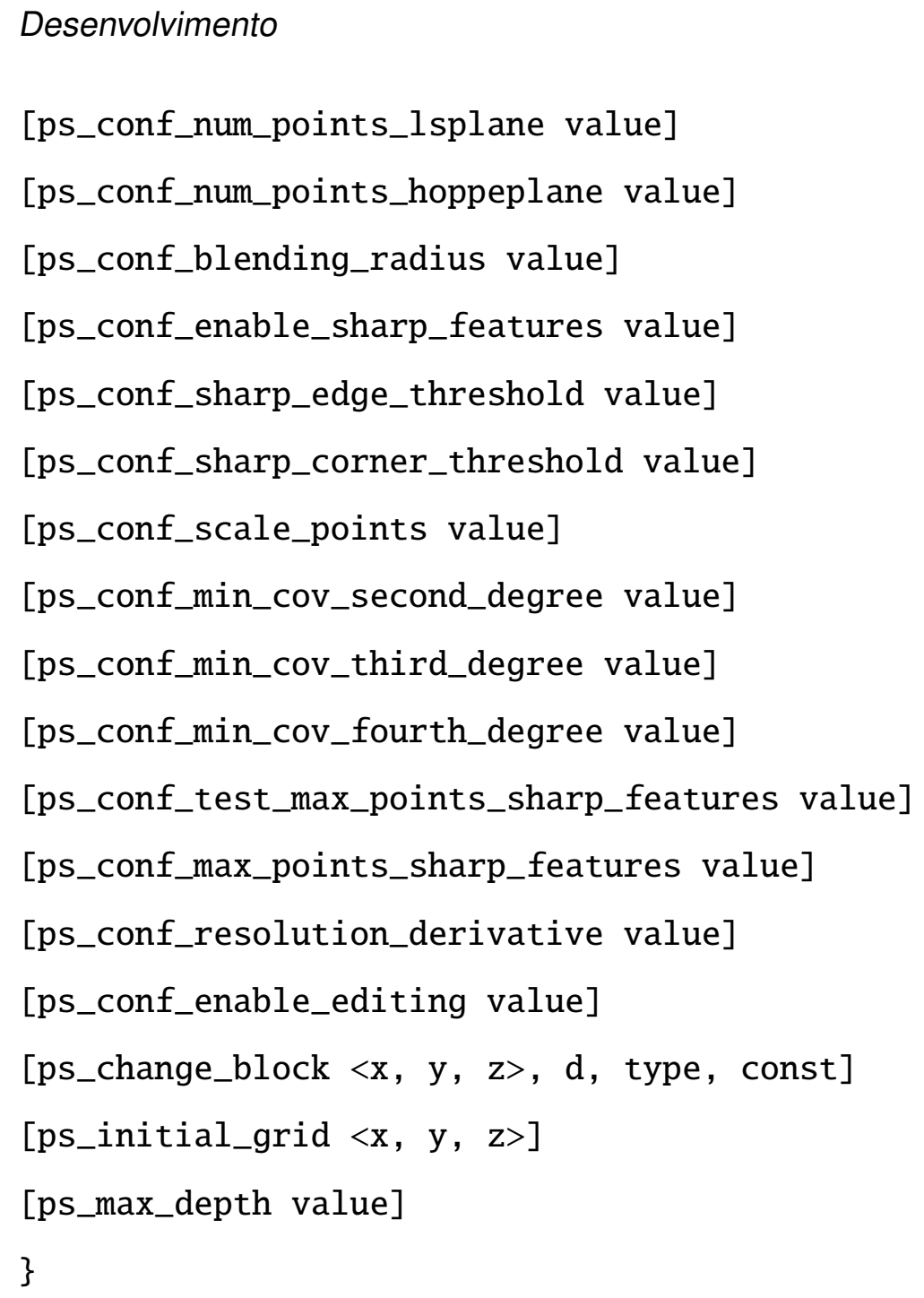

As linhas entre colchetes representam parâmetros opcionais que, se não fornecidos, recebem valores padrão. A seguir, é descrita a função de cada um dos parâmetros utilizados na configuração do objeto pointset:

- ps_input_file: é o único parâmetro obrigatório que especifica um arquivo que contenha uma nuvem de pontos equipados com normais orientadas;

- ps_accuracy_approximation: determina a precisão desejada para a aproximação das funções locais;

- ps_accuracy_raytracer: determina a precisão desejada para os cálculos de intersecção do ray tracer;

- ps_conf_perturbation_order: determina a ordem de magnitude da perturbação 
aplicada aos vértices da triangulação $J_{1}^{a}$ para evitar que os vértices da triangulação estejam sobre a superfície;

- ps_conf_domain_resize: determina um fator que multiplica o bounding box dos pontos para definir o tamanho do domínio;

- ps_conf_normal_max_flip_threshold: determina qual o valor do co-seno máximo para considerar que o plano aproximado está ortogonal ao desejado;

- ps_conf_num_points_lsplane: determina o número de pontos utilizados na aproximação do plano no cluster de pontos;

- ps_conf_num_points_hoppeplane: determina o número de pontos utilizados na média das normais no caso de a aproximação por mínimos quadrados ser ortogonal ao desejado;

- ps_conf_blending_radius: determina um fator que multiplica o raio da circunsfera dos blocos para definir o raio do suporte;

- ps_conf_enable_sharp_features: determina se serão utilizados os sharp features;

- ps_conf_sharp_edge_threshold: determina o limiar utilizado para definir se uma região contém um sharp feature;

- ps_conf_sharp_corner_threshold: determina o limiar utilizado para definir se uma região contém um corner;

- ps_conf_scale_points: determina a escala aplicada ao domínio de pontos;

- ps_conf_min_cov_second_degree: determina a cobertura mínima para o uso de polinômios de grau dois;

- ps_conf_min_cov_third_degree: determina a cobertura mínima para o uso de polinômios de grau três;

- ps_conf_min_cov_fourth_degree: determina a cobertura mínima para o uso de polinômios de grau quatro; 
- ps_conf_test_max_points_sharp_features: determina se é utilizado o critério de limitar o máximo de pontos que pode ser utilizado para definir um sharp feature;

- ps_conf_max_points_sharp_features: determina o número máximo de pontos que podem ser utilizados na definição de um sharp feature;

- ps_conf_resolution_derivative: define a resolução utilizada para o cálculo das derivadas;

- ps_conf_enable_editing: define se será possível a edição de funções. Quando essa opção está ativada, a $k-d$ - tree utilizada para realizar buscas na nuvem de pontos não é destruída após a etapa de construção;

- ps_change_block: especifica um bloco que terá uma nova função definida através do vetor $x, y, z$ e da profundidade $d$. O tipo da nova função é dada por type e se essa for constante, o parâmetro const deve conter o valor a ser utilizado;

- ps_initial_grid: define a resolução inicial da grade da triangulação $J_{1}^{a}$;

- ps_max_depth: define o nível máximo de refinamento da triangulação $J_{1}^{a}$.

Depois que uma cena é definida, o POV-Ray permite a geração de imagens por traçado de raios ou pela técnica de radiosidade. Dessa maneira, a versão estendida do software pode ser aplicada na prática para a geração de imagens sintética com alta qualidade, que podem incluir não só objetos comuns na área de modelagem, mas também objetos baseados em pontos.

\subsection{Considerações finais}

No presente capítulo, foram descritos de maneira razoavelmente detalhada os métodos desenvolvidos no projeto. As implementações foram todas realizadas de forma a privilegiar o desempenho, no entanto, todos os códigos foram desenvolvidos utilizando o paradigma de orientação a objeto e uma quantidade considerável de comentários foi incluída. No próximo capítulo, serão apresentados os resultados de tais métodos e algumas comparações com outros métodos similares para a reconstrução de superfícies. 


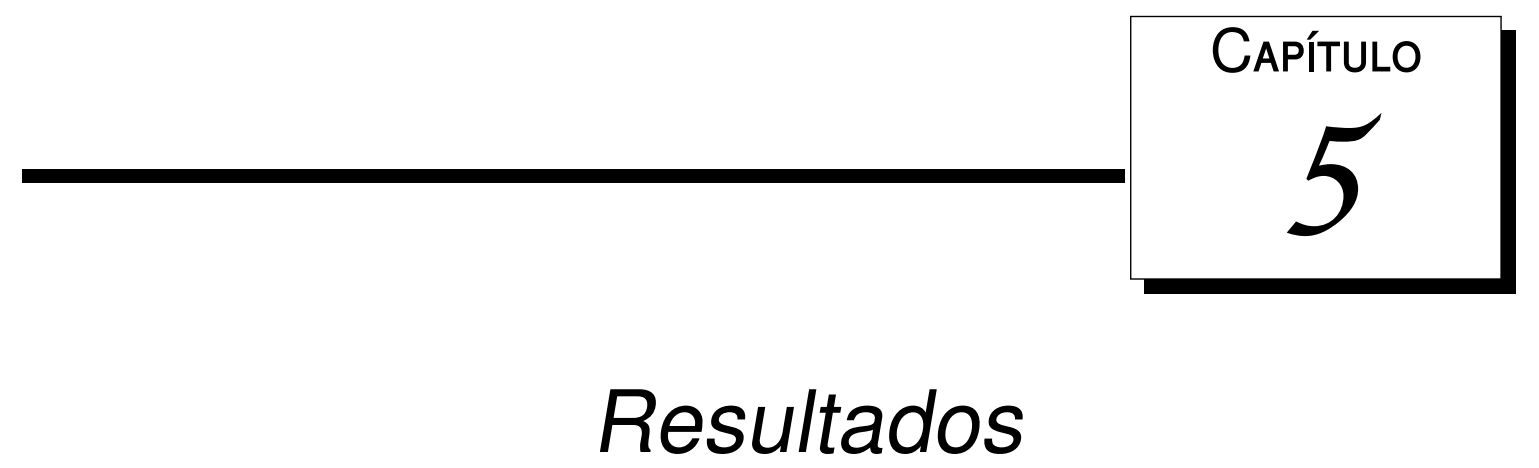

\subsection{Considerações iniciais}

Além de verificar a corretude e a eficiência dos algoritmos propostos, os testes apresentados nesta seção também ilustram algumas das funcionalidades importantes propostas no projeto. O presente capítulo é organizado de forma a realizar os testes tanto quantitativos quanto qualitativos do método descrito no capítulo anterior.

\subsection{Extração de Isosuperfícies}

O primeiro passo do desenvolvimento do extrator de isosuperfícies foi o desenvolvimento da triangulação $J_{1}^{a}$, que pode ser visualizada nas Figuras 5.1 (a) e (b).

Para realizar alguns testes reproduzíveis sobre o algoritmo de extração de isosuperfícies, foi desenvolvido um pequeno analisador sintático de expressões matemáticas, para que pudessem ser avaliadas formulas matemáticas.

O algoritmo de poligonalização pode trabalhar no modo adaptativo, em que as faces geradas inicialmente são usadas para aproximar a curvatura através do cálculo do coseno dos ângulos formados entre as normais das faces. Quando o co-seno fica abaixo de um certo limiar, que na implementação atual corresponde a 0.7 , o bloco contendo as 


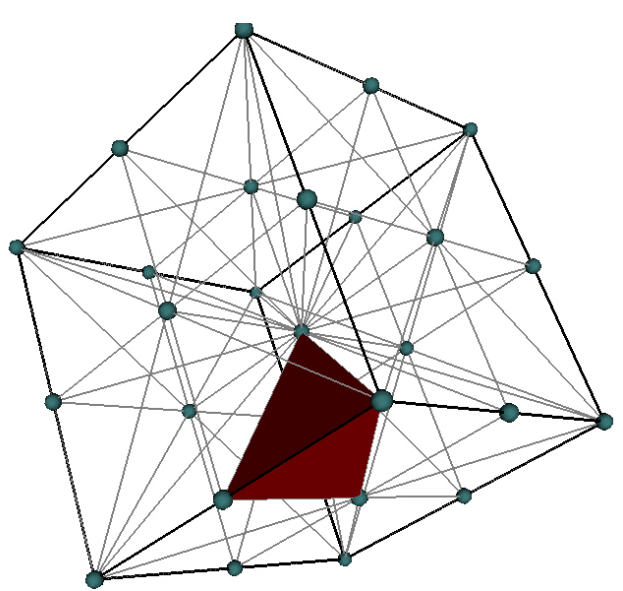

(a)

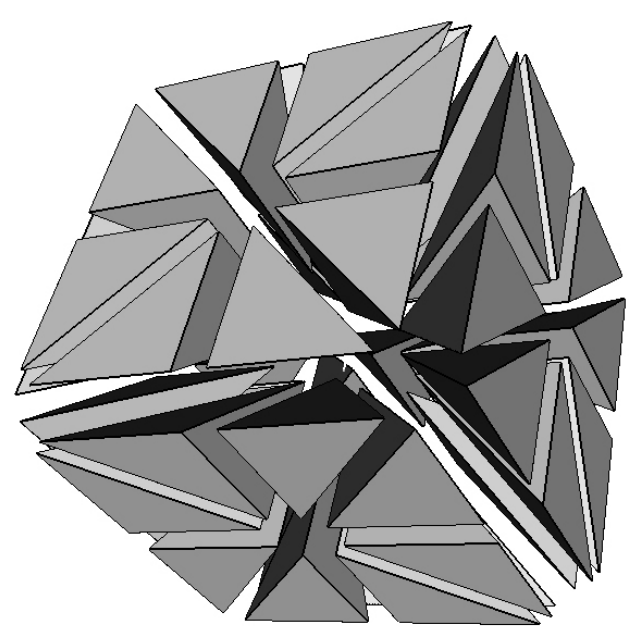

(b)

Figura 5.1: (a) Representação de um bloco básico da triangulação $J_{1}^{a}$ em 3D e de um dos simplexos. (b) Visualização dos simplexos da triangulação através da separação dos mesmos.

faces é refinado e a poligonalização é refeita para os blocos atingidos pela mudança.

Na Figura 5.2 (a) é mostrada a poligonalização de uma esfera em uma grade 2×2×2, na qual um dos blocos da triangulação foi refinado apenas para ilustração, enquanto que na Figura 5.2 (b) e (c) são ilustrados dois exemplos de superfícies obtidas usando o método implementado. O exemplo da Figura 5.2(b) é descrito pela Equação 5.1 e foi reconstruído a partir de uma grade $12 \times 12 \times 12$ sem uso de refinamento a fim de ilustrar o formato dos triângulos. Na Figura 5.2(c), o exemplo é descrito pela equação 5.2 e é poligonalizado com uma grade 5x5x5 usando refinamento limitado a um máximo de três níveis.

$$
\begin{aligned}
& f(x, y, z)=\frac{1}{\left(\frac{x^{2}}{9}+4 y^{2}+4 z^{2}\right)^{4}}+\frac{1}{\left(\frac{y^{2}}{9}+4 x^{2}+4 z^{2}\right)^{4}}+\frac{1}{\left(\frac{z^{2}}{9}+4 y^{2}+4 x^{2}\right)^{4}}+ \\
& \frac{1}{\left(\left(\frac{4 x}{3}-4\right)^{2}+\frac{16 y^{2}}{9}+\frac{16 z^{2}}{9}\right)^{4}}+\frac{1}{\left(\left(\frac{4 x}{3}+4\right)^{2}+\frac{16 y^{2}}{9}+\frac{16 z^{2}}{9}\right)^{4}}+\frac{1}{\left(\left(\frac{4 y}{3}-4\right)^{2}+\frac{16 x^{2}}{9}+\frac{16 z^{2}}{9}\right)^{4}}+ \\
& \left(\frac{1}{\left(\left(\frac{4 y}{3}+4\right)^{2}+\frac{16 x^{2}}{9}+\frac{16 z^{2}}{9}\right)^{4}}\right)^{\frac{-1}{4}}-1=0
\end{aligned}
$$




$$
f(x, y, z)=x^{2} z-y^{2}=0
$$

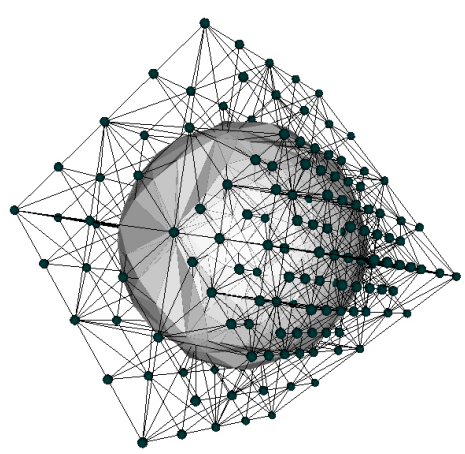

(a)

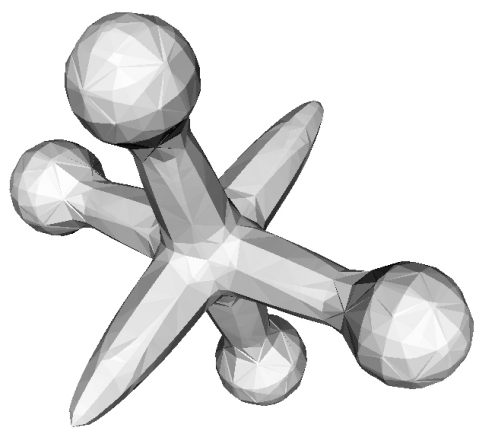

(b)

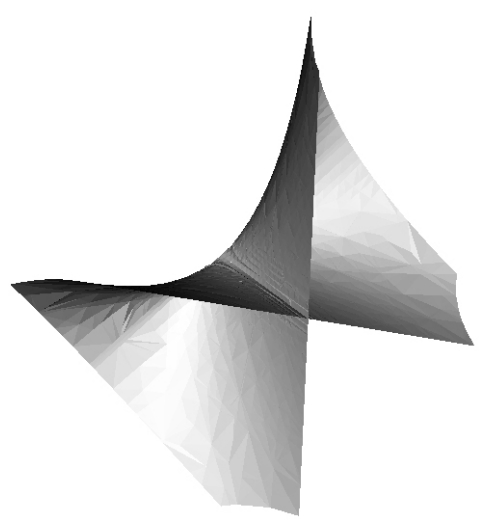

(c)

Figura 5.2: (a) Poligonalização de uma esfera exibindo a grade da triangulação $J_{1}^{a}$.

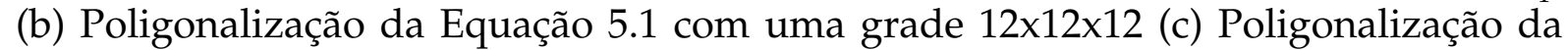
Equação 5.2 com grade adaptativa de resolução 8x8x8.

As principais vantagens no uso da triangulação $J_{1}^{a}$ na poligonalização são a capacidade de gerar superfícies topologicamente coerentes e a adaptatividade. Porém, pode ser verificado que a qualidade das malhas não é muito razoável, fato esse que levou ao desenvolvimento do Algoritmo de melhoramento de malhas descrito na Seção 4.4.5.

\subsection{Reconstrução de Superfície}

A avaliação da qualidade e eficácia de um método de reconstrução é uma tarefa complicada, já que diversos aspectos estão envolvidos. A fim de promover uma visão justa, que aponte não só as vantagens como também algumas fraquezas do método proposto, nas seções seguintes vários testes serão descritos e avaliados.

A fim de oferecer uma maneira mais simples de lidar com o software desenvolvido, foi criada uma interface gráfica que permite a visualização das superfícies de diversas formas, inclusive através da coloração dos polígonos de acordo com o grau de polinômio ou da profundidade dos blocos. A Figura 5.3 (a) mostra a tela da interface enquanto que a figura (b), mostra o modelo Lucy (16M de pontos) com coloração por tipo de função (à esquerda) e por profundidade (à direita). A escala de funções segue a seguinte ordem, da esquerda para a direta: 0 , função constante; 1 , plano; 2 , polinômio de segundo grau; 3 , polinômio de terceiro grau; 4 , polinômio de quarto grau; 5 , aresta 


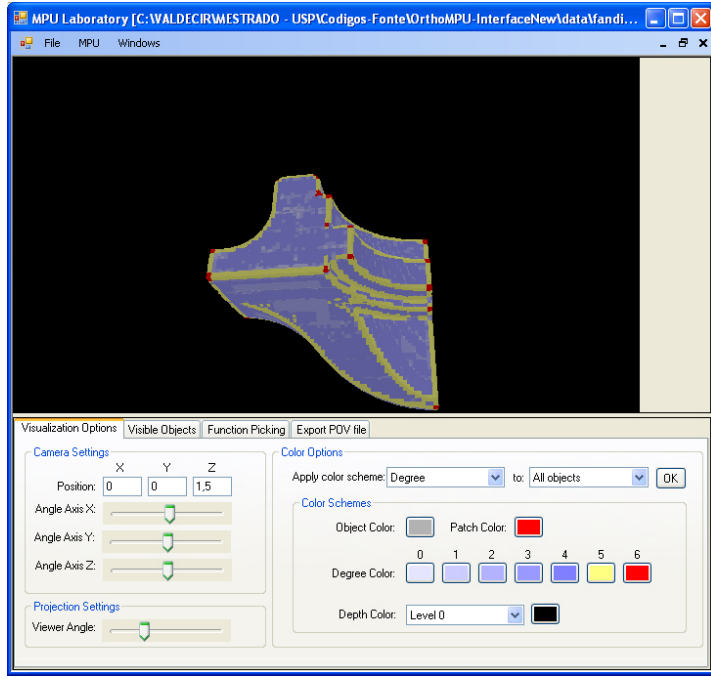

(a)

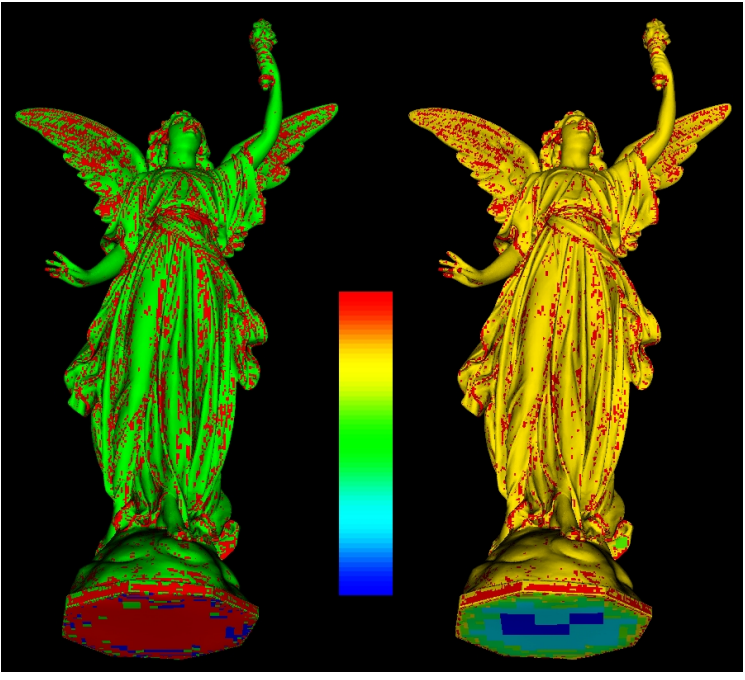

(b)

Figura 5.3: (a) Interface gráfica mostrando os tipos de função usadas no modelo FanDisk, em que as arestas sharp são destacadas em amarelo e os corners, em vermelho. (b) Modelo Lucy (16M de pontos) em duas versões. À esquerda, com escala de tipo de funções e, à direita, com escala de profundidade dos blocos da triangulação $J_{1}^{a}$.

sharp; 6, sharp corner. A escala de profundidade vai de zero a sete, representando o nível dos blocos que contém os triângulos.

O software também permitia a seleção de pontos de modelo mostrando a qual bloco pertencem e também oferecendo a possibilidade de renderizar a função armazenada no bloco selecionado. Na Figura 5.4 (a) está ilustrado um bloco particular da triangulação $J_{1}^{a}$ cuja função (aresta sharp) é renderizada em todo domínio e mostrada em (b) na cor amarela.

Quanto à organização das seções seguintes, na Seção 5.3.1 é feita uma avaliação direta do método, sem comparação com outras técnicas, enquanto que nas seções restantes (Seções 5.3.2 a 5.3.4) são feitas algumas comparações pertinentes entre abordagens.

\subsubsection{Tempo de processamento e exemplos de reconstrução}

Nessa seção, o método será testado com diversos modelos comumente utilizados para o teste dos algoritmos de reconstrução de superfícies. O tempo para a geração das aproximações e o tempo para a poligonalização utilizando a triangulação $J_{1}^{a}$ estão descritos na Tabela 5.1.

É importante ressaltar que as reconstruções foram realizadas com configurações 


\section{Resultados}

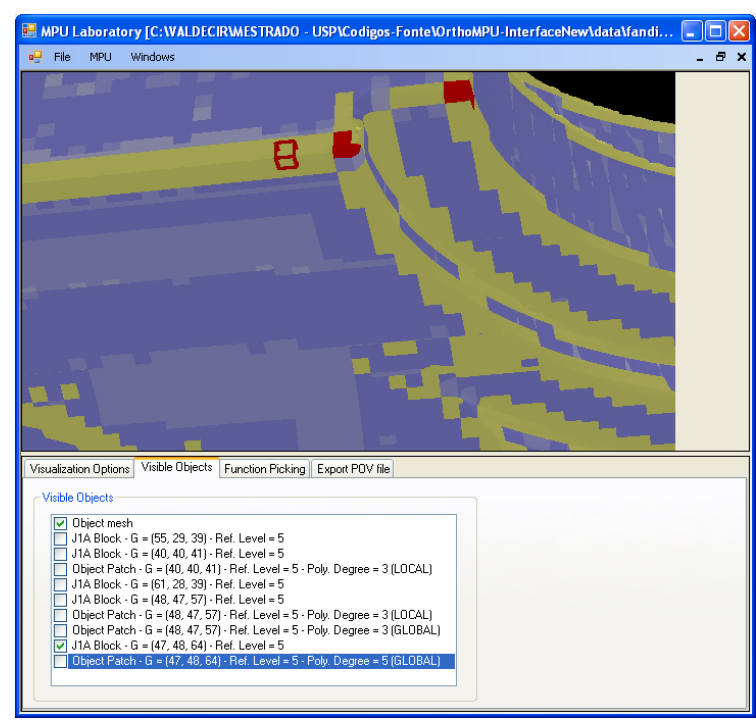

(a)

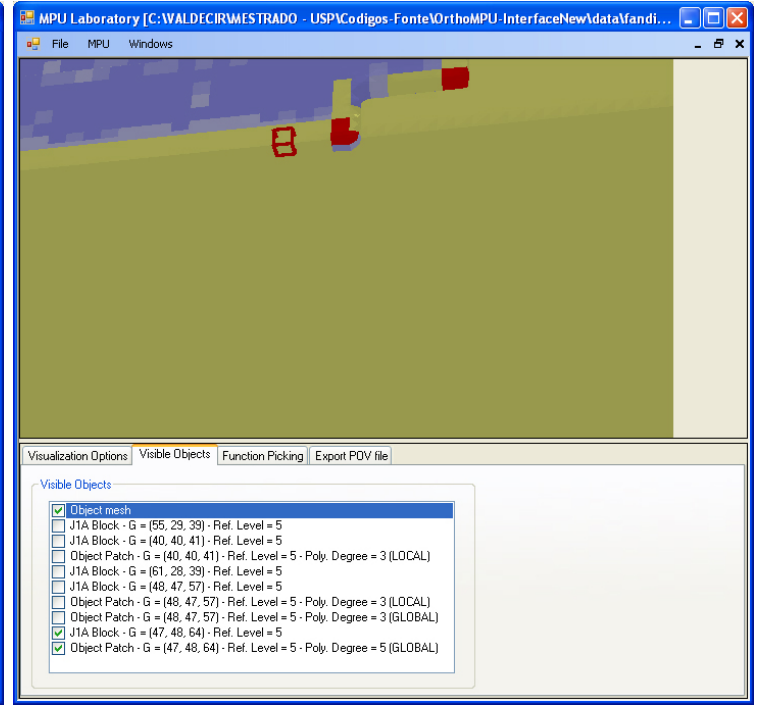

(b)

Figura 5.4: (a) Seleção de um bloco da triangulação $J_{1}^{a}$. (b) Função associada ao bloco da triangulação $J_{1}^{a}$, renderizada em todo o domínio.

Tabela 5.1: Tempo de processamento para a reconstrução de diversos modelos utilizando a abordagem proposta com grade inicial $3 \times 3 \times 3$ com profundidade máxima variável em um computador com processador Intel Core 2 Quad de $2.4 \mathrm{GHz}$

\begin{tabular}{lccccc}
\hline Modelos & $\begin{array}{c}\text { Número } \\
\text { de pontos }\end{array}$ & $\begin{array}{c}\text { Profundidade } \\
\text { máxima }\end{array}$ & $\begin{array}{c}\text { Tempo de } \\
\text { aproximação }\end{array}$ & $\begin{array}{c}\text { Tempo de } \\
\text { poligonalização }\end{array}$ & $\begin{array}{c}\text { Número de } \\
\text { triângulos }\end{array}$ \\
\hline \hline Bunny & $37 \mathrm{~K}$ & 4 & $56,24 \mathrm{~s}$ & $92,18 \mathrm{~s}$ & 346684 \\
\hline Armadillo & $173 \mathrm{~K}$ & 6 & $84,69 \mathrm{~s}$ & $105,90 \mathrm{~s}$ & 968532 \\
\hline Dragon & $399 \mathrm{~K}$ & 6 & $163,90 \mathrm{~s}$ & $108,47 \mathrm{~s}$ & 1005132 \\
\hline Lucy & $16 \mathrm{M}$ & 7 & $5113,48 \mathrm{~s}$ & $158,82 \mathrm{~s}$ & 2229196 \\
\hline \hline
\end{tabular}

que permitissem boa qualidade de reconstrução para o modelo utilizado. Através do modelo do Armadillo e do Dragon, verifica-se que os tempos de reconstrução dependem do tamanho do conjunto de entrada, enquanto que o tempos de poligonalização são comparáveis, já que as resoluções são iguais, logo, o número de triângulos gerados é parecido. As diferenças nesses tempos dependem da quantidade de refinamentos e do custo computacional mais elevado para se avaliar uma função implícita de um modelo mais complicado.

Verifica-se também nos resultados, uma informação interessante: ainda que as configurações iniciais tenham sido satisfatórias para a obtenção da função para o modelo 


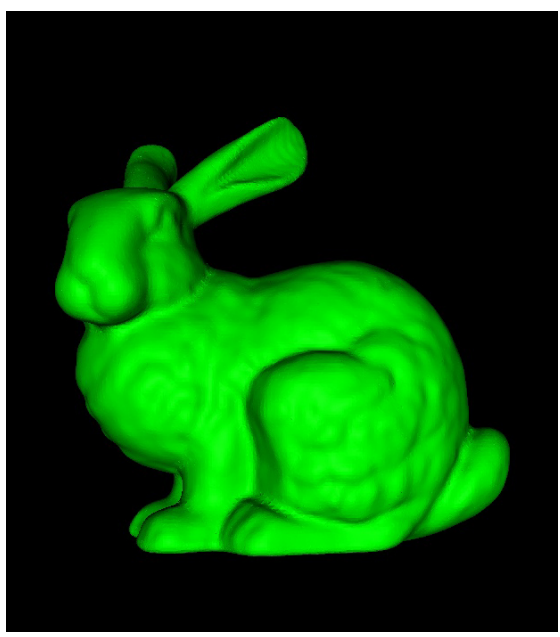

(a)

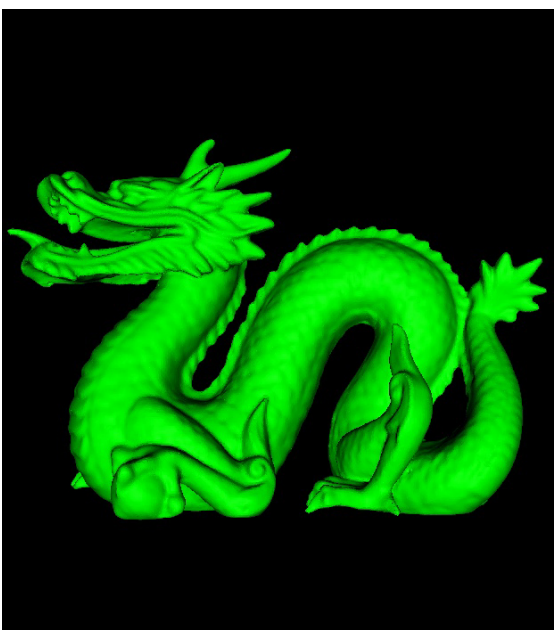

(c)

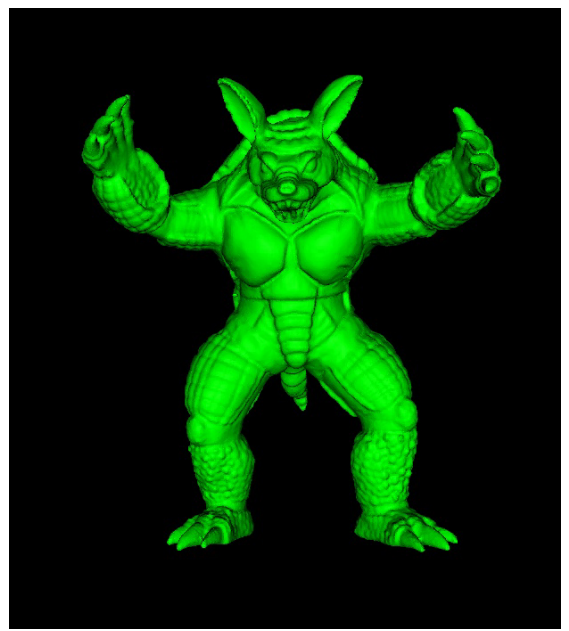

(b)

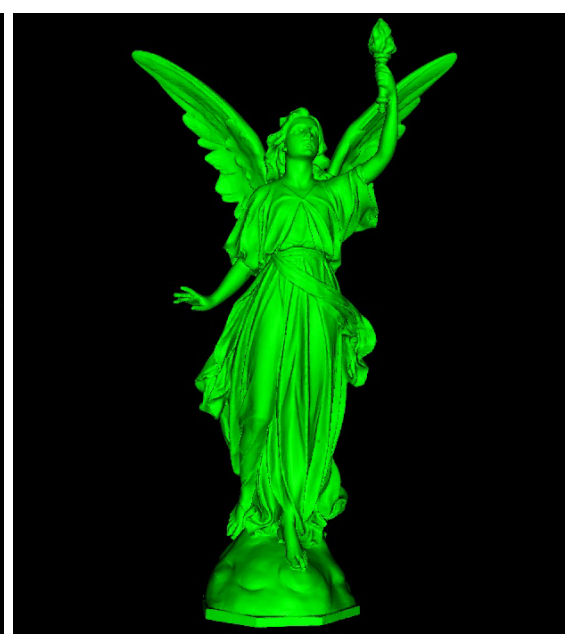

(d)

Figura 5.5: Reconstrução de alguns modelos clássicos: (a) Bunny; (b) Armadillo; (c) Dragon; (d) Lucy.

Lucy, tal resolução não foi capaz de gerar triângulos suficientes para representar a superfície adequadamente. Esse é um problema que pode surgir do acoplamento da triangulação à aproximação cuja solução depende apenas de desenvolver um esquema de aprofundar uma dada triangulação $J_{1}^{a}$ mantendo as informações de detalhes sobre a superfície. Como não houve tempo de implementar tal solução, a mesma fica como sugestão de trabalhos futuros.

As Figuras 5.5 (a), (b), (c) e (d) mostram os modelos citados na Tabela 5.1 em suas versões geradas através de malhas. Como já citado, o modelo Lucy precisaria de uma grade de poligonalização mais fina. 


\section{Resultados}

Quanto ao pico de memória, para o modelo de Netuno (2M pontos) da Figura 5.6, a etapa de geração da função alcançou o pico de 660MB. Quando o poligonalizador da triangulação $J_{1}^{a}$ é considerado, o pico foi de $850 \mathrm{MB}$. Como uma forma de ilustrar as capacidades do modelador genérico foram criadas duas cenas sintéticas em que a estátua de Netuno, dada na forma de nuvem de pontos, foi renderizada juntamente com um modelo paramétrico de um cilindro usando uma operação CSG de subtração entre os objetos (Figura 5.6 (a)), e dentro de uma cena complexa ${ }^{1}$ que emprega várias técnicas de modelagem geométrica (Figura $5.6(b)$ ).

\subsubsection{Representação de sharp features}

Não houve nenhuma contribuição significativa com relação à representação de sharp features, porém é importante mostrar que o método desenvolvido pode suportar tal funcionalidade, conforme mostra o seguinte teste.

Na Figura 5.7, há uma comparação entre o método proposto (metade direta das figuras) e o método de Ohtake et al. (2003) (metade esquerda das figuras) utilizando parâmetros similares para o limiar de erro e para a profundidade máxima. Pode-se notar que o método proposto foi capaz de gerar uma aproximação ligeiramente melhor a um custo computacional um pouco mais elevado. Enquanto o método de Ohtake gerou a viewport de $1280 \times 1024$ da visão frontal através de traçado de raios em 1527s, o método proposto levou 1620s para completar a mesma tarefa em um processador Quad Core de 2.4GHz. Uma diferença grande entre os métodos é que, no método proposto, a avaliação é desacoplada da aproximação da função, no sentido que toda a função é construída antes que a primeira avaliação seja realizada. Esse fato significa que, para grades grossas ou viewports pequenas para traçado de raios, o método de Ohtake tende a ser mais rápido, no entanto, ao passo que o número de avaliações de função requeridas aumenta, os métodos passam a ser similares em termos de tempo de processamento.

Outra diferença substancial entre os métodos é o comportamento da função em regiões afastadas do conjunto zero da função. O método proposto apresenta um gradiente máximo limitado em todo o domínio devido a todos os critérios de robustez

\footnotetext{
${ }^{1}$ Copyright 2004 Gilles Tran http://www.oyonale.com
} 


\section{Resultados}

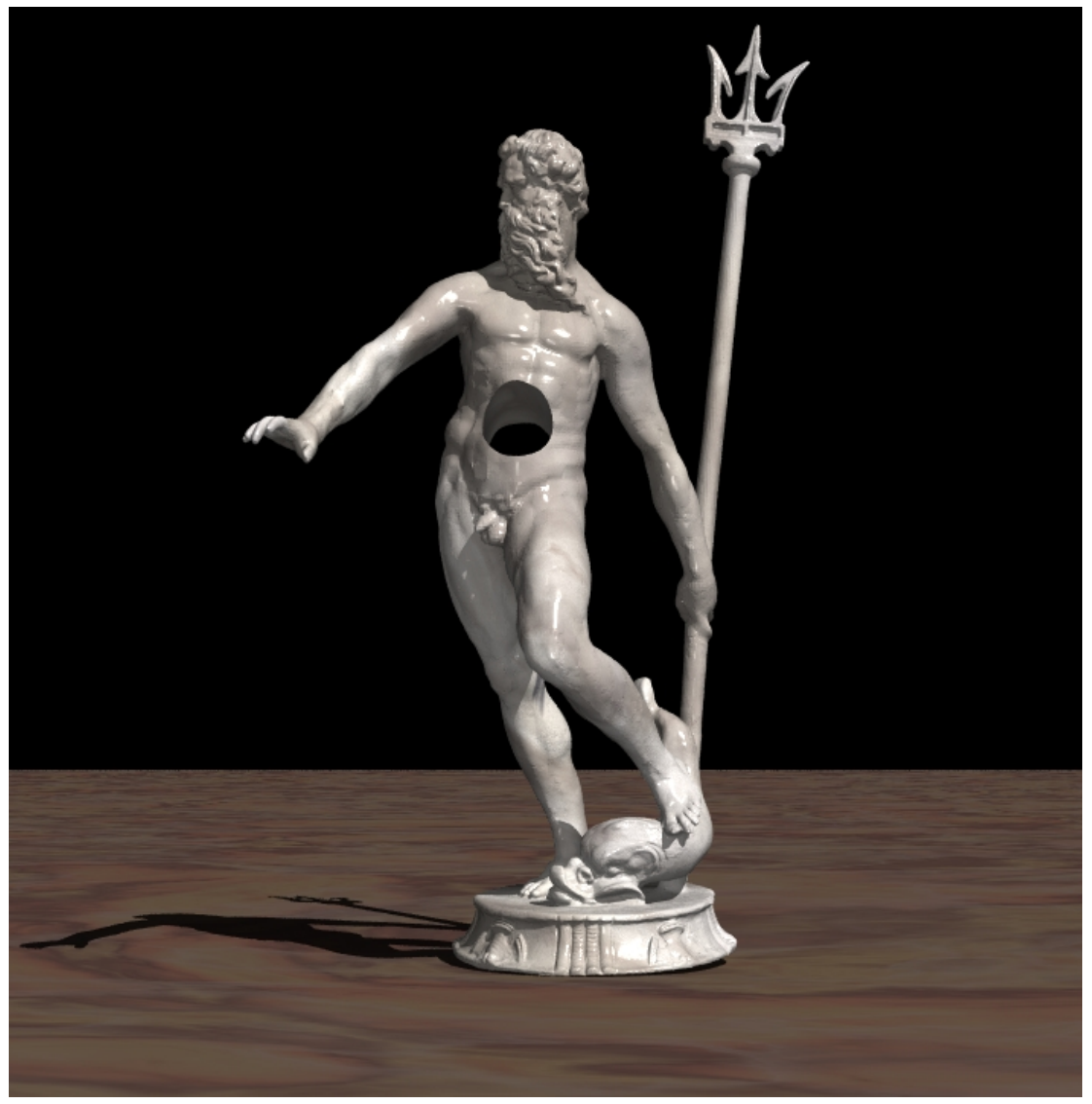

(a)

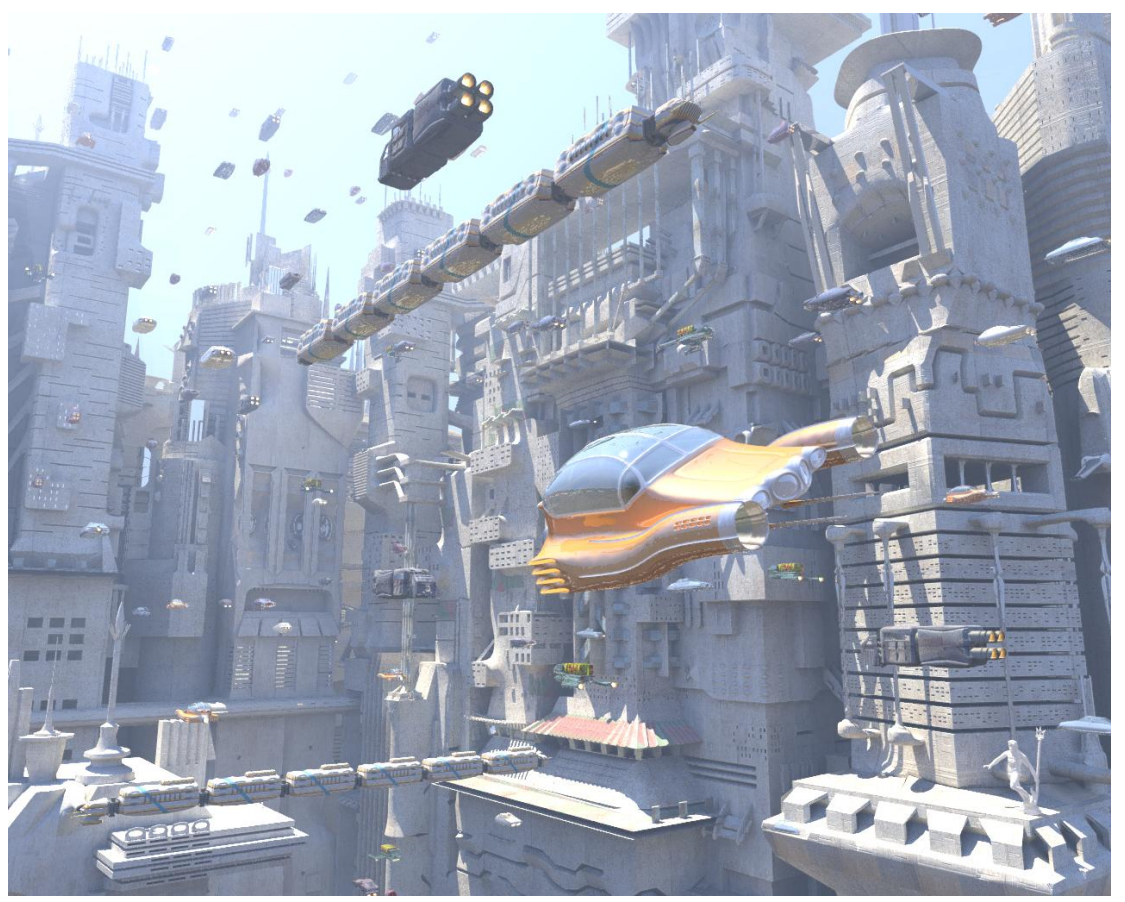

(b)

Figura 5.6: (a) Uma operação CSG de diferença entre a estátua de Netuno e um cilindro. (b) uma cena complexa que contém um objeto baseado em pontos (Netuno) no canto inferior direito da imagem. 


\section{Resultados}

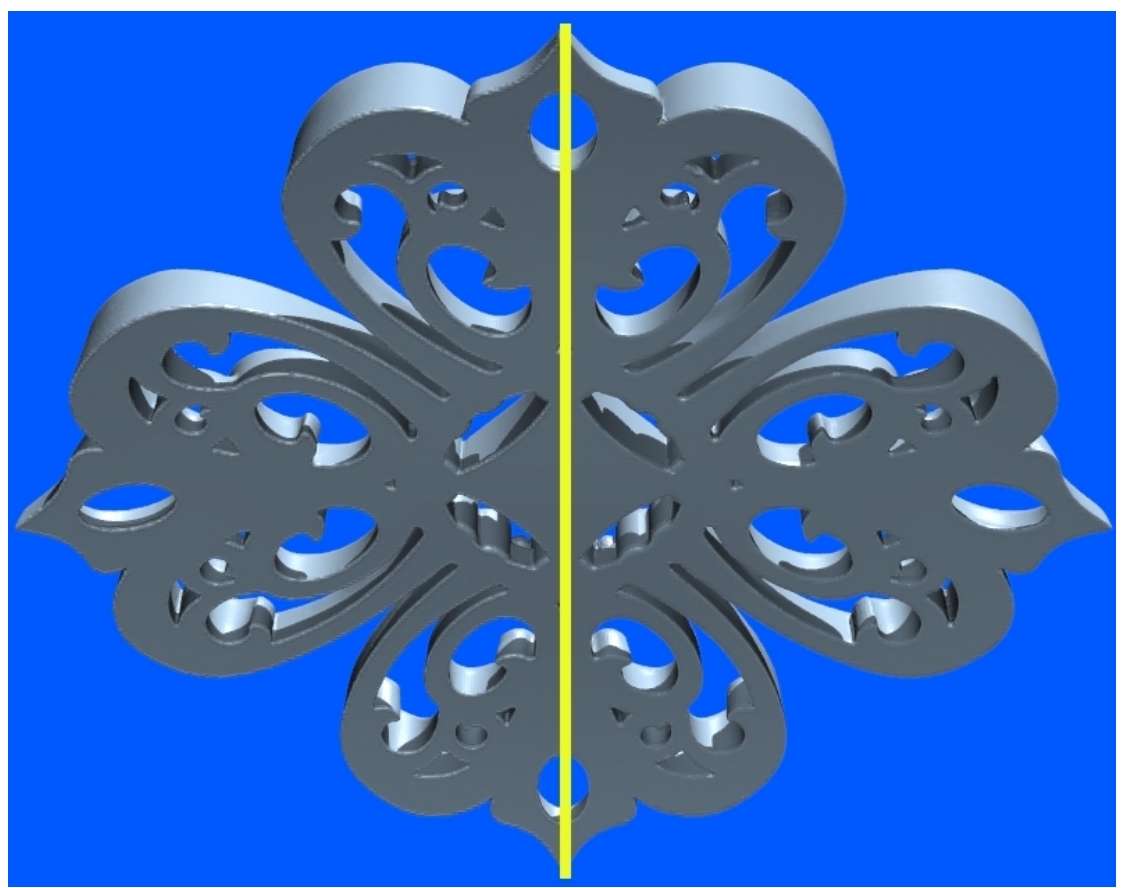

(a)

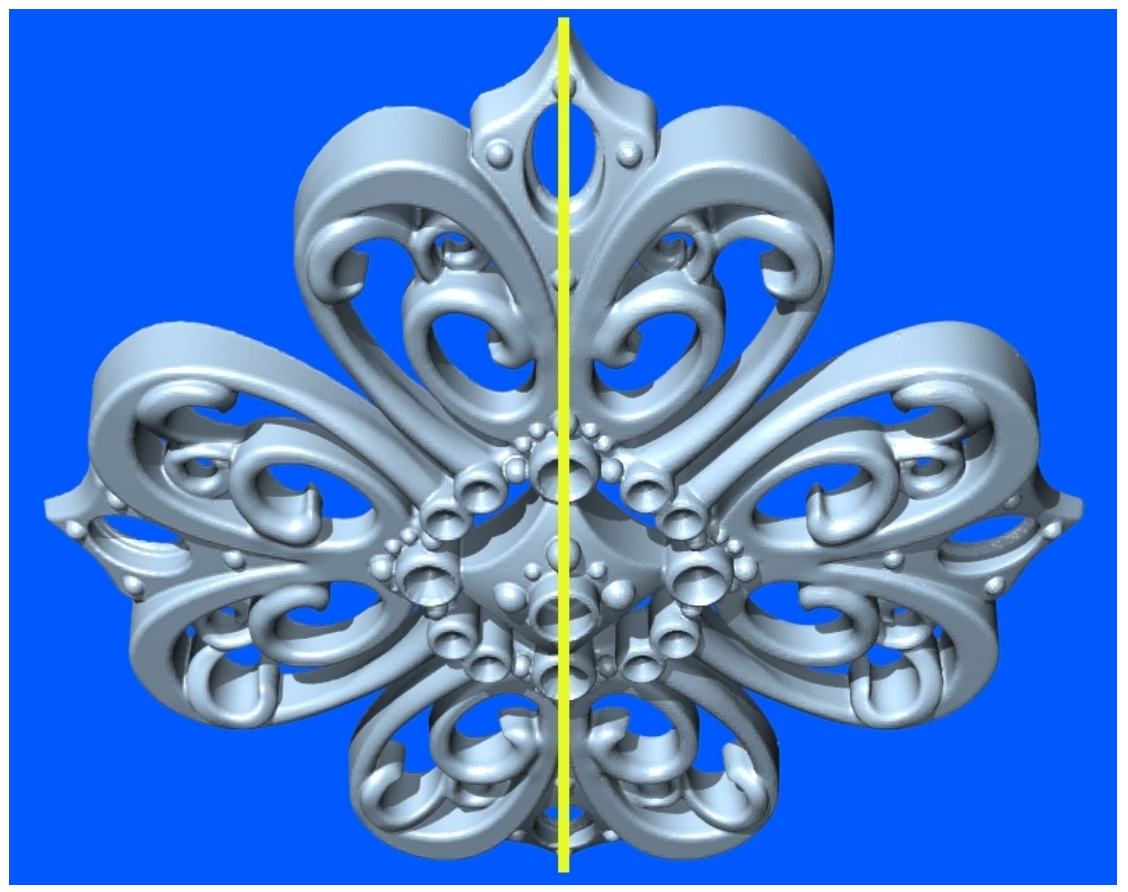

(b)

Figura 5.7: Funcionalidade de Sharp features ilustrada através do modelo Filigree (514K points): (a) e (b) são as visões anteriores e posteriores nas quais a metade à esquerda foram geradas pela técnica de Ohtake et al., enquanto que a metade à direita foi gerada pelo método proposto. 


\section{Resultados}

aplicados durante a fase de aproximação. Por exemplo, para os modelos apresentados na Figura 5.7, o algoritmo de traçado de raios empregado acusou uma magnitude máxima de gradiente de 1.9, enquanto que para o método de Ohtake, esse valor é consideravelmente maior estando na ordem de $10^{10}$.

Para fins de ilustração, a Figura 5.3 (a) mostra funções de arestas e vértices afiados sobre o modelo do FanDisk.

\subsubsection{Critérios de Robustez}

Na Figura 5.8, está ilustrada a importância do critério de cobertura de domínio, bem como a utilidade do procedimento de edição de função. Na Figura 5.8(a), o Bunny de Stanford de 362K pontos de dados não filtrados (com ruídos e dados redundantes) foi reconstruído com o método de Ohtake et al. (2003), porém sem sharp features já que o uso dessa funcionalidade com ruídos apresenta resultados muito ruins. Em (b), foram selecionados parâmetros que ficassem próximos aos utilizados pelo método proposto nesse projeto (refinamento máximo de 9 níveis e limiar de erro de 0.0002), mais uma vez sem sharp features. Em (c), a técnica proposta foi utilizada para reconstruir o mesmo modelo sem a utilização do critério de cobertura. Pode-se notar a presença de uma série de artefatos e algumas folhas extras, que são praticamente eliminadas com o uso do teste de cobrimento (5.8(d)). Em (e), foi utilizada a funcionalidade de edição de função para definir uma função constante para um conjunto de blocos utilizando valores positivos (0.002), a fim de eliminar as falhas presentes na superfície. Por fim, na 5.8(f) o modelo é apresentado após a edição das funções ter sido realizada.

A escolha do modelo na Figura 5.8 foi devida ao fato de Kazhdan et al. (2006) realizarem uma comparação bastante completa dos métodos de reconstrução utilizando tal modelo. No referido artigo, é possível verificar os padrões de qualidade de reconstrução de algumas técnicas muito conhecidas tais como o Crust e Power Crust. No entanto, no que diz respeito ao método de Ohtake et al., a comparação foi feita utilizando o software disponibilizado pelo autor em que uma malha é gerada por um poligonalizador que percorre apenas uma componente conexa. Por essa razão, as folhas extras da superfície apresentadas na Figura 5.8, não são encontradas nas figuras disponibilizadas no artigo de Kazhdan et al. (2006). 


\section{Resultados}

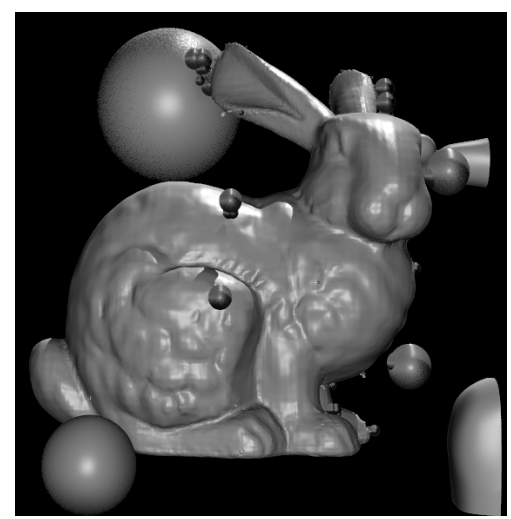

(a)

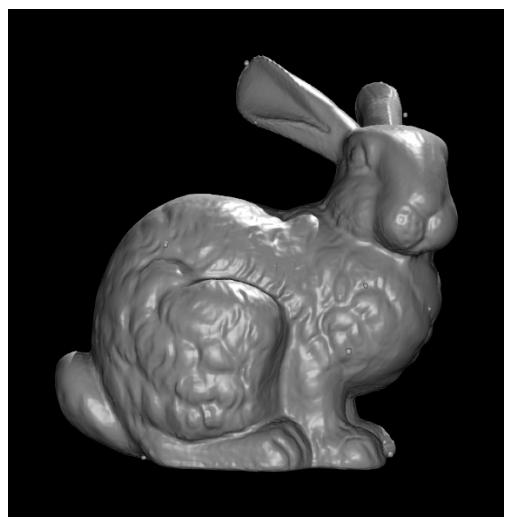

(d)

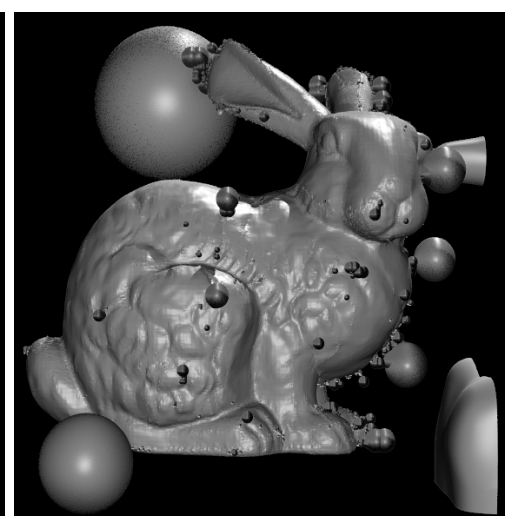

(b)

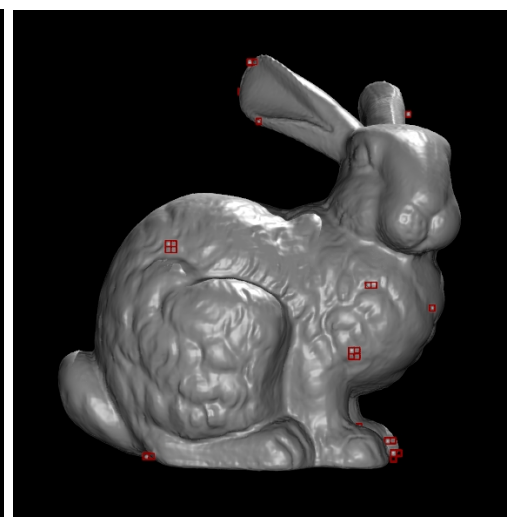

(e)

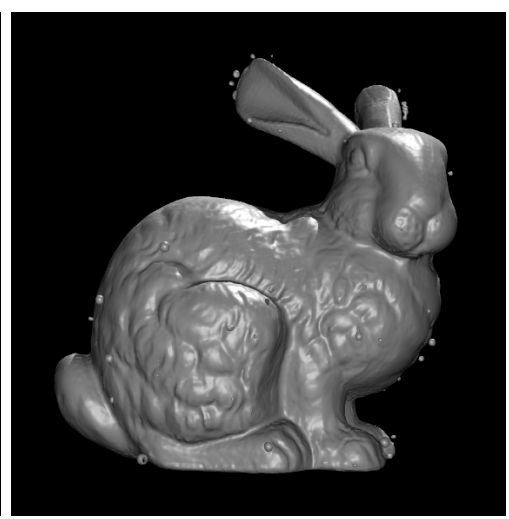

(c)

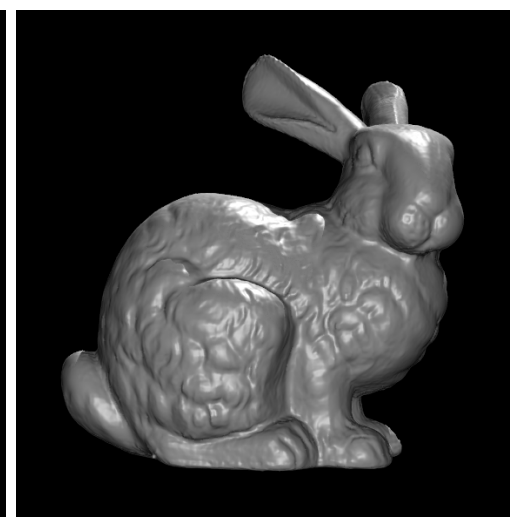

(f)

Figura 5.8: Critério de robustez e edição de função: (a)-(b) método de Ohtake et al. com seus parâmetros padrão e com parâmetros sugeridos, respectivamente; (c) reconstrução utilizando o método proposto sem o teste de cobertura; $(d)$ reconstrução com teste de cobertura; (e) seleção manual dos defeitos da superfície; (f) função modificada a fim de eliminar as imperfeições. Comparações com outros métodos de reconstrução utilizando o mesmo modelo podem ser encontrados no trabalho de Kazhdan et al. (2006).

Em termos de comparação dos métodos apresentados por Kazhdan et al. (2006) com o método proposto, pode-se verificar que esse último é capaz de capturar detalhes de forma mais precisa que todos os outros e não produz tantos efeitos indesejáveis, quanto os métodos de esculpimento e a técnica de Ohtake et al. (2003). No entanto, apresenta alguns pequenos defeitos que não estão presentes nos métodos baseados em FFT (Fast Fourier Transform) e no método de Kazhdan et al.

A situação ilustrada na Figura 5.8 mostra que o conjunto de soluções propostas nesse trabalho melhora consideravelmente a robustez de reconstrução dos métodos baseados em Partição de Unidade, devido ao fato de que, mesmo sem o critério de robustez e na presença de ruídos, o método foi capaz de minimizar o número de 


\section{Resultados}

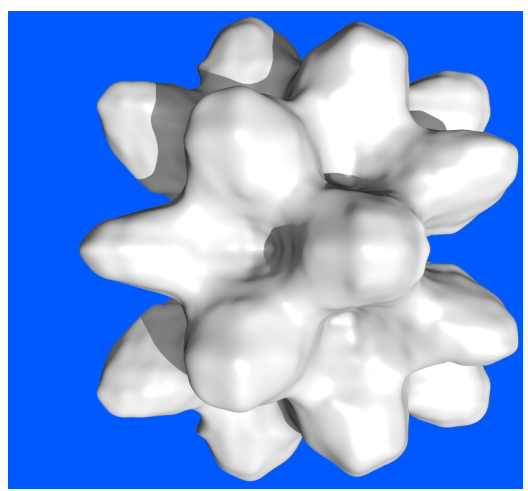

(a)

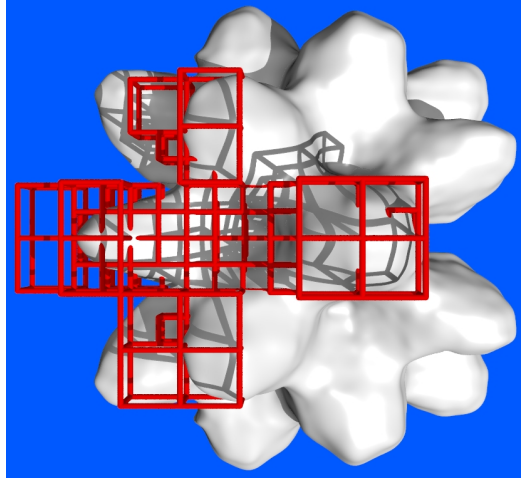

(b)

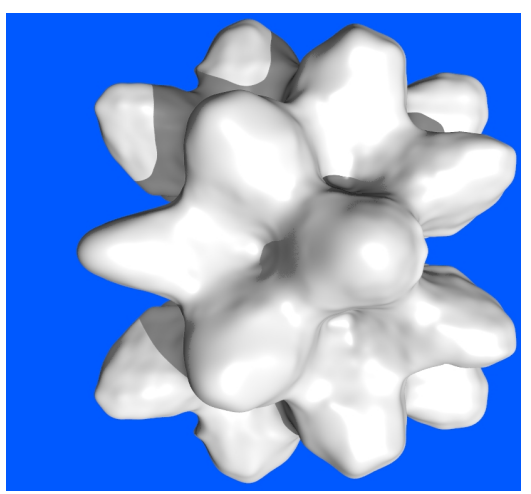

(c)

Figura 5.9: Melhorando a reconstrução através da edição de função: (a) modelo sem aproximações de alta ordem (devido à configuração intencional), (b) blocos selecionados para a mudança de função; (c) resultado final.

defeitos encontrados na técnica de Ohtake et al. Na verdade, no artigo original Ohtake et al. (2003) não faz menção a pequenos erros e artefatos que são encontrados sobre as superfícies reconstruídas com sua técnica, no entanto, em seu artigo, na figura que faz a subtração de um dragão das costas da estátua de Davi, é possível perceber a presença de defeitos.

\subsubsection{Edição de Função}

Na Seção 5.3.3, já foi ilustrada uma situação em que a edição de funções foi empregada para remover alguns defeitos aparentes sobre a superfície. No entanto, essa não é a única utilidade para a funcionalidade de edição, já que a mesma pode ser interessante para melhorar a qualidade de uma superfície reconstruída. Os principais fatores que levam a reconstruções insuficientes são a má escolha de parâmetros, ou a escolha de parâmetros de robustez excessivamente severos. Nesse último caso, em particular, os critérios de robustez podem evitar o uso de polinômios de alta ordem em locais onde os mesmos seriam adequados.

Na Figura 5.9(a), é apresentado um exemplo de reconstrução para o qual os parâmetros foram intencionalmente insuficientes para representar detalhes importantes do objeto (baixa resolução da grade e pouca profundidade) e com parâmetros de robustez excessivos. Pode-se notar que as extremidades do objeto apresentam-se facetadas, devido ao uso de funções (planos, no caso) que não permitem a captura de tais ca- 


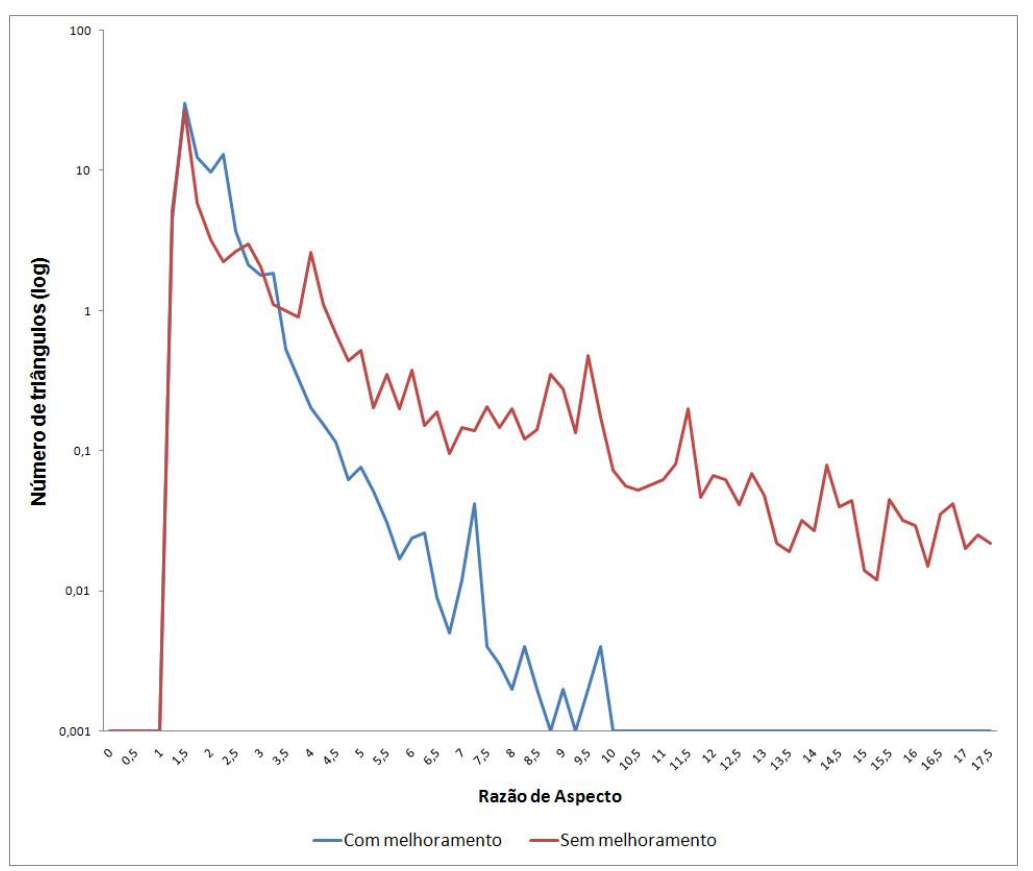

Figura 5.10: Histograma da razão de aspecto das malhas melhorada e original.

racterísticas. Através da função de edição (Figura 5.9(b)), foram selecionados alguns blocos para os quais os planos foram substituídos por funções de segundo grau. A comparação entre as Figuras 5.9(a) e (c) mostra o considerável ganho de qualidade na superfície dos objetos.

\subsection{Qualidade de malha}

Para ilustrar a técnica de deslocamento de malha, o modelo do dragão Chinês (667K pontos) foi reconstruído utilizando refinamento máximo 7, sem o uso de sharp features. A Figura 5.11 mostra, acima, a malha original e, abaixo, o modelo gerado com a técnica de melhoramento de malhas. Ambas as malhas são compostas de 535605 triângulos e o tempo consumido para a poligonalização dos modelos foi de 39,43 s e 202,9s para a versão original e a versão com deslocamento, respectivamente. Essa queda de desempenho era esperada, já que a versão com deslocamento requer mais avaliações de função para computar a aproximação do gradiente e a estimativa para o valor máximo da função. De qualquer forma, essa perda de desempenho é constante e não afeta a complexidade assintótica do algoritmo.

Para avaliar o melhoramento dos triângulos induzido pela movimentação dos vér- 


\section{Resultados}

tices, foi usada a seguinte medida de razão de aspecto para os triângulos:

$$
\alpha_{\Delta}=\frac{\sqrt{3} e_{\max } P}{12 A}
$$

em que $e_{\max }$ é o tamanho da maior aresta, $P$ é o perímetro e $A$ é a área do triângulo. Vale a pena notar que a melhor razão de aspecto é obtida com um triângulo eqüilátero e corresponde ao valor 1.0.

Para a malha original, a média da razão de aspecto foi 5,55 e o desvio padrão foi 128,09, enquanto que para a malha melhorada, a média foi 1,68 e o desvio, 0,61. Esse resultado confirma a efetividade da técnica já que a mesma foi capaz não apenas de melhorar a média de razão de aspecto, mas também para reduzir a variação da mesma, o que significa que a malha como um todo apresenta uma razão de aspecto geral razoável, sem a presença de pontos discrepantes. Na Figura 5.10 encontram-se os histogramas (com escala logarítmica) para as duas malhas descritas anteriormente. É possível verificar no histograma a ausência de triângulos com razão de aspecto maior que 10.0 para a malha melhorada, enquanto que para a malha original, não só existem triângulos com razões de aspecto maior, como também existem pontos discrepantes que nem puderam ser representados no gráfico.

Outro fato que pode ser percebido a partir da Figura 5.11 é a adaptatividade da malha gerada a partir da triangulação $J_{1}^{a}$. Em regiões mais complicadas, as faces triangulares são mais refinadas, enquanto que regiões mais simples apresentam faces maiores. Por fim, pode-se dizer uma das maiores vantagens desse algoritmo é a manutenção da topologia da superfície e a manutenção da estrutura da $J_{1}^{a}$.

Mais um exemplo da melhoria da malha obtida com a técnica de movimentação de vértices pode ser observada na Figura 5.12, na qual um detalhe da malha de um modelo Dragon é destacado. O tempo para gerar a malha sem melhoramento foi de 108,47 s enquanto que o tempo para gerar a malha melhorada foi de 592,35s em um processador Intel Core 2 Quad de $2.4 \mathrm{GHz}$.

A Tabela 5.2 sumariza as informações disponibilizadas nessa seção a respeito da técnica de melhoramento de malhas. 


\section{Resultados}
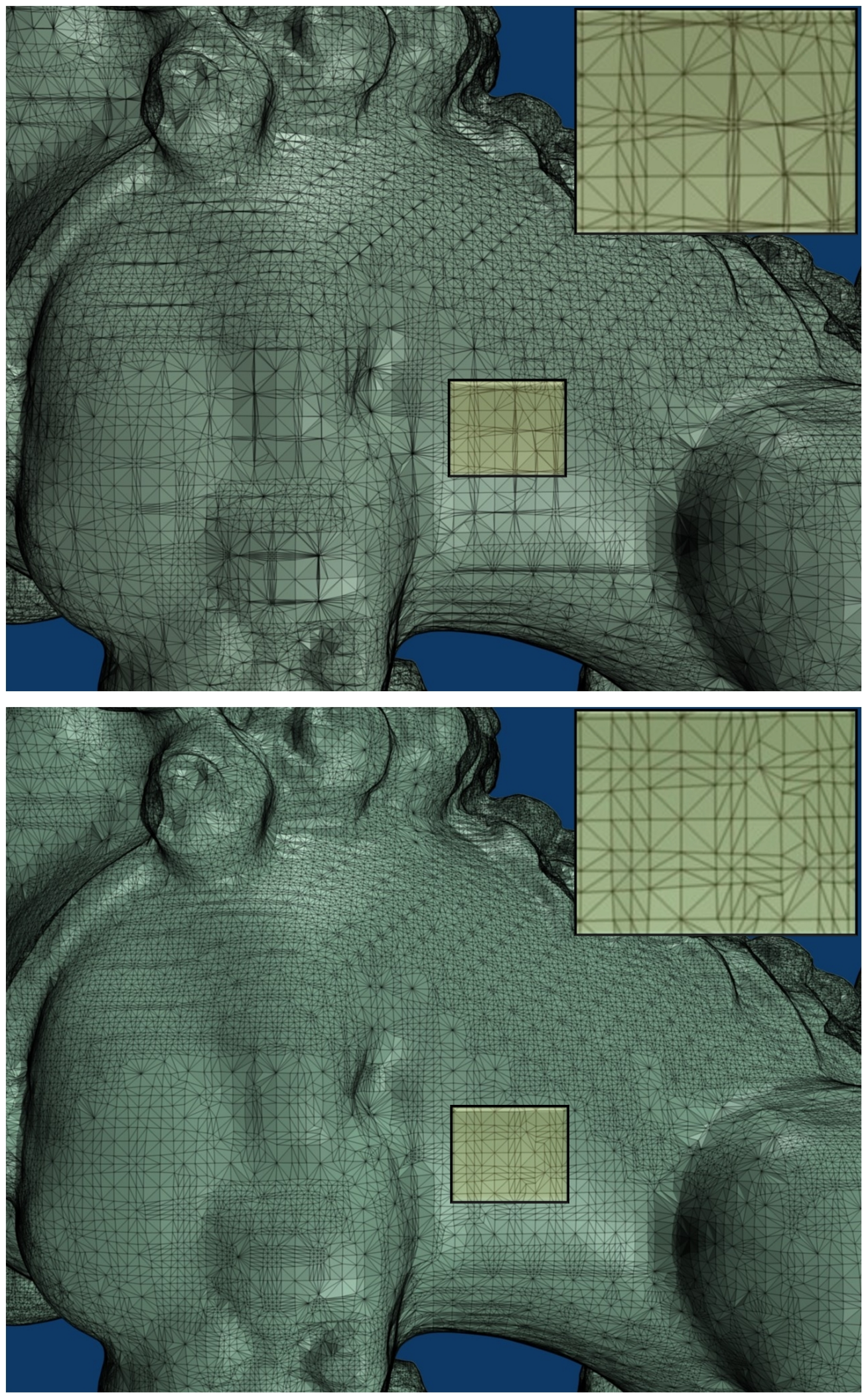

Figura 5.11: Comparação da malha original produzida para o modelo do Chinese Dragon, acima, com a malha melhorada pela técnica da movimentação de vértices, abaixo. 


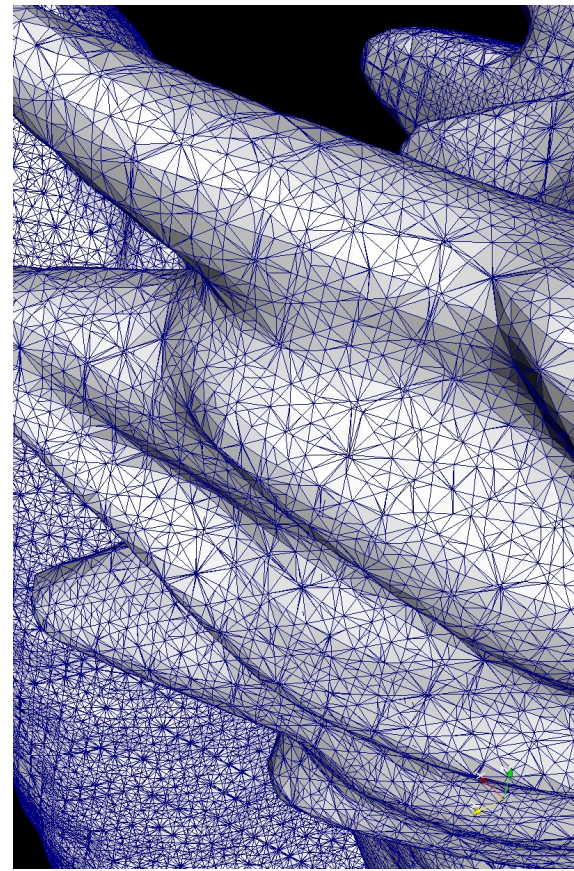

(a)

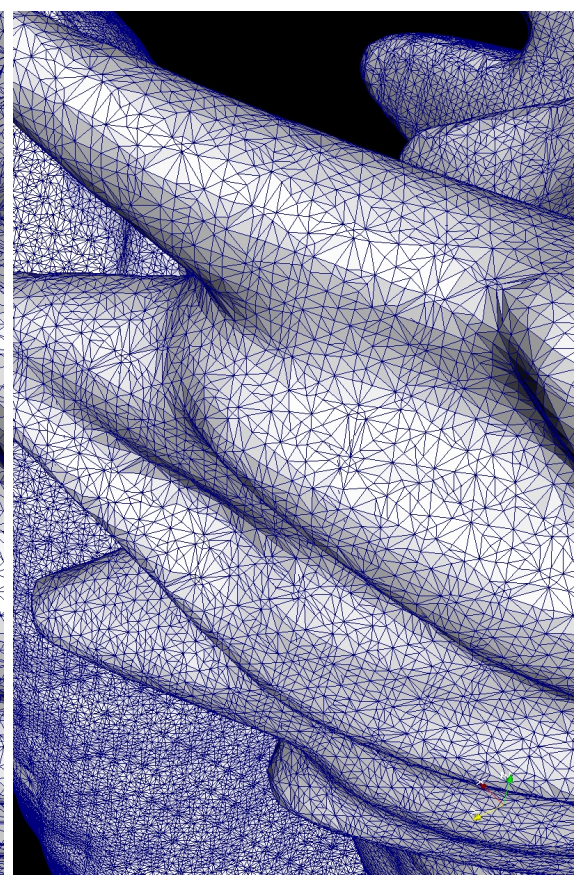

(b)

Figura 5.12: Melhoramento da malha aplicado ao modelo Dragon.

Tabela 5.2: Tempos para a poligonalização de três modelos com e sem melhoramento de malha

\begin{tabular}{lccccc}
\hline Modelos & $\begin{array}{c}\text { Número } \\
\text { de pontos }\end{array}$ & $\begin{array}{c}\text { Tempo } \\
\text { original }\left(t_{1}\right)\end{array}$ & $\begin{array}{c}\text { Tempo com } \\
\text { melhoramento }\left(t_{2}\right)\end{array}$ & $\begin{array}{c}\text { Razão } \\
\left(\frac{t_{2}}{t_{1}}\right)\end{array}$ & $\begin{array}{c}\text { Número de } \\
\text { triângulos }\end{array}$ \\
\hline \hline Bunny & $37 \mathrm{~K}$ & $19,93 \mathrm{~s}$ & $109,13 \mathrm{~s}$ & 5,48 & 85172 \\
\hline Chinese Dragon & $667 \mathrm{~K}$ & $39,43 \mathrm{~s}$ & $202,9 \mathrm{~s}$ & 5,15 & 535605 \\
\hline Dragon & $399 \mathrm{~K}$ & $108,47 \mathrm{~s}$ & $592,35 \mathrm{~s}$ & 5,46 & 1005132 \\
\hline \hline
\end{tabular}

\subsection{Considerações finais}

Nesse capítulo foram apresentados os principais resultados obtidos ao fim do desenvolvimento do projeto. Tais resultados foram satisfatórios e são comparáveis às melhores técnicas implícitas de reconstrução de superfície. No entanto, há vários aspectos a serem melhorados que serão discutidos em maiores detalhes na conclusão da presente dissertação. 


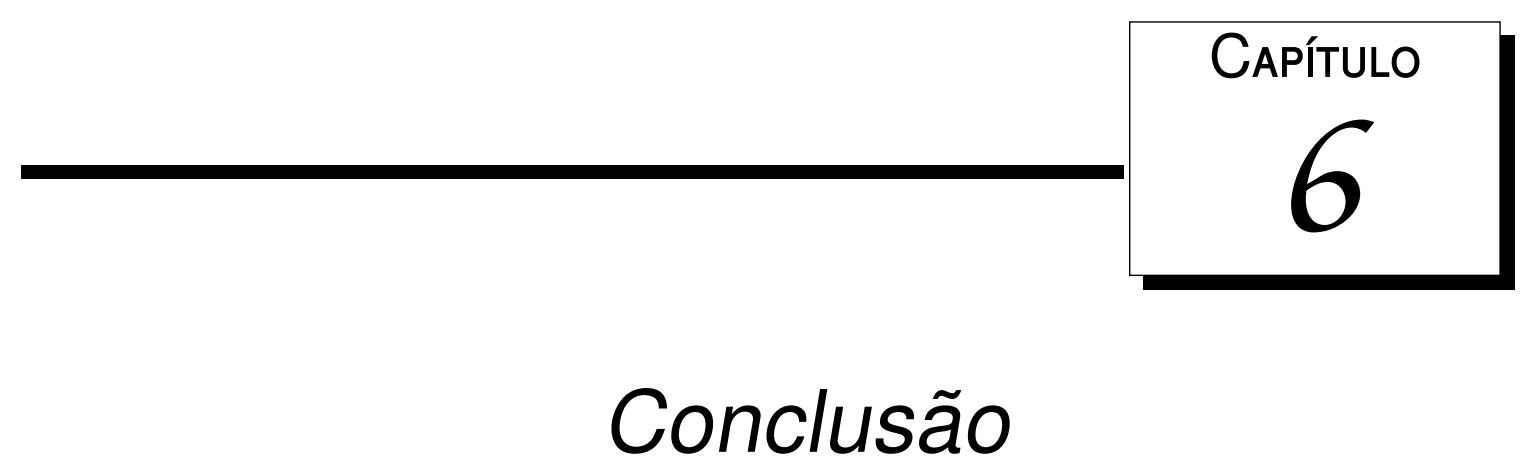

\subsection{Discussão dos resultados}

O problema da reconstrução de superfícies vem sendo estudado com grande ênfase nas duas últimas décadas. Dentre todas, as técnicas por métodos implícitos têm recebido maior atenção nos últimos anos. Essa linha de pesquisa, iniciada por trabalhos que tratavam de métodos de cálculo de distância baseada em planos e de união de primitivas, atualmente tem duas grandes frentes, representadas pelos métodos de Partição da Unidade e pelos métodos baseados em RBFs. Recentemente, o problema também tem sido abordado como um problema de Poisson.

Os métodos baseados em Partição da Unidade, dentre todos os métodos, apresentam um bom compromisso entre precisão e eficiência computacional, porém ainda carecem de robustez. Um dos objetivos desse trabalho foi o de estudar e propor algumas soluções que pudessem melhorar a forma como as soluções locais são escolhidas. Os resultados mostram que o método proposto apresenta soluções para muitos dos problemas anteriormente existentes, ainda que existam casos em que determinar os parâmetros corretos de robustez seja uma tarefa não trivial. Além disso, o uso de polinômios ortogonais permitiu uma adaptatividade de duas vias, já que tal técnica 


\section{Conclusão}

permite aumentar o grau do polinômio utilizado de maneira computacionalmente eficiente.

Outro propósito do trabalho foi o de unir a capacidade da triangulação $J_{1}^{a}$ de oferecer adaptatividade ao fato de o processo de construção das funções locais usadas nas superfícies implícitas de Partição da Unidade ser capaz de oferecer informações relevantes sobre a complexidade local da superfície. A partir disso, o método proposto é capaz de gerar uma triangulação adaptativa a partir da função implícita obtida. No capítulo anterior, foram dados exemplos em que a adaptatividade da malha ficou evidente, portanto, sugerem que o método cumpra o que foi planejado.

Ao analisar as malhas geradas pela triangulação $J_{1}^{a}$, ficou claro que os elementos triangulares careciam de qualidade. Por essa razão, foi proposta uma técnica de melhoramento de malha a partir da movimentação dos vértices da $J_{1}^{a}$. Os resultados apresentados mostram um significativo ganho na conformação dos elementos da malha, porém para atingir os níveis necessários de qualidade para uma ambiente de simulação computacional, por exemplo, ainda seria necessário um pós-processamento.

\subsection{Trabalhos futuros}

A discussão da seção anterior permite vislumbrar uma série de extensões e novos trabalhos que podem ser desenvolvidos a fim de gerar novas contribuições. A seguinte lista está ordenada com relação à facilidade de desenvolvimento dos trabalhos:

- Refinamento e decimação da $J_{1}^{a}$ : foi citado na Seção 5.3.1 que o acoplamento das fases de aproximação e poligonalização pode levar a situações em que a triangulação seja mais refinada ou menos refinada que o necessário. Por essa razão, seria importante dispor de um esquema que pudesse refinar ou decimar uma triangulação $J_{1}^{a}$ mantendo-se as propriedades de refinamento da mesma, ou seja, fazendo com que os trechos mais refinados continuassem sendo refinados;

- Uso de paralelismo: pelo fato de tanto a construção da estrutura, quanto o processo de avaliação serem paralelizáveis, seria importante desenvolver uma versão multiprocessada do sistema apresentado, de forma a melhorar o desempenho e, conseqüentemente, a usabilidade; 
- Pós-processamento da malha melhorada: outro fator que não foi considerado é o uso de pós-processamentos para melhorar, ainda mais, a qualidade da malha final. Também seria interessante verificar dentre várias técnicas conhecidas, qual o impacto do uso do método de deslocamento de vértices proposto, ou seja, encontrar respostas para questões, tais como se o algoritmo converge mais rapidamente se tiver como entrada uma malha melhorada pelo algoritmo de deslocamento de vértices;

- Novos tipos funções locais: o trabalho desenvolvido apenas considerou funções polinomiais e quádricas por partes para a representação de corners ou arestas sharp. No entanto, ficou claro que a qualidade e a robustez da aproximação global pode se beneficiar de uma escolha cuidadosa das funções locais. Por essa razão, seria um avanço interessante estudar outros tipos de funções e se obter uma avaliação geral para esse aspecto;

- Construção bottom-up da estrutura: uma observação acerca dos principais problemas que surgem ao se particionar o domínio para a construção local mostra que a maioria desses ocorrem devidos a blocos que contenham poucos pontos ou pontos mal distribuídos. Isso leva à consideração de que se a construção pudesse ser feita de maneira bottom-up através de uma estrutura de blocos livre de linhas de grade, os blocos poderiam ser posicionados de maneira a otimizar o processo de aproximação de funções;

- Resultados teóricos: seria interessante estudar de forma mais detalhada as propriedades do domínio das funções obtidas por implícitas de partição da unidade, como já foi feito com as superfícies MLS (Amenta and Kil, 2004). 
Conclusão 


\section{Referências Bibliográficas}

A. Adamson and M. Alexa. Approximating and intersecting surfaces from points. In Proc. of Eurographics/ACM Symposium on Geometry Processing, pages 230-239. Eurographics Assoc., 2003. ISBN 1-58113-687-0.

U. Adamy, J. Giesen, and M. John. Surface reconstruction using umbrella filters. Computational Geometry Theory and Applications, 21:63-86, 2002.

N. Amenta and Y. J. Kil. The domain of a point set surfaces. Eurographics Symposium on Point-based Graphics, 1(1):139-147, June 2004. URL http://graphics.cs.ucdavis.edu/ yjkil/pub/domain.html.

N. Amenta, M. Bern, and D. Eppstein. The crust and the $\beta$-skeleton: Combinatorial curve reconstruction. Graphical models and image processing, 60(2):125-135, 1998a.

N. Amenta, M. Bern, and M. Kamvysselis. A new voronoi-based surface reconstruction algorithm. In SIGGRAPH '98: Proceedings of the 25th annual conference on Computer graphics and interactive techniques, pages 415-421, New York, NY, USA, 1998b. ACM Press. ISBN 0-89791-999-8. doi: http://doi.acm.org/10.1145/280814.280947.

N. Amenta, S. Choi, T. K. Dey, and N. Leekha. A simple algorithm for homeomorphic surface reconstruction. In SCG '00: Proceedings of the sixteenth annual symposium on Computational geometry, pages 213-222, New York, NY, USA, 2000. ACM Press. ISBN 1-58113-224-7. doi: http://doi.acm.org/10.1145/336154.336207. 


\section{Referências Bibliográficas}

C. L. Bajaj, F. Bernardini, and G. Xu. Automatic reconstruction of surfaces and scalar fields from 3d scans. In SIGGRAPH '95: Proceedings of the 22nd annual conference on Computer graphics and interactive techniques, pages 109-118, New York, NY, USA, 1995. ACM Press. ISBN 0-89791-701-4. doi: http://doi.acm.org/10.1145/218380.218424.

E. Bardinet, L. D. Cohen, and N. Ayache. A parametric deformable model to fit unstructured 3d data. Computer Vision and Image Understanding, 71(1):39-54, 1998.

R. H. Bartels and J. J. Jezioranski. Least-squares fitting using orthogonal multinomials. ACM Transactions on Mathematical Software, 11(3):201-217, 1985.

F. Bernardini and C. Bajaj. Sampling and reconstructing manifolds using alpha-shapes. In Proc. 9th Canad. Conf. Comput. Geom, pages 193-198, 1997.

F. Bernardini, C. L. Bajaj, J. Chen, and D. Schikore. Automatic reconstruction of 3d cad models from digital scans. International Journal of Computational Geometry and Applications, 9(4/5):327-369, 1999a. URL citeseer . ist.psu.edu/153875.html.

F. Bernardini, J. Mittleman, H. Rushmeier, C. Silva, and G. Taubin. The ball-pivoting algorithm for surface reconstruction. IEEE Transactions on Visualization and Computer Graphics, 5(4):349-359, 1999 b.

P. Bhaniramka, R. Wenger, and R. Crawfis. Isosurface construction in any dimension using convex hulls. IEEE Transactions on Visualization and Computer Graphics, 10(2): 130-141, 2004. ISSN 1077-2626. doi: http://dx.doi.org/10.1109/TVCG.2004.1260765.

J. F. Blinn. A generalization of algebraic surface drawing. ACM Transactions on Graphics, 1(3):235-256, July 1982.

J. Bloomenthal. Polygonization of implicit surfaces. Comput. Aided Geom. Des., 5(4): 341-355, 1988. ISSN 0167-8396. doi: http://dx.doi.org/10.1016/0167-8396(88)90013-1.

J. Bloomenthal. An implicit surface polygonizer. In P. Heckbert, editor, Graphics Gems IV, pages 324-349. Academic Press, Boston, 1994. URL citeseer.ist.psu.edu/bloomenthal94implicit.html. 


\section{Referências Bibliográficas}

J.-D. Boissonnat. Geometric structures for three-dimensional shape representation. ACM Transactions on Graphics, 3(4):266-286, 1984.

J.-D. Boissonnat and F. Cazals. Smooth surface reconstruction via natural neighbour interpolation of distance functions. Computational Geometry, 22(1-3):185-203, May 2002.

J. D. Boissonnat and S. Oudot. Provably good surface sampling and approximation. In SGP '03: Proceedings of the 2003 Eurographics/ACM SIGGRAPH symposium on Geometry processing, pages 9-18, Aire-la-Ville, Switzerland, Switzerland, 2003. Eurographics Association. ISBN 1-58113-687-0.

J. C. Carr, R. K. Beatson, J. B. Cherrie, T. J. Mitchell, W. R. Fright, B. C. McCallum, and T. R. Evans. Reconstruction and representation of $3 \mathrm{~d}$ objects with radial basis functions. In SIGGRAPH '01: Proceedings of the 28th annual conference on Computer graphics and interactive techniques, pages 67-76, New York, NY, USA, 2001. ACM Press. ISBN 1-58113-374-X. doi: http://doi.acm.org/10.1145/383259.383266.

A. Castelo, L. G. Nonato, M. Siqueira, R. Minghim, and G. Tavares. The $j_{1}^{a}$ triangulation: An adaptive triangulation in any dimension. Computer $\mathcal{E}$ Graphics, 30(5):737-753, 2006.

S. L. Chan and E. O. Purisima. A new tetrahedral tesselation scheme for isosurface generation. Computer E Graphics, 22(1):83-90, 1998.

S.-W. Cheng, T. K. Dey, E. A. Ramos, and T. Ray. Sampling and meshing a surface with guaranteed topology and geometry. In SCG '04: Proceedings of the twentieth annual symposium on Computational geometry, pages 280-289, New York, NY, USA, 2004. ACM. ISBN 1-58113-885-7. doi: http://doi.acm.org/10.1145/997817.997861.

E. V. Chernyaev. Marching cubes 33: construction of topologically correct isosurfaces. Technical report, CERN, 1995.

C. S. Co, S. D. Porumbescu, and K. I. Joy. Meshless isosurface generation from multi- 


\section{Referências Bibliográficas}

block data. In Proceedings of Joint EUROGRAPHICS - IEEE TCVG Symposium on Visualization (2004), pages 21-29. IEEE Computer Society, 2004.

T. K. Dey. Geometric and Algorithmic Aspects of Computer-Aided Design and Manufacturing, chapter Sample Based Geometric Modeling, pages 111-222. ..., 2005.

T. K. Dey and S. Goswami. Tight cocone : A water-tight surface reconstruction. Technical report, The Ohio State University, 2002.

T. K. Dey and S. Goswami. Provable surface reconstruction from noisy samples. In Proceedings of the twentieth annual symposium on Computational Geometry, pages 330339. ACM Press, 2004.

H. Edelsbrunner. Surface reconstruction by wrapping finite sets in space. Technical report, Raindrop Geomagic, 2002.

H. Edelsbrunner and E. P. Mücke. Three-dimensional alpha-shapes. ACM Transaction on Graphics, 13(1):43-72, 1994.

L. H. Figueiredo, J. de Miranda Gomes, D. Terzopoulos, and L. Velho. Physically-based methods for polygonization of implicit surfaces. In Proceedings of the conference on Graphics interface '92, pages 250-257, San Francisco, CA, USA, 1992. Morgan Kaufmann Publishers Inc. ISBN 0-9695338-1-0.

D. Freedman. An incremental algorithm for reconstruction of surfaces of arbitrary codimension. Computational Geometry, 36(2):106-116, February 2007.

M. Gavriliu, J. Carranza, D. E. Breen, and A. H. Barr. Fast extraction of adaptive multiresolution meshes with guaranteed properties from volumetric data. In VIS '01: Proceedings of the conference on Visualization '01, pages 295-303, Washington, DC, USA, 2001. IEEE Computer Society. ISBN 0-7803-7200-X.

J. P. Gois. Reconstrução de superfícies a partir de nuvens de pontos. Master's thesis, Instituto de Ciências Matemáticas e de Computação, Universidade de São Paulo, 2004. 


\section{Referências Bibliográficas}

J. P. Gois, A. C. Filho, L. G. Nonato, and H. H. Bíscaro. Surface reconstruction: Classification, comparisons and applications. In Proceedings of XXV CILAMCE - Iberian Latin American Congress on Computational Methods, 2004.

J. P. Gois, V. Polizelli-Junior, T. Etiene, E. Tejada, A. Castelo, T. Ertl, and L. G. Nonato. Robust and adaptive surface reconstruction using partition of unity implicits. In Brazilian Symposium on Computer Graphics and Image Processing, pages 95-102, 2007.

J. P. Gois, A. Nakano, L. G. Nonato, and G. C. Buscaglia. Front-tracking with movingleast-squares. Journal of Computational Physics-submetido, 2008.

M. Gopi, S. Krishnan, and C. T. Silva. Surface reconstruction based on lower dimensional localized delaunay triangulation. Computer Graphics Forum (Eurographics 2000), 19(3), 2000.

M. Hall and J. Warren. Adaptive polygonalization of implicitly defined surfaces. Computer Graphics and Applications, IEEE, 10(6):33-42, Nov. 1990. doi: 10.1109/38.62694.

H. Hoppe, T. DeRose, T. Duchampy, J. McDonaldz, and W. Stuetzlez. Surface reconstruction from unorganized points. Computer Graphics, 26(2):71-78, 1992.

H. Hoppe, T. DeRose, T. Duchamp, M. Halstead, H. Jin, J. McDonald, J. Schweitzer, and W. Stuetzle. Piecewise smooth surface reconstruction. In SIGGRAPH '94: Proceedings of the 21st annual conference on Computer graphics and interactive techniques, pages 295-302, New York, NY, USA, 1994. ACM Press. ISBN 0-89791-667-0. doi: http://doi.acm.org/10.1145/192161.192233.

J. Huang and C. H. Menq. Combinatorial manifold mesh reconstruction and optimization from unorganized points with arbitrary topology. Computer-Aided Design, 34: 149-165, February 2002.

M. Kazhdan, M. Bolitho, and H. Hoppe. Poisson surface reconstruction. In Proceedings of Eurographics Symposium on Geometry Processing, 2006.

L. P. Kobbelt, M. Botsch, U. Schwanecke, and H.-P. Seidel. Feature sensitive surface extraction from volume data. In SIGGRAPH' 01 : Proceedings of the 28th annual conference 


\section{Referências Bibliográficas}

on Computer graphics and interactive techniques, pages 57-66, New York, NY, USA, 2001. ACM Press. ISBN 1-58113-374-X. doi: http://doi.acm.org/10.1145/383259.383265.

R. Kolluri. Provably good moving least squares. In SODA'05: Proceedings of the sixteenth annual ACM-SIAM symposium on Discrete algorithms, pages 1008-1017, Philadelphia, PA, USA, 2005. Society for Industrial and Applied Mathematics. ISBN 0-89871-585-7.

R. K. Kolluri, J. R. Shewchuk, and J. F. OB́rien. Spectral watertight surface reconstruction. In Proceedings of the SIGGRAPH 2003 conference on Sketches E applications, 2003.

T. Lewiner, H. Lopes, A. W. Viera, and G. Tavares. Efficient implement of marching cubes cases with topological guarantees. Journal of Graphics Tools., 8(2):1-15, 2003.

A. Lopes and K. Brodlie. Improving the robustness and accuracy of the marching cubes algorithm for isosurfacing. IEEE Transactions on Visualization and Computer Graphics, 09(1):16-29, 2003. ISSN 1077-2626. doi: http://doi.ieeecomputersociety.org/10.1109/TVCG.2003.1175094.

W. E. Lorensen and H. E. Cline. Marching cubes: A high resolution 3d surface construction algorithm. In SIGGRAPH '87: Proceedings of the 14th annual conference on Computer graphics and interactive techniques, pages 163-169, New York, NY, USA, 1987. ACM Press. ISBN 0-89791-227-6. doi: http://doi.acm.org/10.1145/37401.37422.

B. Mederos, L. Velho, and L. H. de Figueiredo. Moving least squares multiresolution surface approximation. In Proceedings SIBGRAPI 2003, 2003.

B. Mederos, N. Amenta, L. Velho, and L. H. de Figueiredo. Surface reconstruction from noisy point clouds. In M. Desbrun and H. Pottmann, editors, Proceedings Eurographics Symposium on Geometry Processing, 2005.

B. Mederos, S. Arouca, M. Lage, H. Lopes, and L. Velho. Improved partition of unity implicit surface reconstruction. Technical Report TR-0406, IMPA, Brazil, 2006. 


\section{Referências Bibliográficas}

C. Montani, R. Scateni, and R. Scopigno. A modified look-up table for implicit disambiguation of marching cubes. The Visual Computer, 10(6):353-355, December 1994. URL http://www .crs4.it/vic/cgi-bin/bib-page.cgi?id='Montani : 1994 : MLT'.

S. Muraki. Volumetric shape description of range data using blobby model. Computer Graphics, 25(4):237-235, July 1991.

G. M. Nielson and B. Hamann. The asymptotic decider: resolving the ambiguity in marching cubes. In Proceedings of IEEE Conference on Visualization, 1991.

L. G. Nonato, A. J. Cuadros-Vargas, R. Minghim, and M. C. F. D. Oliveira. Beta-connection: Generating a family of models from planar cross sections. ACM Trans. Graph., 24(4):1239-1258, 2005. ISSN 0730-0301. doi: http://doi.acm.org/10.1145/1095878.1095879.

Y. Ohtake, A. Belyaev, M. Alexa, G. Turk, and H.-P. Seidel. Multi-level partition of unity implicits. ACM Trans. Graph., 22(3):463-470, 2003. ISSN 0730-0301. doi: http://doi.acm.org/10.1145/882262.882293.

Y. Ohtake, A. Belyaev, and H.-P. Seidel. 3d scattered data interpolation and approximation with multilevel compactly supported RBFs. Graphical Models, 67(3):150-165, 2004.

A. Paiva, H. Lopes, T. Lewiner, and L. H. de Figueiredo. Robust adaptive meshes for implicit surfaces. In Proceedings of SIBGRAPI, 2006.

P. A. Payne and A. W. Toga. Surface mapping brain function on $3 \mathrm{~d}$ models. IEEE Computer Graphics and Applications, 10(5):33-41, 1990.

S. Petitjean and E. Boyer. Regular and non-regular points sets: Properties and reconstruction. Computational Geometry Theory and Applications,, 19:101-126, 2001.

PovRay. Persistence of vision - http://www.porvay.org. website, 2007.

A. Rodriguez, J. M. Espadero, D. Lopez, and L. Pastor. Delaunay surface reconstruction from scattered points. In Proceedings of Discrete Geometry for Computer Imagery - 9th International Conference, DGCI, 1994. 


\section{Referências Bibliográficas}

J. Schreiner, C. Scheidegger, and C. Silva. High-quality extraction of isosurfaces from regular and irregular grids. Visualization and Computer Graphics, IEEE Transactions on, 12(5):1205-1212, 2006. ISSN 1077-2626. doi: 10.1109/TVCG.2006.149.

C. Shen, J. F. O'Brien, and J. R. Shewchuk. Interpolating and approximating implicit surfaces from polygon soup. ACM Transactions on Graphics, 23(3):896-904, 2004.

R. Shu, C. Zhou, and M. S. Kankanhalli. Adaptive marching cubes. The Visual Computer, 11(4):202-217, 1995. URL citeseer.ist.psu.edu/shu95adaptive.html.

M. Teichmann and M. Capps. Surface reconstruction with anisotropic density-scaled alpha shapes. In VIS '98: Proceedings of the conference on Visualization' '98, pages 67-72, Los Alamitos, CA, USA, 1998. IEEE Computer Society Press. ISBN 1-58113-106-2.

G. M. Treece, R. W. Prager, and A. H. Gee. Regularised marching tetrahedra: improved iso-surface extraction. Computer $\mathcal{E}$ Graphics, 23(4):583-598, 1999.

G. Turk and J. F. O'brien. Modelling with implicit surfaces that interpolate. ACM Trans. Graph., 21(4):855-873, 2002. ISSN 0730-0301. doi: http://doi.acm.org/10.1145/571647.571650.

C. Weigle and D. C. Banks. Complex-valued contour meshing. In R. Yagel and G. M. Nielso, editors, IEEE Visualization '96, pages 173-180, 1996. URL citeseer.ist.psu.edu/weigle96complexvalued.html.

H.-K. Zhao, S. Osher, B. Merriman, and M. Kang. Implicit and nonparametric shape reconstruction from unorganized data using a variational level set method. Comput. Vis. Image Underst., 80(3):295-314, 2000. ISSN 1077-3142. doi: http://dx.doi.org/10.1006/cviu.2000.0875.

H.-K. Zhao, S. Osher, and R. Fedkiw. Fast surface reconstruction using the level set method. In Proceedings of IEEE Workshop on Variational and Level Set Methods in Computer Vision, 2001., pages 194-201, 2001. 